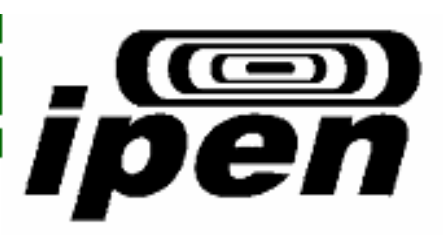

Autarquia associada à Universidade de São Paulo

\title{
PROJETO, CONSTRUÇÃO E CARACTERIZAÇÃO DE UM DOSÍMETRO PARA RADIAÇÃO DE NÊUTRONS
}

Eduardo de Brito Souto

Dissertação apresentada como parte dos requisitos para obtenção do Grau de Mestre em Ciências na Área de Tecnologia Nuclear - Aplicações.

Orientadora:

Dra. Letícia L.C. Rodrigues

SÃo PAULO 
INSTITUTO DE PESQUISAS ENERGÉTICAS E NUCLEARES

Autarquia associada à Universidade de São Paulo

\section{PROJETO, CONSTRUÇÃO E CARACTERIZAÇÃO DE UM DOSÍMETRO PARA RADIAÇÃO DE NÊUTRONS}

Eduardo de Brito Souto

Dissertação apresentada como parte dos requisitos para obtenção do Grau de Mestre em Ciências na Área de Tecnologia Nuclear - Aplicações.

Orientadora:

Dra. Letícia L.C. Rodrigues

SÃO PAULO 
Dedico este trabalho ao meu pai, Sérgio Luiz Lena Souto, mentor dessa idéia. 


\section{AGRADECIMENTOS}

Primeiramente a Deus pela vida e pelas pessoas que Ele colocou no meu caminho até hoje e aos avanços da medicina que nos permitem estar aqui hoje.

Ao Instituto de Pesquisas Energéticas e Nucleares - IPEN, na pessoa do Sr. Superintendente, Dr. Cláudio Rodrigues, pela oportunidade de desenvolvimento deste trabalho.

À minha orientadora Dra. Letícia L. C. Rodrigues pela orientação sempre concisa, contatos feitos em outras instituições, empenho em atender-me e resolver tudo que fosse preciso para o andamento e conclusão deste trabalho.

Ao meus pais, Sérgio e Josmari, incentivadores e patrocinadores desse trabalho e da minha estada em São Paulo; por nunca permitirem que eu deixasse de estudar.

Aos meus irmãos: Laura que dividiu o apartamento comigo nesses três anos, pela companhia e pela segurança de voltar para casa sabendo que teria alguém ao meu lado e ao Gabriel que mesmo morando longe, seguidamente veio nos trazer conforto, ordem e alegria.

À minha amada que tive que deixar, por esperar ansiosamente minha volta, entender-me e apoiar-me para terminar esse mestrado.

À minha prima Lívia por ter se transferido para Porto Alegre e preenchido o vazio e o silêncio deixados na nossa casa pela perda da minha avó.

A todos do CMR na pessoa da Dra. Linda V. E. Caldas, que sempre foi solícita e na ausência da Dra. Letícia ajudou-me conforme suas possibilidades.

À PRO-RAD pelos materiais e equipamentos disponibilizados, não só no nome do meu pai, mas de todos que participaram da história dessa empresa desde 1979.

À Dra. Cláudia Maurício por me receber e abrir as portas do IRD e pela placa de Makrofol.

À toda a equipe do Laboratório de Nêutrons do IRD, na pessoa do Dr. Evaldo S. da Fonseca. 
Ao Dr. Tufic Madi Filho por dar-me total liberdade no uso da fonte de Amerício-Berílio do IPEN.

À Dra. Brigitte S. Pecequilo e à colega Simone Alberigi por ensinaremme os meandros do ataque químico.

Ao Claudinei, Gélson e Valdir, pelas irradiações com radiação alfa, beta e gama.

Aos meus grandes colegas de mestrado, mais do que colegas, amigos e companheiros. Sem eles, eu não teria me adaptado tão rápido nessa cidade, nem gostaria tanto dela como eu gosto hoje, Mestre André, Branco Carneiro, Mestre Cristiane, Flávio, Mestre Juanito, Maíra, Mestre Müller, Mestre Patrícia Mara e Mestre Priscilla Roberta.

Aos também amigos Ana Carolina, Ana Maia, Érik, Giuliano, Guilherme, Hélio, Lílian, Mércia, Maíra, Oscar, Paula, Vanessa e Zé.

Aos amigos Aline e Mártin e ao primo Emliano que em suas vindas à capital paulista hospedaram-se conosco, dando vida nova a mim e minha irmã.

Aos amigos que fiz na Vila Mariana: Edmar, Guto e Rodrigo.

Aos gremistas de São Paulo e gaúchos de coração: Jota Erre Santiago, Zizo e Katy, Richard e Cíntia, Teixeira e Mavi, Jana, Pedrinho, Michele, Guilherme e Ricardo. Juntos, era como se estivéssemos em casa, na querência amada do Rio Grande do Sul. 
"O conformismo é o carcereiro da liberdade e o inimigo do crescimento" John Kennedy 


\title{
PROJETO, CONSTRUÇÃO E CARACTERIZAÇÃO DE UM DOSÍMETRO PARA RADIAÇÃO DE NÊUTRONS
}

\author{
Eduardo de Brito Souto
}

\section{RESUMO}

Com o objetivo de monitorar o crescente número de trabalhadores potencialmente expostos à radiação de nêutrons, foi projetado e desenvolvido um dosímetro individual para campos mistos nêutron-gama. $\mathrm{O}$ dosímetro proposto foi caracterizado para o espectro de energia de uma fonte de Amerício-Berílio e para o intervalo de dose de interesse da proteção radiológica (até $20 \mathrm{mSv}$ ). Para tanto utilizou-se a dosimetria termoluminescente de albedo e a dosimetria de traços nucleares, técnicas consagradas na literatura internacional, empregando materiais de fabricação nacional e de baixo custo. Um policarbonato comercial, denominado SS-1, foi caracterizado para aplicação como detector sólido de traços nucleares. Os parâmetros para revelação química e ampliação dos traços, assim como a metodologia de avaliação dos detectores foram determinados. Estudou-se a resposta dos detectores TLD-600, TLD-700 e SS-1 em campos mistos nêutrongama de uma fonte de Amerício-Berílio e definiu-se um algoritmo para cálculo da dose de nêutrons e de radiação gama. A razão entre as respostas para nêutrons térmicos, de albedo e rápidos permite analisar o espectro ao qual o dosímetro foi submetido e corrigir a resposta do detector de traços para variações no ângulo de incidência da radiação. $O$ novo dosímetro está pronto e apresenta desempenho para ser usado como dosímetro de nêutrons no Brasil. 


\title{
DESIGN, CONSTRUCTION AND CHARACTERIZATION OF A DOSIMETER FOR NEUTRON RADIATION
}

\author{
Eduardo de Brito Souto
}

\begin{abstract}
An individual dosimeter for neutron-gamma mixed field dosimetry was design and developed aiming monitoring the increasing number of workers potentially exposed to neutrons. The proposed dosimeter was characterized to an Americium-Beryllium source spectrum and dose range of radiation protection interest (up to $20 \mathrm{mSv}$ ). Thermoluminescent albedo dosimetry and nuclear tracks dosimetry, traditional techniques found in the international literature, with materials of low cost and national production, were used. A commercial polycarbonate, named SS-1, was characterized for solid state tack detector application. The chemical etching parameters and the methodology of detectors evaluation were determined. The response of TLD-600, TLD-700 and SS-1 were studied and algorithms for dose calculation of neutron and gamma radiation of AmericiumBeryllium sources were proposed. The ratio between thermal, albedo and fast neutrons responses, allows analyzing the spectrum to which the dosimeter was submitted and correcting the track detector response to variations in the radiation incidence angle. The new dosimeter is fully characterized, having sufficient performance to be applied as neutron dosimeter in Brazil.
\end{abstract}




\section{SUMÁRIO}

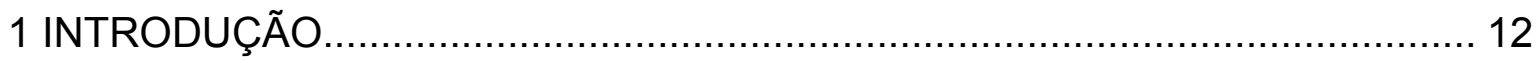

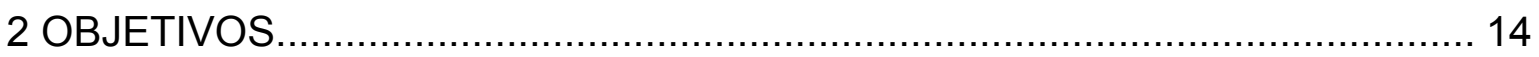

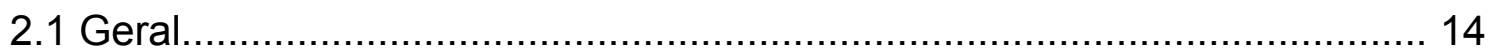

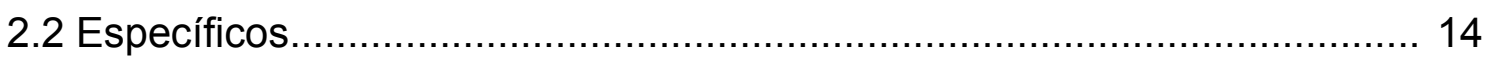

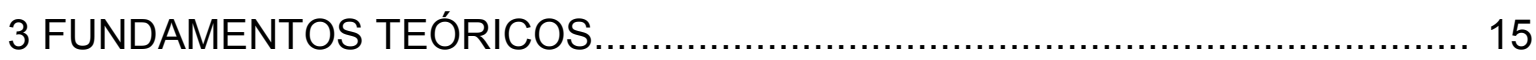

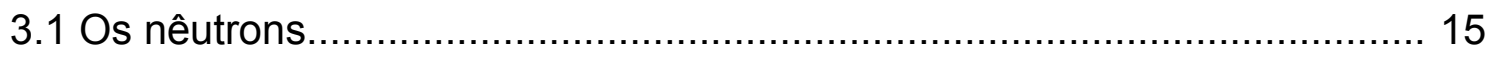

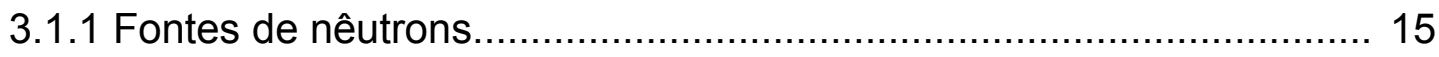

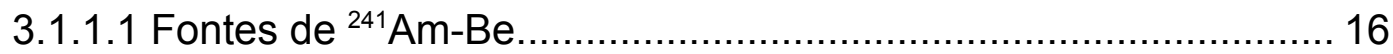

3.1.2 Classificação dos nêutrons........................................................... 19

3.1.3 Interação dos nêutrons com a matéria................................................ 20

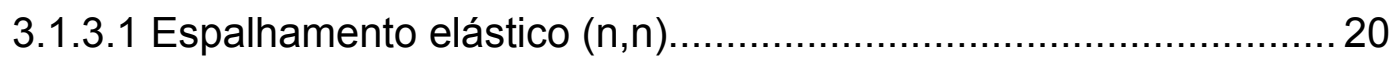

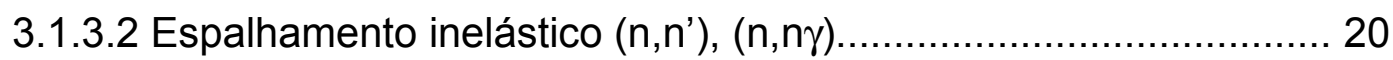

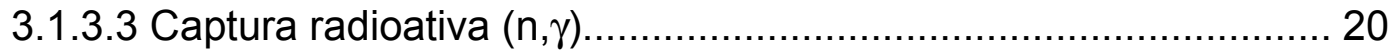

3.1.3.4 Reações não-elásticas $(n, p),(n, d),(n, \alpha),(n, t),(n, \alpha p),(n, 2 n)$, etc 21

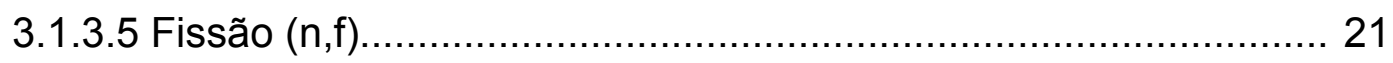

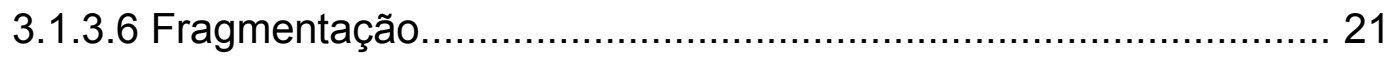

3.1.4 Seção de choque ....................................................................... 21

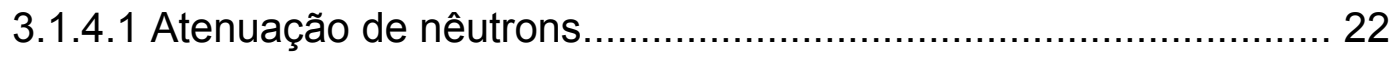

3.1.5 Interação dos nêutrons com o tecido humano.................................... 23

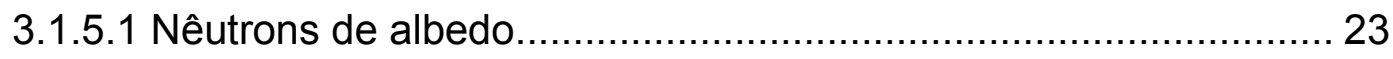

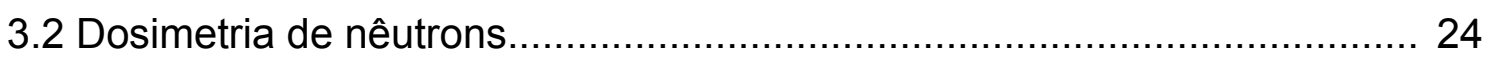

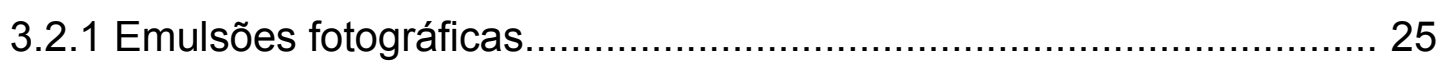

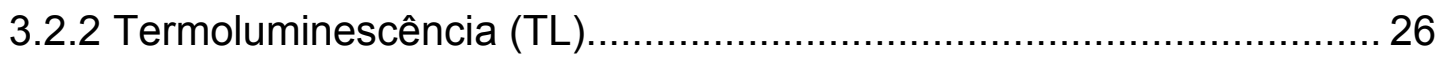

3.2.2.1 Dosimetria de albedo............................................................. 30

3.2.2.1.1 Blindagem de cádmio...................................................... 31

3.2.3 Detectores sólidos de traços nucleares (DSTN)............................... 32

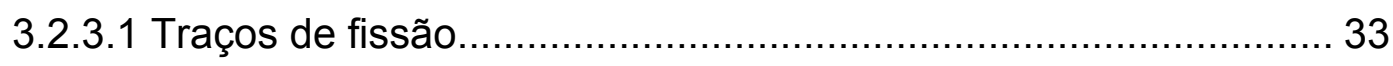

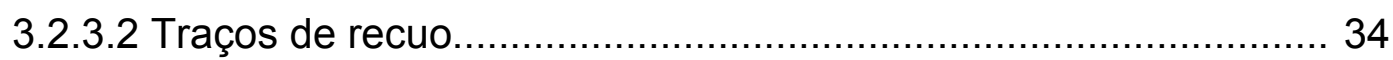


3.2.3.3 Uso de policarbonatos como detectores de traços. 34

3.3 Grandezas e unidades para dosimetria de nêutrons................................... 35

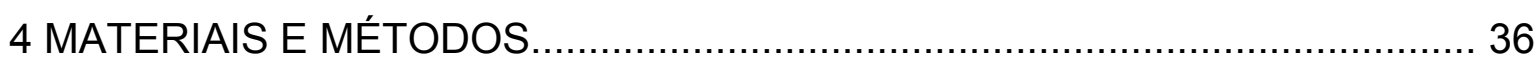

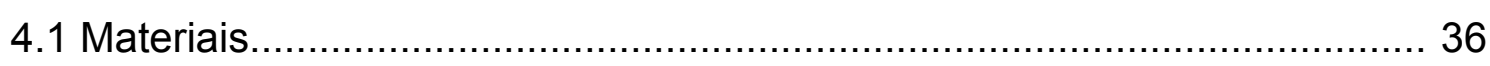

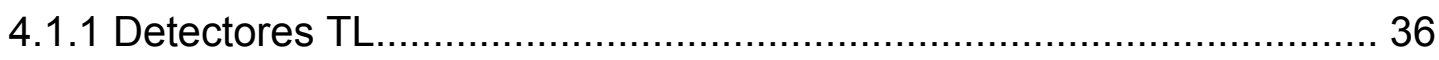

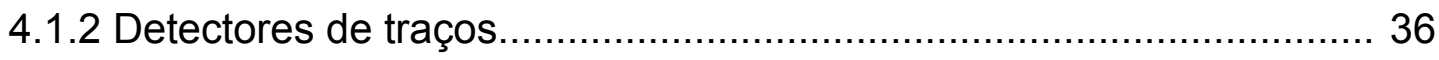

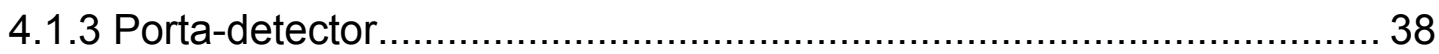

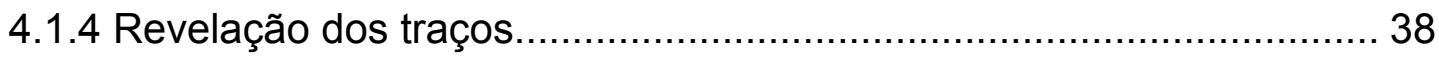

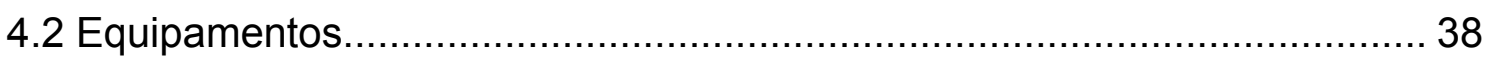

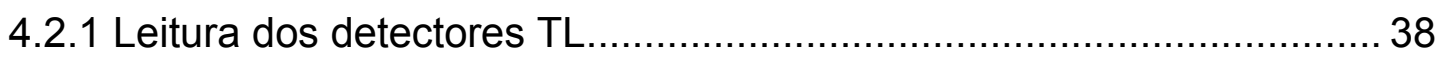

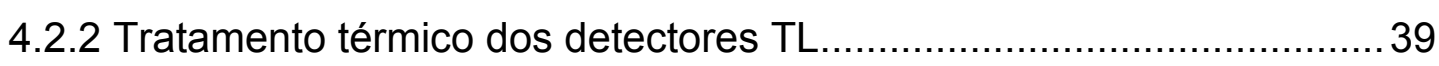

4.2.3 Revelação dos traços nucleares..................................................... 39

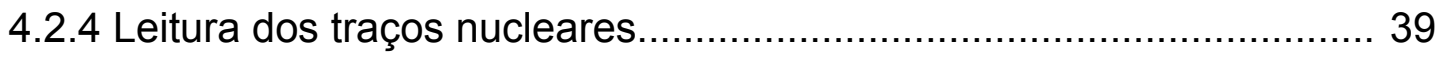

4.3 Irradiação de amostras e protótipos...................................................... 39

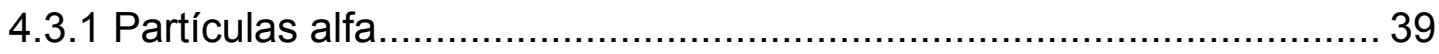

4.3.2 Partículas beta

4.3.3 Radiação gama...................................................................... 40

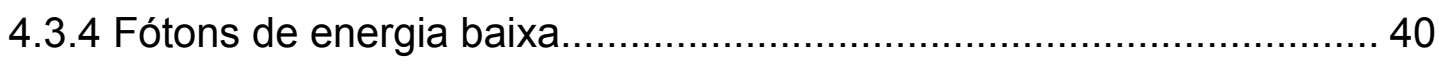

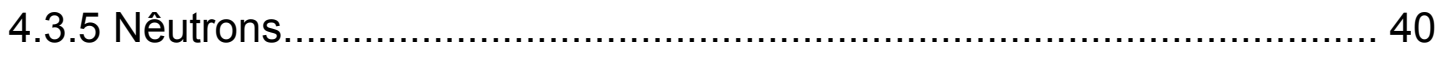

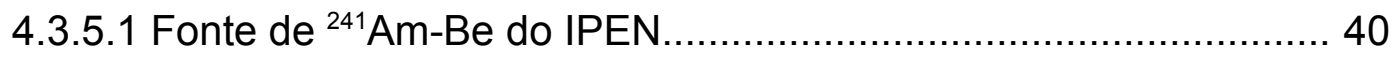

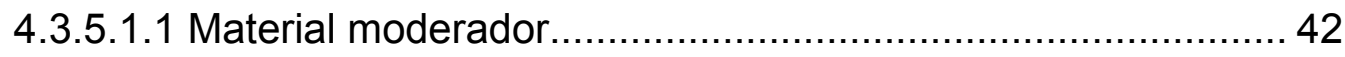

4.3.5.2 Fonte de ${ }^{241} \mathrm{Am}-\mathrm{Be}$ do IRD...................................................... 43

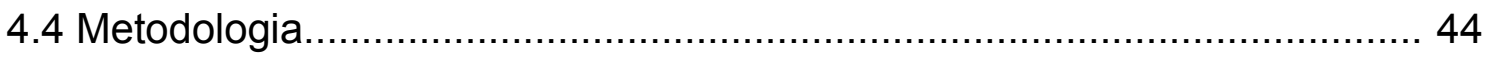

4.4.1 Curva de emissão TL e parâmetros da leitora.................................... 45

4.4.2 Tratamento térmico dos detectores TL................................................ 45

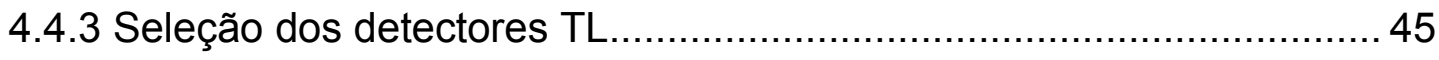

4.4.4 Resposta TL para fótons................................................................... 47

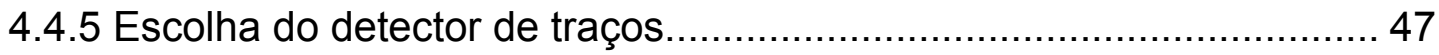

4.4.6 Determinação da face mais sensível do SS-1 …………………....... 47

4.4.7 Leitura e contagem dos traços no SS-1 ........................................... 47

4.4.8 Sensibilidade do SS-1 à outras radiações.......................................... 49

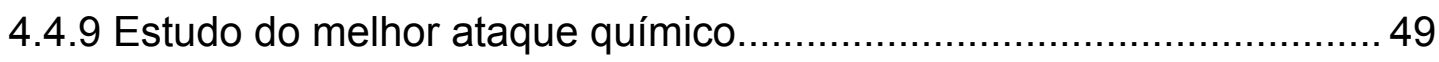

4.4.10 Comparação entre o SS-1 e o Makrofol............................................. 50

4.5 Projeto do porta-dosímetro.................................................................. 50 


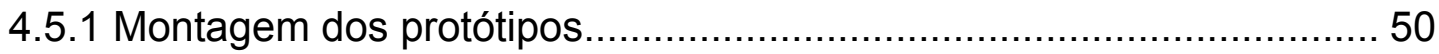

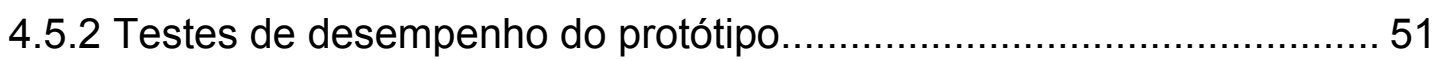

4.5.3 Irradiação de protótipos com espectro diferente................................. 52

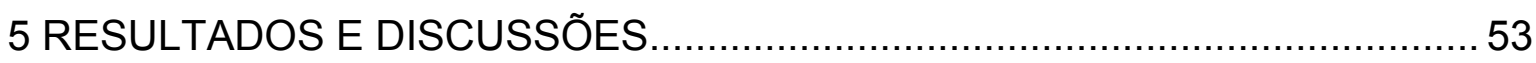

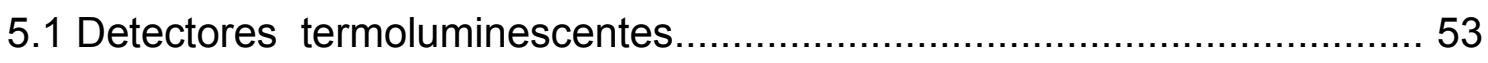

5.1.1 Curva de emissão TL e parâmetros da leitora..................................... 53

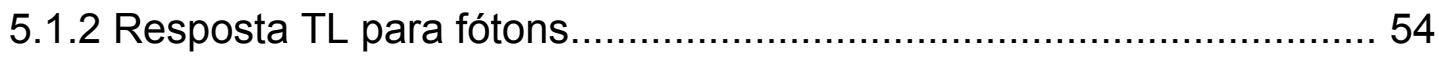

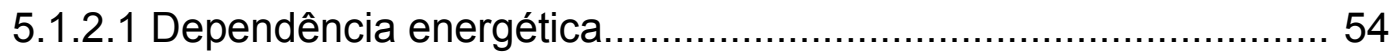

5.1.2.2 Resposta para 59,7 keV........................................................ 54

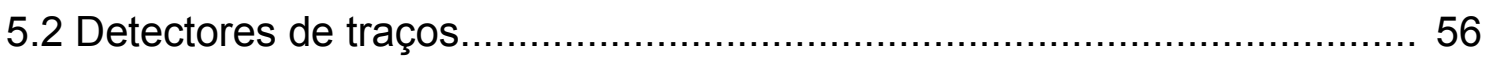

5.2.1 Determinação da face mais sensível do policarbonato SS-1 ............... 56

5.2.2 Contagem dos traços na superfície do detector.................................56

5.2.3 Sensibilidade do SS-1 à outros tipos de radiação................................ 57

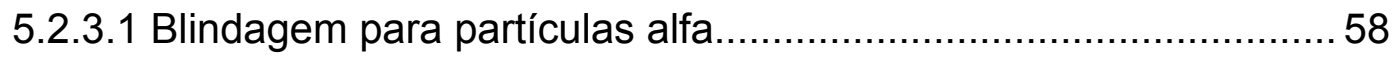

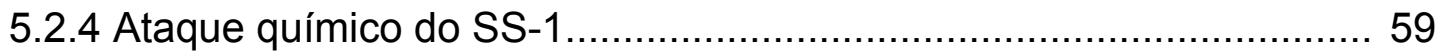

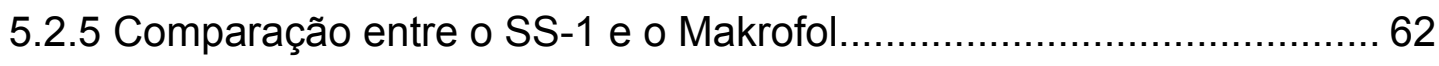

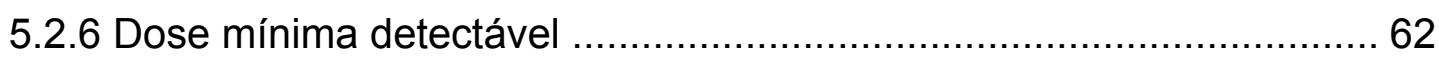

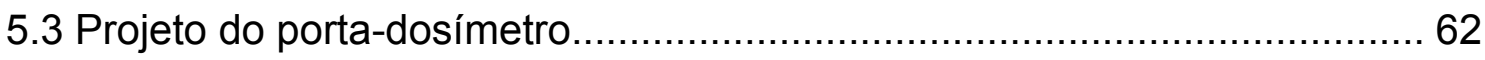

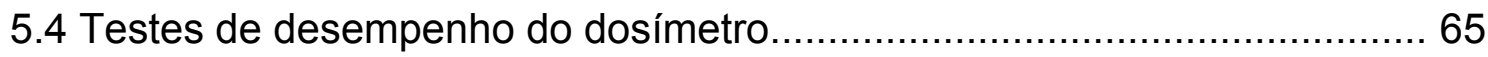

5.4.1 Resposta do dosímetro em função da dose de nêutrons....................... 65

5.4.2 Dependência angular da resposta do dosímetro.................................70

5.5 Algoritmos para cálculo da dose ...........................................................

5.5.1 Cálculo da dose de radiação gama................................................. 72

5.5.2 Cálculo da dose de nêutrons.......................................................... 73

5.5.2.1 Cálculo da dose pela dosimetria de albedo................................ 73

5.5.2.2 Cálculo da dose pela dosimetria de traços nucleares.................... 74

5.5.2.3 Correção angular para o cálculo da dose por traços nucleares....74

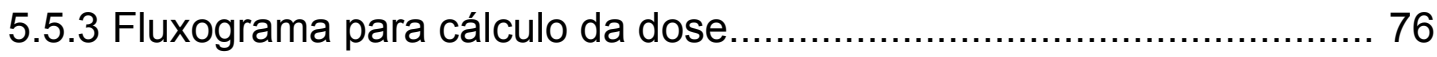

5.6 Irradiação de protótipos com espectro diferente...................................... 78

5.7 Considerações sobre o uso do dosímetro................................................ 79

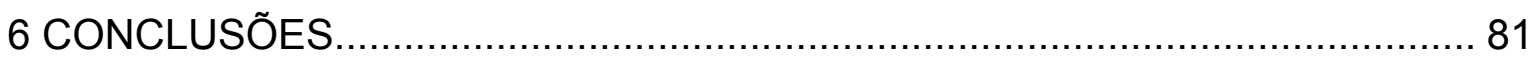

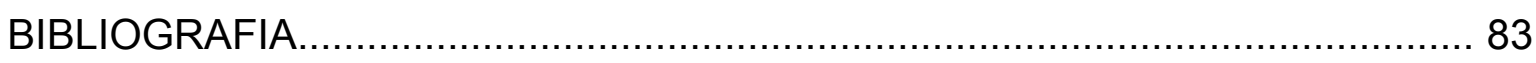

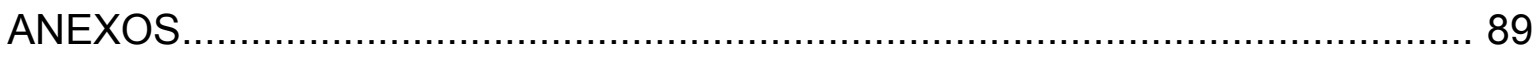

ANEXO A - Exemplos da Aplicação do Critério de Chauvenet......................... 89 


\section{INTRODUÇÃO}

No passado a exposição a nêutrons era muito limitada e somente os trabalhadores de reatores e plantas nucleares precisavam ser monitorados. Atualmente há um aumento do uso de técnicas industriais e médicas que utilizam nêutrons ou radiações que os geram indiretamente. Em virtude disso, é crescente o número de trabalhadores potencialmente expostos à radiação de nêutrons, agravando-se a necessidade de uma monitoração individual adequada para suprir essa demanda.

$\mathrm{Na}$ indústria, fontes de nêutrons são utilizadas na exploração de recursos minerais, controle de umidade em processos agronômicos e da construção civil, controle de qualidade e análise de materiais (neutrongrafia) e na detecção não destrutiva de explosivos e narcóticos. Na medicina, o uso da BNCT (Boron-Neutron Capture Therapy) como técnica de tratamento de câncer é cada vez maior.

A dosimetria de nêutrons é muito mais complexa que a de fótons, não havendo nenhum dosímetro ou técnica dosimétrica capaz de medir respostas independentemente da energia dos nêutrons. No âmbito da proteção radiológica brasileira, a dosimetria de nêutrons é bastante limitada, não somente pela complexidade da medida, mas principalmente pelo alto custo dos detectores importados. Os dosímetros comercialmente disponíveis são capazes de medir apenas nêutrons térmicos, todavia, a maior fração da dose absorvida pelo corpo humano é decorrente dos nêutrons de energias mais altas. Para estes últimos, o alto custo das técnicas disponíveis torna restrita a produção de dosímetros.

Para atender essa crescente demanda pela monitoração individual para nêutrons, novos materiais e métodos têm sido estudados, buscando praticidade de aplicação e redução dos custos. As técnicas de termoluminescência ( $T L)$ e de traços nucleares são as mais praticadas. Os materiais termoluminescentes fluoreto de lítio e tetraborato de lítio e os detectores de traços CR-39 e Makrofol foram os mais estudados (Oberhofer e Scharmann, 1981; Becker, 1973).

Uma das maiores dificuldades na dosimetria de nêutrons é a detecção 
de nêutrons em todo o espectro de energia com um mesmo equipamento. Como solução é possível decompor o espectro neutrônico em três regiões: energia térmica, energia intermediária e energia rápida, e utilizar diferentes técnicas dosimétricas. No presente trabalho foram utilizadas as técnicas de dosimetria termoluminescente (DTL) para nêutrons térmicos, dosimetria termoluminescente de albedo (DTLA) para nêutrons intermediários e dosimetria de traços nucleares (DSTN) para nêutrons rápidos. Um dos pontos importantes neste trabalho é a utilização de técnicas consagradas na literatura internacional com materiais de custo reduzido.

O uso conjunto destas diferentes técnicas não é recente. Em 1984 o Karlsruhe Nuclear Research Center, da Alemanha suplementou seu dosímetro de albedo com detectores de traços (Piesch et al., 1984). No ano seguinte a IAEA (International Atomic Energy Agency), no TRS-252 (IAEA, 1985), citava: "... o uso do CR-39 combinado com dosímetros de albedo parece ser o mais promissor...". Em 1993 o Los Alamos National Laboratory, dos EUA comparou dosímetros termoluminescentes e de traços e planejou a utilização combinada das duas técnicas (Harvey et al., 1993). Mais recentemente, Fernandez (2004), também fez a calibração de um dosímetro destes em uma usina nuclear. 


\section{OBJETIVOS}

\section{$2.1 \quad$ Geral}

Projeto, construção e caracterização de um dosímetro para dosimetria pessoal de nêutrons para o espectro de energia de uma fonte de ${ }^{241} \mathrm{Am}-\mathrm{Be}$ e o intervalo de dose de interesse da proteção radiológica (até $20 \mathrm{mSv}$ ).

\subsection{Específicos}

- Estudar a resposta dos detectores TLD-600 e TLD-700 em campos mistos nêutron-gama;

- Selecionar e caracterizar um policarbonato comercial para aplicação como detector de traços de nêutrons;

- Determinar os parâmetros de ataque químico para revelação dos detectores de traços;

- Determinar e padronizar a metodologia de avaliação (contagem de traços) dos detectores de traços;

- Definir o material do porta-dosímetro e filtros a serem utilizados;

- Projetar e construir protótipos do dosímetro;

- Efetuar testes de desempenho em campos mistos nêutron-gama;

- Padronizar um dosímetro para campos mistos nêutron-gama. 


\section{FUNDAMENTOS TEÓRICOS}

\subsection{Os nêutrons}

"O nêutron foi, provavelmente, a primeira partícula do universo há $10^{10}$ anos. Refletida na inteligência humana, sua existência foi antecipada por Rutherford em 1920, produzida em 1930 por Bothe e Becker e, finalmente, identificada por Chadwick em 1932" (Byrne, 1994). É uma partícula fundamental de massa ligeiramente maior que a do próton, nominalmente $1,6749.10^{-27} \mathrm{~kg}$, carga elétrica zero e encontram-se presos ao núcleo dos átomos.

Em conseqüência da neutralidade de sua carga, os nêutrons são partículas indiretamente ionizantes. Assim como a radiação eletromagnética, os nêutrons não interagem com a matéria por meio de forças Coulombianas, precisam chegar suficientemente próximos do núcleo para sofrer a ação das forças nucleares. Podem, portanto, penetrar profundamente no material alvo sem sofrer interações. Quando interagem diretamente com os núcleos da substância que está sendo atravessada, os nêutrons desaparecem e podem dar origem a radiações secundárias, como partículas carregadas pesadas e radiação gama.

Desta maneira, a interação dos nêutrons com a matéria é fortemente dependente da energia do nêutron e do próprio material alvo. Além disso, a radiação de nêutrons é intrinsecamente acompanhada de radiação gama, que interfere na resposta de alguns materiais dosimétricos.

Em vista disso, a detecção e a dosimetria de nêutrons são muito mais complexas do que para partículas carregadas e radiação eletromagnética. $\mathrm{O}$ desenvolvimento de um dosímetro pessoal para nêutrons sempre apresentou muitas dificuldades.

\subsubsection{Fontes de nêutrons}

Os nêutrons são produzidos naturalmente na atmosfera pelos chamados raios cósmicos e também podem ser produzidos por meio de outras formas: 
- Reações com Radionuclídeos $((\alpha, n)$ e $(\gamma, n))$;

- Fissão Espontânea;

- Aceleradores de Partículas;

- Reatores Nucleares;

- Reprocessamento de Combustíveis Nucleares.

Não há nenhuma ocorrência natural significativa de emissores de nêutrons, pois a ocorrência natural de um núcleo instável em razão do excesso de nêutrons transforma nêutrons em prótons e libera partículas beta ao invés de nêutrons. Radionuclídeos emissores de nêutrons podem ser produzidos artificialmente bombardeando átomos com nêutrons, mas apenas o Califórnio $\left({ }^{252} \mathrm{Cf}\right)$ pode ser utilizado como tal (IAEA, 1985). Outra forma de produzir fontes de nêutrons é a partir de reações nucleares. A reação mais comum é o bombardeamento do Berílio com partículas alfa. As fontes de nêutrons de uso mais freqüente são as de ${ }^{241} \mathrm{Am}-\mathrm{Be},{ }^{210} \mathrm{Po}-\mathrm{Be},{ }^{226} \mathrm{Ra}-\mathrm{Be}$ e ${ }^{293} \mathrm{Pu}-\mathrm{Be}$.

Os Aceleradores de Partículas são amplamente utilizados na medicina para irradiações de pacientes com câncer, bem como em experimentos de física nuclear e produção de radionuclídeos. Nestes casos, os nêutrons são produzidos na colisão das partículas aceleradas em alvos ou por reações $(\gamma, n)$ oriundas do bremsstrahlung de aceleradores de elétrons.

Em reatores nucleares a produção de nêutrons é obtida pelo processo de reação em cadeia da fissão do urânio-235. São produzidos, em média, de dois a três nêutrons rápidos por fissão. Esses nêutrons sofrem colisões com átomos leves (moderadores), perdendo energia até se tornarem térmicos. Após termalizados, os nêutrons produzem novas fissões.

No reprocessamento do combustível nuclear, o decaimento dos radioisótopos presentes no material induz reações nucleares com outros elementos, produzindo nêutrons.

\subsubsection{Fontes de ${ }^{241} \mathrm{Am}-\mathrm{Be}$}

A fonte de ${ }^{241} \mathrm{Am}-\mathrm{Be}$ é a mais utilizada comercialmente por causa de sua longa meia vida, 433 anos, e pela pouca emissão de radiação gama, se comparada com outras fontes de nêutrons. Esta fonte é produzida a partir da 
mistura compactada de óxido de amerício e de berílio metálico em pó.

O Amerício decai pela emissão de fótons de $59,5 \mathrm{keV}$ e de partículas alfa. As partículas alfa interagem com o Berílio e geram os nêutrons. $O$ espectro energético da fonte de ${ }^{241} \mathrm{Am}$-Be (FIG.1) é compreende nêutrons com energias entre $100 \mathrm{keV}$ e $10 \mathrm{MeV}$. A moda da energia dos nêutrons emitidos é 4,5 MeV.

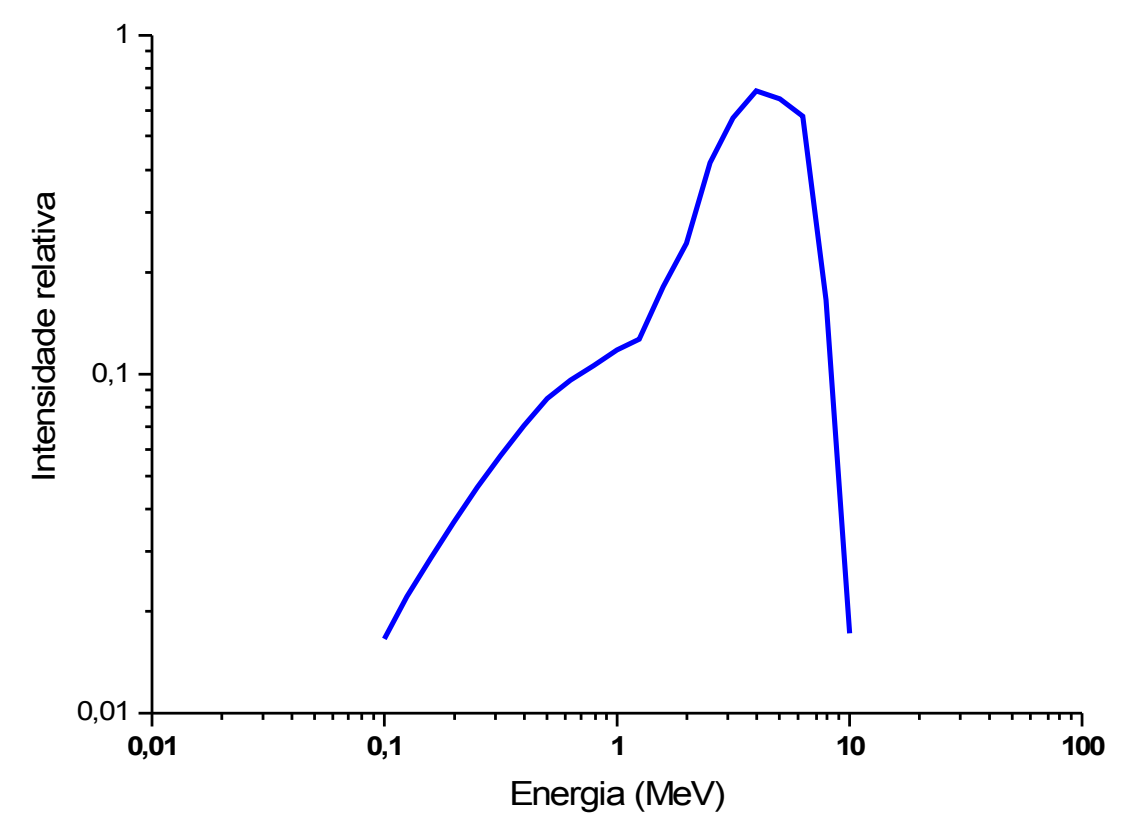

Figura 1: Espectro da fonte de ${ }^{241} \mathrm{Am}-\mathrm{Be}$ (IAEA, 2001)

As principais aplicações comerciais das fontes de ${ }^{241} \mathrm{Am}-\mathrm{Be}$ (Szabo e Boutaine, 1997) são:

\section{- Medição de umidade}

Medidores nucleares com fontes de nêutrons são úteis para detecção de líquidos e medidas de teor de umidade. $O$ método de medida é baseado na moderação ou frenagem de nêutrons rápidos; a umidade contida no meio é medida em termos da taxa de contagem do detector. As maiores aplicações desta técnica encontram-se na:

- Agricultura:

Relações planta-solo-água, umidade e movimento do solo, irrigação e 
drenagem, evaporação e evapo-transpiração.

- Engenharia Civil:

Compactação e movimento do solo e medida da espessura de camadas de concreto e asfalto.

- Hidrologia:

Quantidade de água em reservatórios, taxa de infiltração e irrigação, consumo de água por plantas e evaporação do solo.

- Indústria:

Controle de qualidade de materiais e processos e medida da quantidade de gás em reservatórios.

\section{- Exploração de recursos minerais}

Com o propósito de medir porosidade ou densidade, uma fonte de nêutrons é inserida dentro de poços de perfilagem (FIG.2). Os nêutrons são moderados e espalhados por elementos hidrogenados contidos no meio.

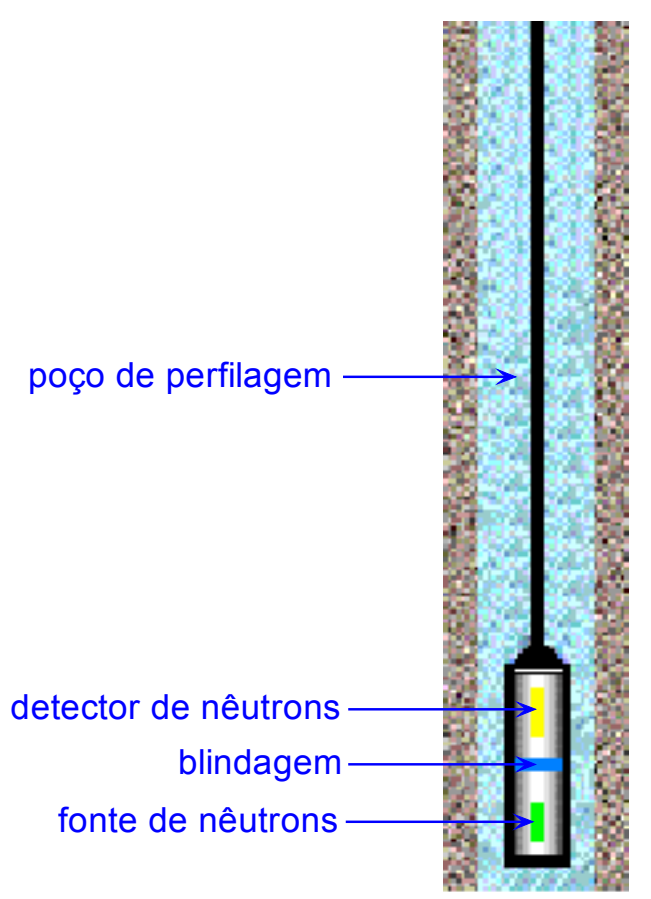

Figura 2: Esquema do sistema de medida de porosidade utilizando nêutrons

A taxa de nêutrons detectada corresponde à quantidade de hidrogênio presente no local, que é correlacionada com a porosidade ou densidade. 


\section{- Radiografia industrial}

Fontes radioativas são utilizadas para controle de qualidade e análise de materiais. $O$ ensaio consta de uma varredura do material na área de interesse. Falhas ou fissuras são detectadas pela variação na taxa de contagem dos detectores. Em geral são utilizadas fontes de radiação gama, todavia fontes de nêutrons, como ${ }^{241} \mathrm{Am}-\mathrm{Be}$, também são empregadas para esta finalidade quando o material a ser examinado apresentar alta seção de choque para nêutrons.

\section{- Detecção de explosivos e narcóticos}

Mediante um método chamado Análise de Nêutrons Rápidos Pulsados é possível a detecção não-destrutiva de explosivos e narcóticos. É feita uma análise da distribuição espectral da radiação gama induzida pela interação de nêutrons rápidos com os elementos do material inspecionado.

\subsubsection{Classificação dos nêutrons}

Os nêutrons são subdivididos em intervalos de energia de acordo com o comportamento apresentado. Esta classificação apresenta um caráter mais qualitativo do que quantitativo; é possível, para determinada aplicação, alterar ligeiramente os limites dos intervalos.

A classificação utilizada no presente trabalho é a seguinte:

- Térmicos: $E_{n} \leq 0,5$ eV (energia de corte do cádmio para absorção de nêutrons);

- Intermediários: $0,5 \mathrm{eV}<\mathrm{E}_{\mathrm{n}}<1 \mathrm{MeV}$;

- Rápidos: $1 \mathrm{MeV} \leq \mathrm{E}_{\mathrm{n}}<10 \mathrm{MeV}$;

- Relativísticos: $\mathrm{E}_{\mathrm{n}} \geq 10 \mathrm{MeV}$.

- Nêutrons de Albedo: nêutrons que ao entrarem no corpo humano são moderados e retro-espalhados para fora do mesmo com energias térmicas;

São de interesse para este trabalho os nêutrons com energias entre a térmica e $20 \mathrm{MeV}$, ou seja, no intervalo de energia de importância para dosimetria 
pessoal de nêutrons (ISO, 2002).

\subsubsection{Interação dos nêutrons com a matéria}

A interação dos nêutrons com a matéria envolve diversos processos e é bastante dependente do material irradiado e da energia dos nêutrons. A transferência de energia dos nêutrons para o meio se dá em duas etapas: produção de radiação diretamente ionizante por reações nucleares e transferência da energia dessa radiação secundária para o meio, através de colisões eletrônicas e nucleares.

Dentre os processos de interação, os principais são o espalhamento elástico, o espalhamento inelástico, a captura radioativa, as reações nãoelásticas, a fissão e a fragmentação (Lamarsh, 1983).

\subsubsection{Espalhamento elástico $(n, n)$}

Ocorre quando um nêutron interage com um núcleo leve. O momento e a energia cinética são conservados, o núcleo alvo sofre apenas um recuo, não ficando excitado. Este processo pode ocorrer com nêutrons de qualquer energia, porém é mais efetivo para nêutrons rápidos e intermediários.

\subsubsection{Espalhamento inelástico (n, n'), $(n, n \gamma)$}

Acontece pela interação dos nêutrons com núcleos pesados. O nêutron é momentaneamente capturado pelo núcleo e re-emitido com menor energia, deixando o núcleo alvo em estado excitado. O limiar de energia para esse processo é de aproximadamente $4 \mathrm{MeV}$.

Em processos ( $n, n \gamma)$ a energia de excitação é liberada pelo núcleo pela emissão instantânea de um raio gama, enquanto que em processos (n,n') o núcleo permanece durante certo tempo em um estado meta-estável.

\subsubsection{Captura radioativa $(n, \gamma)$}

É um processo terminal, onde os nêutrons são completamente freados. A captura radioativa de nêutrons térmicos é possível em quase todos os 
nuclídeos. Neste processo, o núcleo alvo captura o nêutron incidente e forma um núcleo composto em estado excitado. A energia de excitação pode ser liberada pela emissão de um ou mais raios gama.

A seção de choque para captura radioativa é inversamente proporcional à velocidade do nêutron para energias térmicas.

3.1.3.4 Reações não-elásticas $(n, p),(n, d),(n, \alpha),(n, t),(n, \alpha p),(n, 2 n)$, etc

Nestes processos o nêutron é capturado pelo núcleo alvo, que emite partículas carregadas, como prótons, dêuterons, alfas e trítions, ou dois ou mais nêutrons para se estabilizar.

Como essas partículas precisam superar a barreira de potencial Coulombiano, os nêutrons devem possuir energias altas. Particularmente para reações $(n, 2 n)$ é necessário energias acima de $10 \mathrm{MeV}$.

Reações como essas são caracterizadas por ressonâncias no espectro energético dos nêutrons.

\subsubsection{Fissão $(n, f)$}

A interação de nêutrons com materiais físseis provoca a formação de um núcleo composto que geralmente divide-se em dois fragmentos de fissão, emitindo um ou mais nêutrons.

\subsubsection{Fragmentação}

Neste caso, o núcleo bombardeado com nêutrons de energias iguais ou superiores a $20 \mathrm{MeV}$ é fracionado em várias partículas e fragmentos nucleares.

\subsubsection{Seção de choque}

A seção de choque é uma medida quantitativa da probabilidade de ocorrer determinada reação nuclear com nêutrons; corresponde à área efetiva em que o nêutron pode interagir com o material alvo. Para todos os meios a seção de 
choque é uma função da energia do nêutron incidente e da natureza do núcleo alvo (Lamarsh, 1983).

Considerando uma taxa de fluência de nêutrons $\Phi$ (nêutrons $/ \mathrm{cm}^{2} . s$ ) incidente em um material de densidade de átomos $\mathrm{N}$ e espessura $\mathrm{X}$, gerando $\mathrm{T}$ colisões por $\mathrm{cm}^{2}$.s, a Seção de Choque Microscópica para o material será dada por:

$$
\sigma=\frac{T}{\Phi N X}\left[\mathrm{~cm}^{2}\right]
$$

Os valores das seções de choque são da ordem de ceptilionésimos de centímetros quadrados, por isso, utiliza-se o barn (b) como unidade de seção de choque. Um barn corresponde a $10^{-24} \mathrm{~cm}^{2}$.

É também comumente utilizada a Seção de Choque Macroscópica $\Sigma$, que corresponde à probabilidade do nêutron sofrer interação com os átomos de um material de $1 \mathrm{~cm}$ de espessura.

$$
\Sigma=N \sigma\left[\mathrm{cm}^{-1}\right]
$$

\subsubsection{Atenuação de nêutrons}

A intensidade de nêutrons que não interagem com átomos ao atravessar um material segue a lei exponencial:

$$
\Phi=\Phi_{o} e^{-\Sigma x}
$$

A probabilidade dos dos nêutrons se moverem através de um meio sem sofrer colisões pode ser aproximada pela distância média percorrida por um nêutron até sofrer uma colisão com um átomo do material. Essa espessura de material é denominada Livre Caminho Médio $(\lambda)$.

$$
\lambda=\frac{1}{\Sigma}[\mathrm{cm}]
$$




\subsubsection{Interação dos nêutrons com o tecido humano}

O tecido humano é composto basicamente de oxigênio, carbono, hidrogênio e nitrogênio. Nêutrons rápidos sofrem espalhamento elástico ao colidirem com os constituintes do tecido humano; entre 90 e $70 \%$ da dose é resultante da interação dos nêutrons com o hidrogênio, enquanto que o restante cabe aos elementos pesados. Já os nêutrons térmicos e intermediários interagem principalmente por captura radioativa com o hidrogênio, ${ }^{1} \mathrm{H}(\mathrm{n}, \gamma)^{2} \mathrm{H}$, e com o nitrogênio, ${ }^{14} \mathrm{~N}(n, p){ }^{14} \mathrm{C}$. Reações ${ }^{10} \mathrm{~B}(\mathrm{n}, \alpha){ }^{7} \mathrm{Li}$ e ${ }^{31} \mathrm{P}(\mathrm{n}, \gamma){ }^{32} \mathrm{P}$ também são comuns (Attix et al., 1968).

O hidrogênio e outros elementos leves (de baixo número atômico) são eficientes moderadores de nêutrons. Além de serem moderados, os nêutrons são espalhados, podendo ser retro-espalhados (nêutrons de albedo).

Há, portanto, uma variedade de radiações secundárias criadas no tecido humano, as quais depositam sua energia de modos muito diferentes, trazendo importantes conseqüências biológicas ao mesmo.

\subsubsection{Nêutrons de albedo}

Nêutrons rápidos e intermediários ao colidirem com o corpo humano interagem com os materiais hidrogenados que o compõem, sendo termalizados e espalhados para fora do corpo. A estes, acrescenta-se ainda os nêutrons térmicos incidentes que também são espalhados.

Em razão deste processo, um fluxo de nêutrons térmicos é criado em direção oposta aos nêutrons incidentes. A fluência de nêutrons retro-espalhados depende da energia do nêutron incidente, como mostra a FIG.3. Estes nêutrons retro-espalhados são os chamados nêutrons de albedo.

A palavra albedo provem de "albus", que significa Branco em Latim. Em física, é a razão da radiação espalhada pela incidente, uma medida adimensional da reflectividade do corpo ${ }^{1}$. 


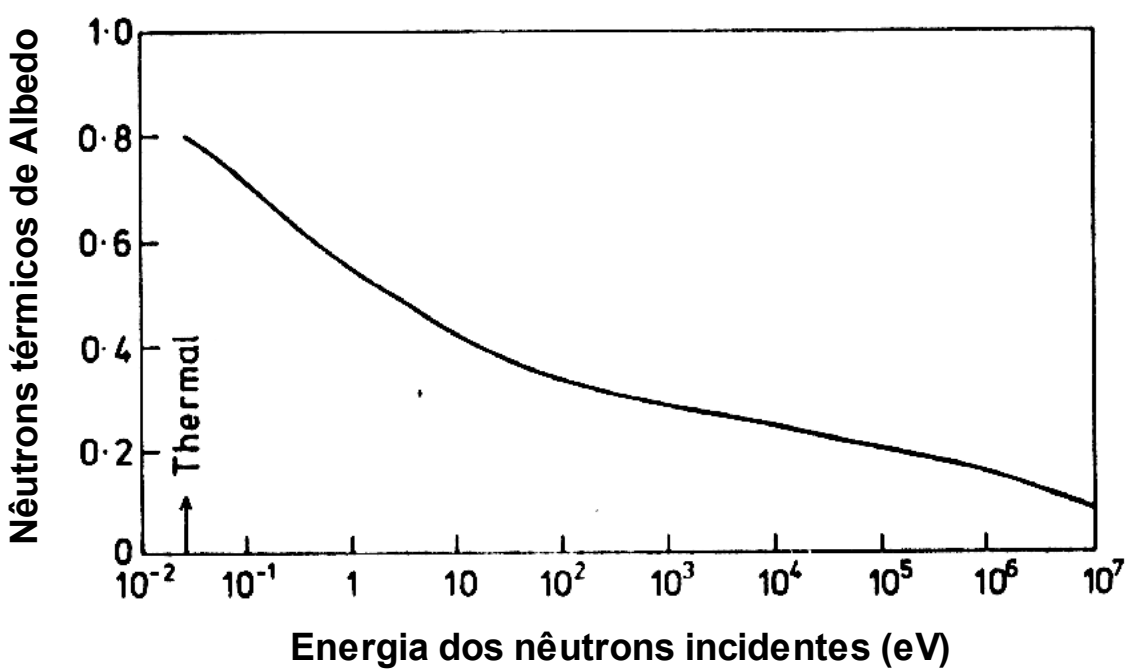

Figura 3: Nêutrons retro-espalhados pelo corpo humano em função da energia do nêutron incidente (Oberhofer e Scharmann, 1981)

\subsection{Dosimetria de nêutrons}

Os nêutrons podem ser detectados por vários tipos de detectores tais como: câmaras de ionização, câmaras de fissão, cintiladores, detectores proporcionais gasosos, semicondutores etc. Porém esses métodos não podem ser utilizados para dosimetria pessoal, mesmo que apresentem instrumentação simples e baixa sensibilidade à radiação gama, uma vez que essas vantagens são contrabalançadas com suas massas $(7-14 \mathrm{~kg})$ e seus altos custos (Harvey et al., 1976; Harrison et al., 1978).

Segundo a publicação número 39 da International Commission on Radiation Units and Measurements (ICRU, 1985), os dosímetros para uso em proteção radiológica devem apresentar as seguintes características:

- resposta em energia que siga a curva para dose equivalente em função da energia apresentada pela ICRP (International Commission on Radiological Protection) ou ser capaz de indicar diretamente a energia dos nêutrons de modo a possibilitar uma interpretação direta destes dados;

- limite mínimo de detecção de aproximadamente 0,3 mSv;

- insensibilidade a fótons e partículas beta;

- não apresentar decaimento da resposta com o tempo; 
- não ser afetado por condições ambientais como temperatura, umidade, pressão ou choque mecânico;

- ser atóxico;

- ter baixo custo;

- possuir massa e dimensões reduzidas.

As técnicas de dosimetria pessoal para nêutrons mais conhecidas e utilizadas são a Emulsão Fotográfica, a Termoluminescência e a Detecção de Traços Nucleares.

\subsubsection{Emulsões fotográficas}

Conhecido como dosimetria de filme, é um método passivo que envolve a contagem de traços de prótons produzidos pelo espalhamento elástico dos nêutrons em um extrato de gelatina contendo grãos de brometo de prata.

As emulsões fotográficas foram os primeiros dosímetros individuais para nêutrons, na década de 1950, quando Cheka (1954) e Cook (1958) estudaram os efeitos da irradiação de dosímetros fotográficos comerciais com nêutrons.

Este sistema de dosimetria apresenta varias restrições: alto decaimento da resposta (desvanecimento), dificuldade de conservação sob diferentes condições ambientais, sensibilidade à partículas beta e radiação gama e limiar energético de detecção de nêutrons de, aproximadamente, $800 \mathrm{keV}$.

Até a década de 1970 utilizava-se comumente emulsões fotográficas para dosimetria de nêutrons rápidos. Em 1979, Eisen e seus colaboradores desenvolveram um dosímetro para nêutrons rápidos baseado no uso de um detector de policarbonato em substituição aos dosímetros de filme. O não decaimento da resposta e a insensibilidade à radiações beta e gama foram apresentadas como vantagens e o alto limiar energético $(\sim 1 \mathrm{MeV})$ como desvantagem do material utilizado (Eisen et al., 1980). 


\subsubsection{Termoluminescência (TL)}

Amplamente difundida para dosimetria de fótons, também pode ser utilizada na dosimetria de nêutrons de energia baixa. Trata-se de detectores compostos de cristais, que quando irradiados recebem energia suficiente para que elétrons de sua banda de valência tornem-se capazes de passar para a banda de condução. O elétron e a lacuna deixada por ele se movem através do cristal até sofrerem recombinações ou serem capturados em estados metaestáveis de energia (armadilhas) localizados na banda proibida. Quando o cristal é aquecido, os elétrons são desarmadilhados e ocorre a emissão de um fóton termoluminescente (FIG.4). A quantidade de fótons produzidos é proporcional à dose de radiação.

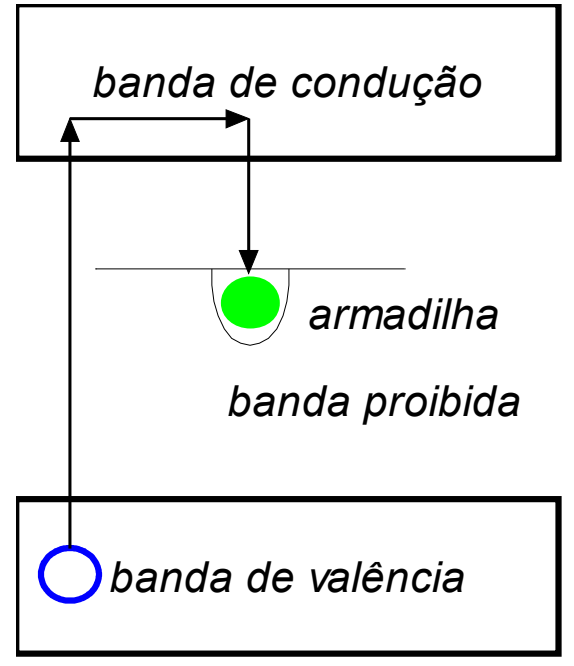

cristal irradiado

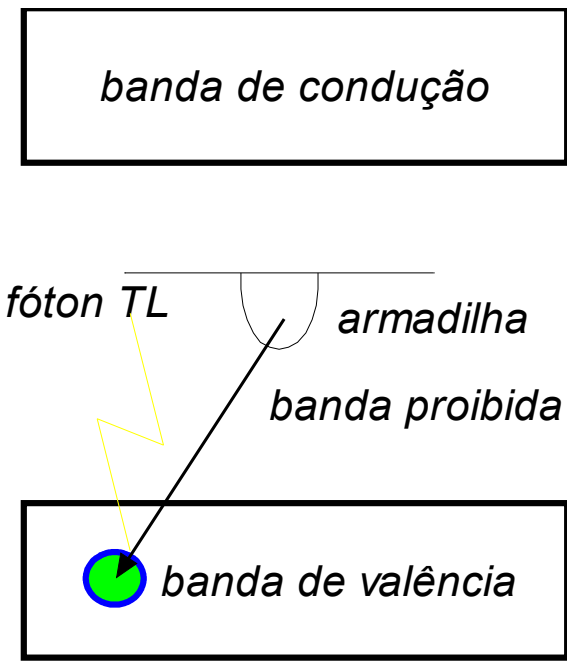

cristal aquecido

Figura 4: Modelo do fenômeno da termoluminescência

Um modelo matemático simplificado para o fenômeno da termoluminescência foi sugerido por Randall e Wilkins (1945). Admitindo que o número de fótons emitidos é proporcional ao número de elétrons que se recombinam, avalia-se a quantidade desses elétrons. A probabilidade, $p$, de um elétron capturado escapar da armadilha é uma distribuição maxwelliana da energia térmica dos elétrons:

$$
p=s \cdot e^{\frac{-E}{K T}}
$$

onde:

$s$ = fator de freqüência, que é relacionado com a freqüência de oscilação 
do elétron na armadilha;

$$
\begin{aligned}
& \mathrm{E}=\text { profundidade da armadilha (energia); } \\
& \mathrm{K}=\text { constante de Boltzmann; } \\
& \mathrm{T}=\text { temperatura. }
\end{aligned}
$$

Mantendo-se a temperatura constante, o número de elétrons nas armadilhas, $\mathrm{n}$, decrescerá com o tempo de acordo com:

$$
\frac{d n}{d t}=-p . n
$$

Considerando um aquecimento linear do fósforo termoluminescente e substituindo (5) em (6):

$$
n=n_{0} \cdot e^{\frac{-s}{\alpha} \int \frac{T}{T_{0}} \cdot e^{\frac{-E}{K T}} \cdot d T}
$$

onde $\alpha$ é a taxa de aquecimento.

As vantagens desta técnica são a alta sensibilidade e dimensão reduzida dos detectores, fácil automação do sistema de leitura, baixo custo e reutilização dos detectores. A forte dependência energética e a perda da informação após a leitura são as desvantagens apresentadas.

Os materiais mais utilizados para a dosimetria de radiação gama e $X$ são o Fluoreto de Lítio e o Sulfato de Cálcio. Para dosimetria de nêutrons são aplicados cristais termoluminescentes contendo isótopos de alta sensibilidade a nêutrons térmicos, como o ${ }^{6} \mathrm{Li}$ e $\circ{ }^{10} \mathrm{~B}$. Os mais utilizados são o sulfato de cálcio(CaSO $\left.\mathrm{C}_{4}\right)$, o fluoreto de lítio $(\mathrm{LiF})$, o tetraborato de lítio $\left(\mathrm{Li}_{2} \mathrm{~B}_{4} \mathrm{O}_{7}\right)$ e o óxido de berílio (BeO). A TAB.1 compara a resposta destes materiais a nêutrons térmicos.

A dosimetria termoluminescentes (DTL) é a metodologia tradicional para avaliação da dose de nêutrons térmicos. Uma vez que, normalmente, os nêutrons são acompanhados de radiação gama e os materiais TL também apresentam sensibilidade a essa radiação, é necessário utilizar um par de detectores. Um detector com alta sensibilidade e outro praticamente insensível a nêutrons para discriminar as respostas. 
Tabela 1: Sensibilidade de cristais TL a nêutrons térmicos (Ayyangar et al., 1974)

\begin{tabular}{lc}
\hline \multicolumn{1}{c}{ Cristal TL da Harshaw } & Resposta a nêutrons térmicos \\
$\mathrm{CaSO}_{4}:$ Dy & 0,52 \\
$\mathrm{CaSO}_{4}:$ Dy enriquecido com ${ }^{6} \mathrm{Li}$ & 6,2 \\
$\mathrm{LiF}$ natural & 330 \\
$\mathrm{LiF}$ enriquecido com ${ }^{6} \mathrm{Li}$ & 1520 \\
$\mathrm{LiF}$ empobrecido de ${ }^{6} \mathrm{Li}$ & 1,1 \\
$\mathrm{BeO}$ & 0,45 \\
$\mathrm{Li}_{2} \mathrm{~B}_{4} \mathrm{O}_{7}: \mathrm{Mn}$ & 390 \\
\hline
\end{tabular}

O detector de fluoreto de lítio é comercialmente disponível pela Harshaw Chemical Company, dos Estados Unidos da América, em três composições isotópicas:

- LIF natural (TLD-100, 7,4\% $\left.{ }^{6} \mathrm{Li}\right)$;

- ${ }^{6} \mathrm{LiF}\left(\mathrm{TLD}-600,96,7 \%{ }^{6} \mathrm{Li}\right)$;

- ${ }^{7} \operatorname{LiF}\left(T L D-700, \sim 0,01-0,04 \%{ }^{6} \mathrm{Li}\right)$

O isótopo ${ }^{6} \mathrm{Li}$ apresenta seção de choque de captura de nêutrons térmicos da ordem de $945 \mathrm{~b}$ através da reação ${ }^{6} \mathrm{Li}(\mathrm{n}, \alpha)^{3} \mathrm{H}$ em contraste com $0,033 \mathrm{~b}$ do isótopo ${ }^{7} \mathrm{Li}$ para a reação ${ }^{7} \mathrm{Li}(\mathrm{n}, \gamma)^{8} \mathrm{Li}$. Fazendo-se uma releitura da TAB.1 é fácil observar que o TLD-600 possui a maior sensibilidade a nêutrons térmicos e considerar o TLD-700 insensível a nêutrons.

O uso do par de detectores TLD-600 e TLD-700 é o mais consagrado na literatura internacional (Oberhofer e Scharman, 1981) e sua aplicação é rotineira em laboratórios de dosimetria pessoal para avaliação da dose de nêutrons na região abaixo da energia de corte do cádmio. Uma importante vantagem deste par de detectores é que ambos respondem de forma idêntica a fótons.

Resumidamente, o algoritmo para o cálculo da dose é o seguinte:

$$
\begin{gathered}
R_{6}=R_{\gamma}+R_{\left(n_{t h}\right)} \\
R_{7}=R_{\gamma}
\end{gathered}
$$


Relacionando (8) e (9):

$$
R_{\left(n_{t h}\right)}=R_{6}-R_{7}
$$

onde:

$$
\begin{aligned}
& R_{6}=\text { resposta do TLD-600 } \\
& R_{7}=\text { resposta do TLD-700 } \\
& R_{\gamma}=\text { resposta à radiação gama } \\
& R_{n \text { nth }}=\text { resposta à nêutrons térmicos }
\end{aligned}
$$

A FIG.5 compara as respostas destes detectores irradiados com a mesma dose de nêutrons.

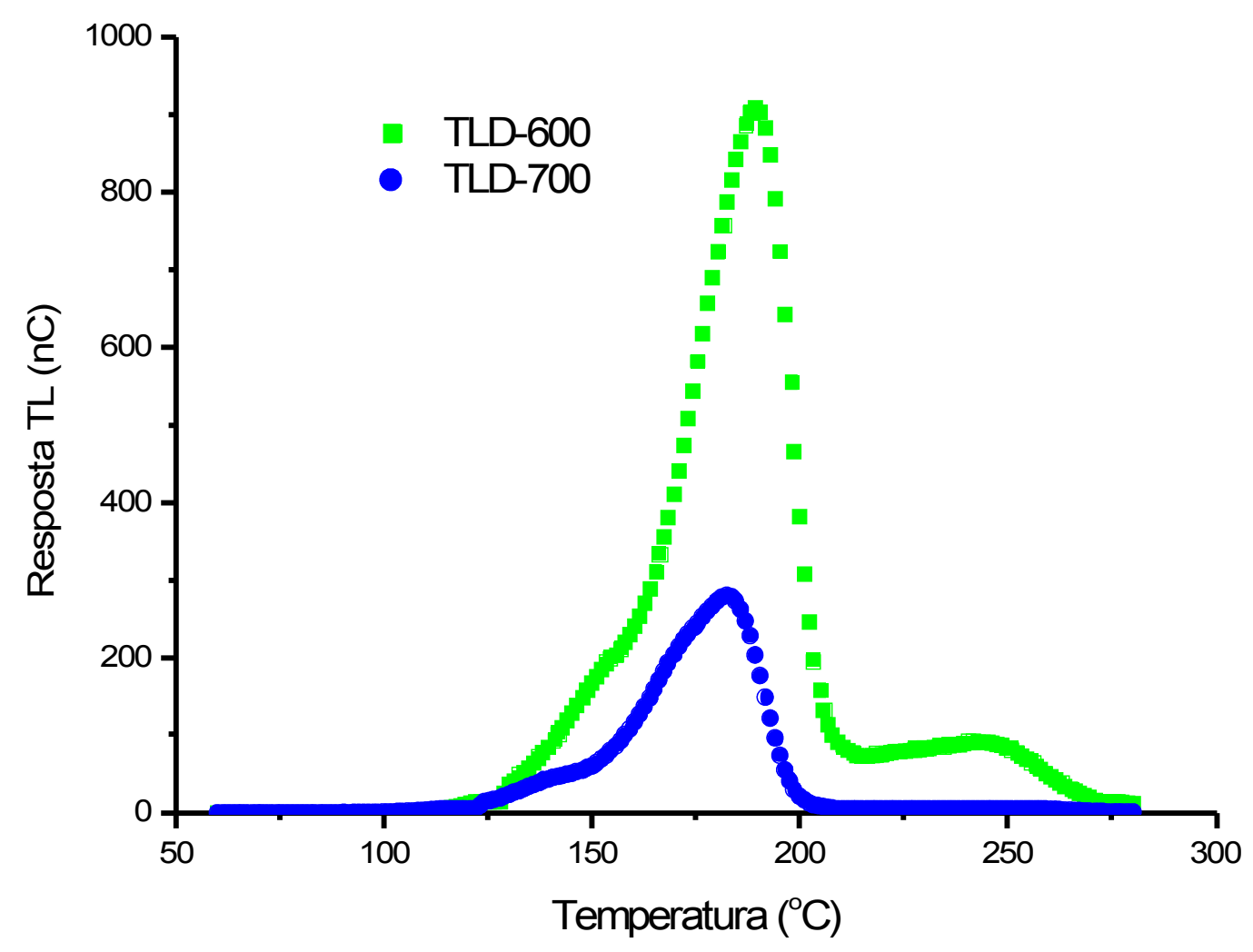

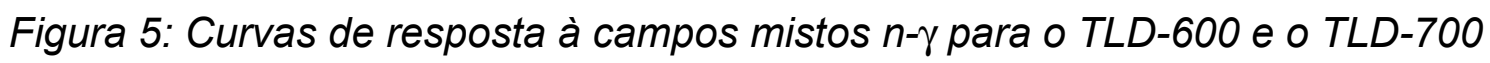

Visto que os materiais TL apresentam baixa resposta para nêutrons 
com energias acima da térmica, várias técnicas já foram estudadas para contornar essa dificuldade. Dentre elas o uso de folhas de material físsil para detecção dos fragmentos e o uso de moderadores para termalizar os nêutrons. Ambas as técnicas aumentam os custos do dosímetro e também apresentam a desvantagem de expor o usuário a uma dose extra, oriunda pela radiação adicional criada pelo próprio equipamento. Outra solução é o uso da dosimetria termoluminescente de albedo (DTLA).

\subsubsection{Dosimetria de albedo}

A técnica de albedo é baseada na premissa de que a fluência dos nêutrons térmicos de albedo gerados pelo corpo humano é proporcional à dose absorvida no corpo. Os primeiros registros do uso rotineiro deste tipo de dosímetro datam da década de 1960, porém, na década seguinte muito esforço foi dispensado para melhorar a resposta dos DTLA, quer seja incorporando materiais moderadores ou mais detectores aos mesmos. Na FIG.6 (Piesch, 1977) estão esquematizados os principais dosímetros que foram desenvolvidos.

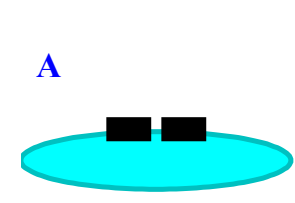

D
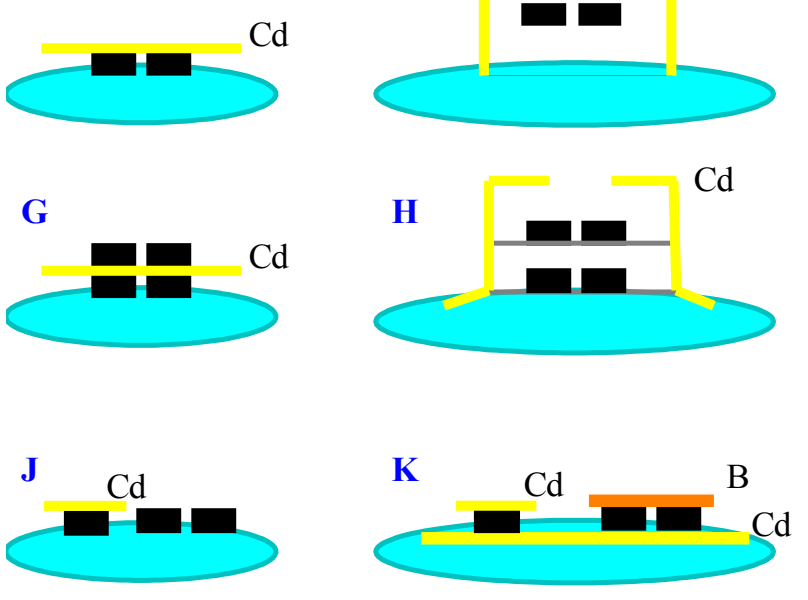

Par de detectores TLD-600 / TLD-700

Detector TLD-600

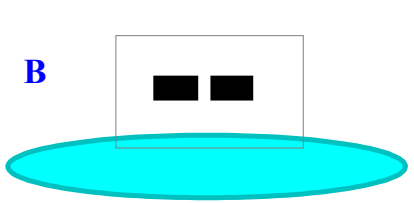

$\mathrm{Cd}$
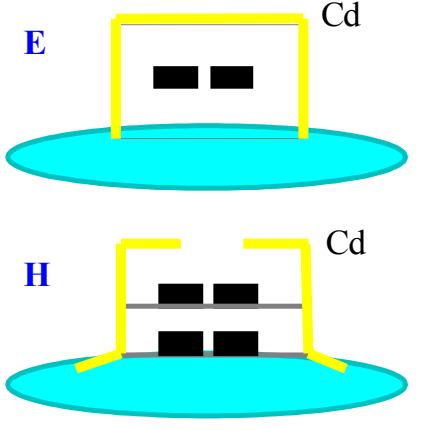

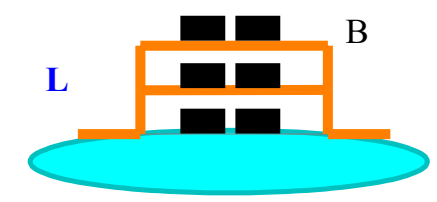

Filtro de Cádmio Encapsulamento de Boro

Figura 6: Tipos de dosímetros $T L$ de albedo 
Os tipos (A), (B) e (C) são as configurações mais simples, não diferenciam nêutrons incidentes e de albedo. Já os tipos $(D),(E)$ e $(F)$ respondem somente e nêutrons de albedo e os tipos $(G),(H)$ e (I) discriminam os nêutrons incidentes dos de albedo. Mais complexos, os tipos $(J),(K)$ e $(L)$ distinguem nêutrons térmicos e epitérmicos incidentes. É notório o uso de cádmio e boro para absorção de nêutrons térmicos.

Hankins (1972) estudou diversas configurações de dosímetros de albedo com detectores de LiF e concluiu que a adição de materiais moderadores aumenta a sensibilidade, porém não modifica o comportamento da resposta em energia e que variações no espectro de energia altera significativamente a sensibilidade do sistema albedo. Em estudo posterior (Hankins, 1973) foi denotado que qualquer dosímetro de albedo usando pares de detectores TLD-600 e TLD-700 apresenta sempre a mesma dependência energética.

Em 1988 o dosímetro de albedo tornou-se o dosímetro oficial para nêutrons na Alemanha Ocidental, uma vez que Piesch e Burgkhardt (1988) demonstraram ser possível estimar a dose de nêutrons em diferentes espectros, desde que aplicado um fator de calibração apropriado.

A resposta do TLD-600 é baixa para nêutrons com energias superiores a $100 \mathrm{keV}$ e nêutrons rápidos praticamente não reagem com $0^{6} \mathrm{Li}$, por conseguinte, a técnica de albedo é igualmente limitada.

\subsection{Blindagem de cádmio}

Filtros de cádmio são utilizados para blindar nêutrons térmicos de tal forma que os nêutrons térmicos incidentes não interajam com o detector para nêutrons de albedo e vice-versa.

O cádmio é um metal subproduto dos minérios de chumbo, cobre e zinco. Por isso seu preço de mercado é barato $(\mathrm{U} \$ 7,50 / \mathrm{kg})^{2}$. Em virtude de sua alta seção de choque, o cádmio é muito utilizado nas barras de controle de reatores nucleares como absorvedor para nêutrons térmicos para controle de potência e desligamento do reator. Contudo, seu uso trivial é menos nobre: eletrodeposição (galvanoplastia) e como anodo de soldas elétricas.

Para nêutrons com energias maiores que $0,5 \mathrm{eV}$ a seção de choque de

2 www.dileta.com.br 
absorção cai rapidamente (FIG.7), permitindo que os nêutrons atravessem o material. Dez livres caminhos médios $(\lambda)$ é a espessura suficiente para garantir que os nêutrons térmicos não atravessem a lâmina de cádmio. Sabendo que a seção de choque de absorção para o cádmio (Lide, 1995) é de $116,8 \mathrm{~cm}^{-1}$ e aplicando a equação (4),

$$
\text { 10. } \lambda=\frac{10}{116,8 \mathrm{~cm}^{-1}}=0,86 \mathrm{~mm}
$$

Com base nesse cálculo utilizou-se lâminas de cádmio de 0,9 mm de espessura para realização deste trabalho.

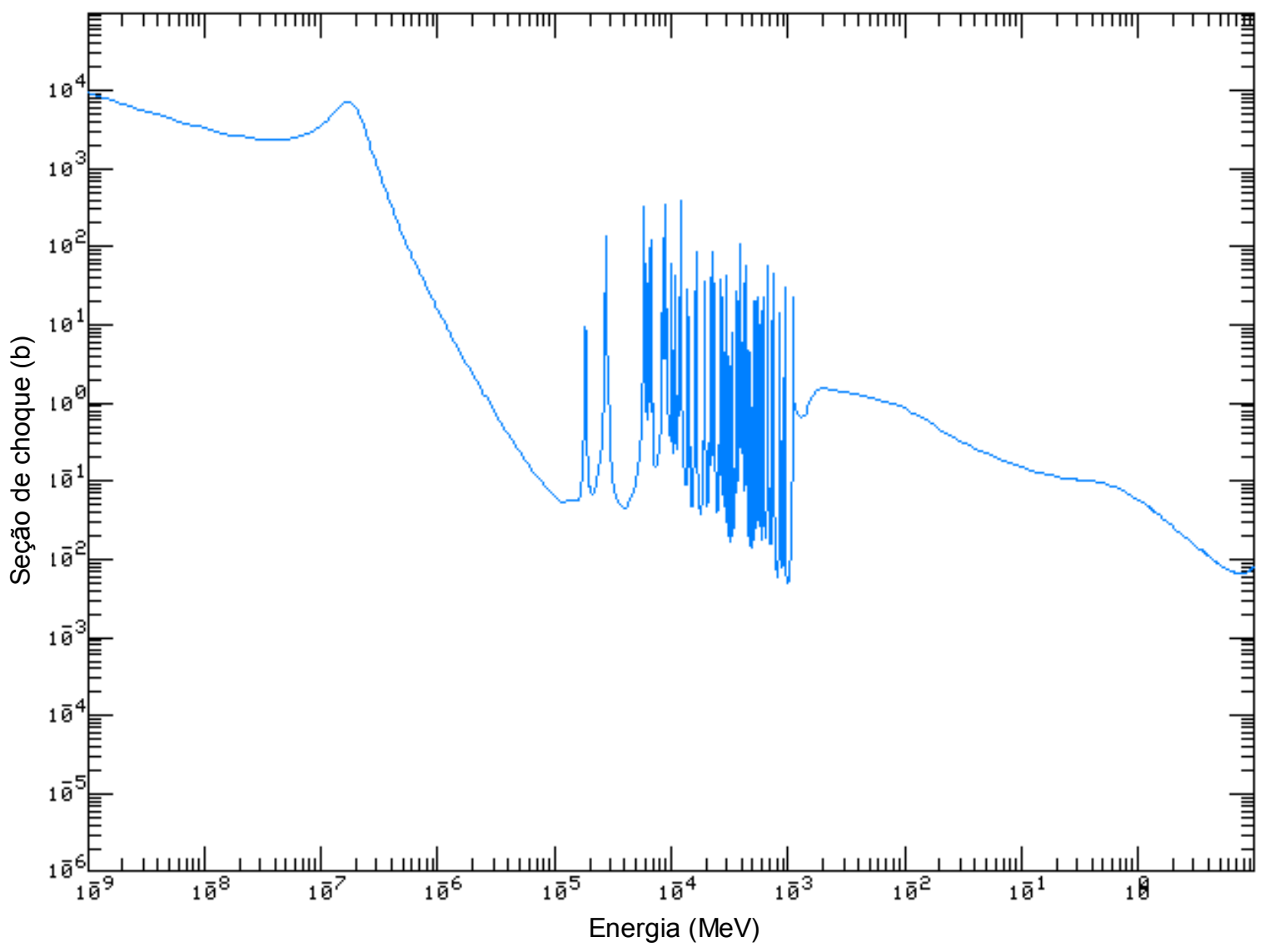

Figura 7: Seção de choque de absorção para o cádmio (http://atom.kaeri.re.kr)

\subsubsection{Detectores sólidos de traços nucleares (DSTN)}

Em inglês "Solid State Nuclear Track Detectors" (SSNTD), este tipo de detector é, em geral, constituído por materiais dielétricos, como silicatos minerais, nitratos de celulose, vidros isolantes ou polímeros. Os materiais mais utilizados são o nitrato de celulose LR-115 e os policarbonatos Makrofol e CR-39. 
Partículas carregadas atravessam estes materiais provocando um rastro de danos que se assemelham a traços, quando vistos através de um microscópio de transmissão. A densidade de traços no detector é proporcional ao fluxo de nêutrons ao qual o mesmo foi submetido, que por sua vez é proporcional à dose.

Os traços formados não são visíveis e precisam ser revelados e ampliados. Por meio do ataque químico, técnica introduzida por Price e Walker (1962), é possível visualizar os traços em microscópio óptico. O ataque químico consta da imersão dos detectores em uma solução alcalina por tempo e temperatura determinados. Esta solução corrói o material preferencialmente no centro dos traços, formando cavidades ocas, enquanto que mantém intacto o restante do material.

A contagem dos traços é efetuada pela leitura da superfície do detector. A contagem visual em um microscópio é a maneira mais simples de se fazer isso, contudo, é um processo muitas vezes demasiadamente longo e tedioso. Além disso, é um processo impreciso e sujeito a erros sistemáticos. Cross e Tomamasino (1970) desenvolveram uma técnica automática para eliminar a fastidiosa contagem em microscópio, o "Spark Counting". Mediante um campo elétrico intenso aplicado entre as faces do detector, o mesmo fica susceptível à rupturas no local dos traços. Cada ruptura provoca uma descarga elétrica que é contada por um equipamento eletrônico. Esta técnica é limitada a detectores delgados, da ordem de mícrons. Existe também a possibilidade do uso de um programa computacional capaz de analisar imagens extraídas de um microscópio e contar automaticamente os traços (Morelli et al., 2003).

Existem dois métodos de dosimetria de traços: Traços de Fissão e Traços de Recuo.

\subsubsection{Traços de fissão}

Este método utiliza folhas delgadas de material físsil (radiador) em contato com o detector. Os nêutrons, ao colidirem com o radiador, originam reações não-elásticas cujas partículas resultantes atingem 0 detector, danificando-o. Uma grande desvantagem torna este método inconveniente para uso em dosimetria pessoal: o usuário fica exposto a uma dose extra de radiação 
proveniente do material físsil do próprio dosímetro, havendo ainda risco de contaminação interna pela ingestão dos compostos radioativos.

\subsubsection{Traços de recuo}

De modo a eliminar os radiadores físseis, este método é fundamentado na interação dos nêutrons com o próprio detector. As reações provocadas pela interação de nêutrons rápidos com policarbonatos tornam promissor o uso da dosimetria de traços nucleares pelo método de traços de recuo. Quando nêutrons rápidos interagem com os constituintes das moléculas de um policarbonato, eles são espalhados elasticamente ou acarretam reações $(n, \alpha)$.

Colisões elásticas podem ocorrer com nêutrons de todas as energias, mas nem sempre resultam em traços. Como não se observam traços de prótons em policarbonatos (Jozèfowicz, 1973), os núcleos de recuo do hidrogênio não contribuem com a formação de traços; somente os núcleos de recuo do carbono e do oxigênio são detectados.

Reações $(n, \alpha)$ são verificadas apenas para nêutrons de energias de alguns $\mathrm{MeV}$ e a seção de choque é relativamente baixa. Mesmo para nêutrons de alta energia, as seções de choque para espalhamento elástico são maiores que para reações $(n, \alpha)$, inferindo que se desconsidere a existência de traços de partículas alfa. Katz e Kobetich (1968) demonstraram que o limiar de energia capaz de produzir um núcleo recuo está entre 1,13 e 1,23 MeV para o carbono e entre 1,65 e 1,80 MeV para o oxigênio. Józefowicz (1971) estimou em 1,2 MeV o limiar de energia para registro da passagem de nêutrons pelo Makrofol E.

\subsubsection{Uso de policarbonatos como detectores de traços}

O Soreq Nuclear Research Center ${ }^{3}$, de Israel, estudou entre as décadas de 1970 e 1980 um policarbonato comercial para deteção de nêutrons (Eisen et al., 1980, 1981; Faermann, 1982). Em virtude da baixa eficiência de contagem deste policarbonato e entusiasmados com os trabalhos de Cartwrite (1978), Eisen et al. (1972) optaram por substituí-lo pelo CR-39, outro policarbonato. O dosímetro-espectrômetro de Faermann (1985) é considerado o primeiro dosímetro pessoal para nêutrons satisfatório.

3 www.soreq.gov.il 
A partir dos anos 90, o foco das pesquisas com DSTN foi verdadeiramente o CR-39, e o ENEA (Ente per le Nuove Tecnologie, l'Energia e l'Ambiente $)^{4}$, da Itália, se destacou pela publicação de trabalhos em relação ao tema. O uso de dosímetros de traços na rotina do ENEA seguiu testes de qualidade e aceitação do CR-39 (Fantuzzi et al., 2002; Mariotti et al., 2003) e calibração e performance do dosímetro (Morelli et al., 1999). Nos últimos anos o Instituto de Engenharia e Ciências Aplicadas do Paquistão ${ }^{5}$ pesquisou os materiais utilizados para realizar o ataque químico (Matiullah, et al., 2005a, 2005b).

No Brasil destacam-se os trabalhos de Cesar e Franco (1986), do IPEN (Instituto de Pesquisas Energéticas e Nucleares), e de Guedes et al. (1998). Os primeiros estudaram o ataque químico do Makrofol para nêutrons rápidos e os últimos concluíram que a eficiência de contagem dos traços no CR-39 é constante entre o BG e o limite para o surgimento de traços superpostos, desde que mantidos os parâmetros do ataque químico; também indicaram que essa afirmação pode ser verdadeira para outros detectores de traços.

O IPEN registrou na década de 1990 duas Dissertações de Mestrado e uma Tese de Doutorado envolvendo a detecção de nêutrons com detectores de traços nucleares. Padilha (1992) apresentou a detecção de nêutrons térmicos e rápidos com CR-39 e radiadores e Vilela estudou os policarbonatos CR-39 e Makrofol para detecção de nêutrons (Vilela, 1990 e 1992).

\subsection{Grandezas e unidades para dosimetria de nêutrons}

A ICRU recomenda o uso do Equivalente de Dose Individual Penetrante na profundidade de $10 \mathrm{~mm}\left(\mathrm{H}_{\mathrm{p}}(10)\right)$ para monitoração individual para nêutrons.

A unidade de dose equivalente no Sistema Internacional de unidades (SI) é o joule por quilograma $(\mathrm{J} / \mathrm{kg})$, porém se utiliza o sievert $(\mathrm{Sv})$, nome especial para esta unidade (ICRU, 1993).

\footnotetext{
4 www.enea.it

5 www.pieas.edu.pk
} 


\section{MATERIAIS E MÉTODOS}

\subsection{Materiais}

\subsubsection{Detectores TL}

- detectores Harshaw TLD-600;

- detectores Harshaw TLD-700.

\subsubsection{Detectores de traços}

- placa plana de policarbonato $\left(1650 \times 2440 \times 1,5 \mathrm{~mm}^{3}\right)$.

Trata-se de um policarbonato comercial de fabricação brasileira, de mesmo monômero químico do Makrofol, $\mathrm{C}_{16} \mathrm{H}_{14} \mathrm{O}_{3}$ (FIG.8). Esta resina é comercializada com um revestimento plástico de proteção. Uma das faces tem proteção contra radiação UV (ultravioleta) e é coberta por um plástico branco e outra face é coberta por um plástico transparente.

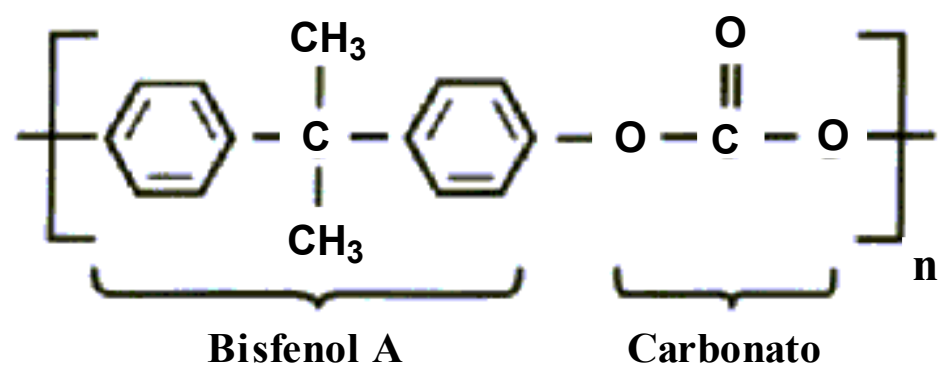

Figura 8: Monômero químico do policarbonato

A aplicação deste policarbonato é cotidiana (ver FIG.9):

- Construção Civil

- toldos e coberturas; 
- parapeitos de sacadas;

- divisórias.

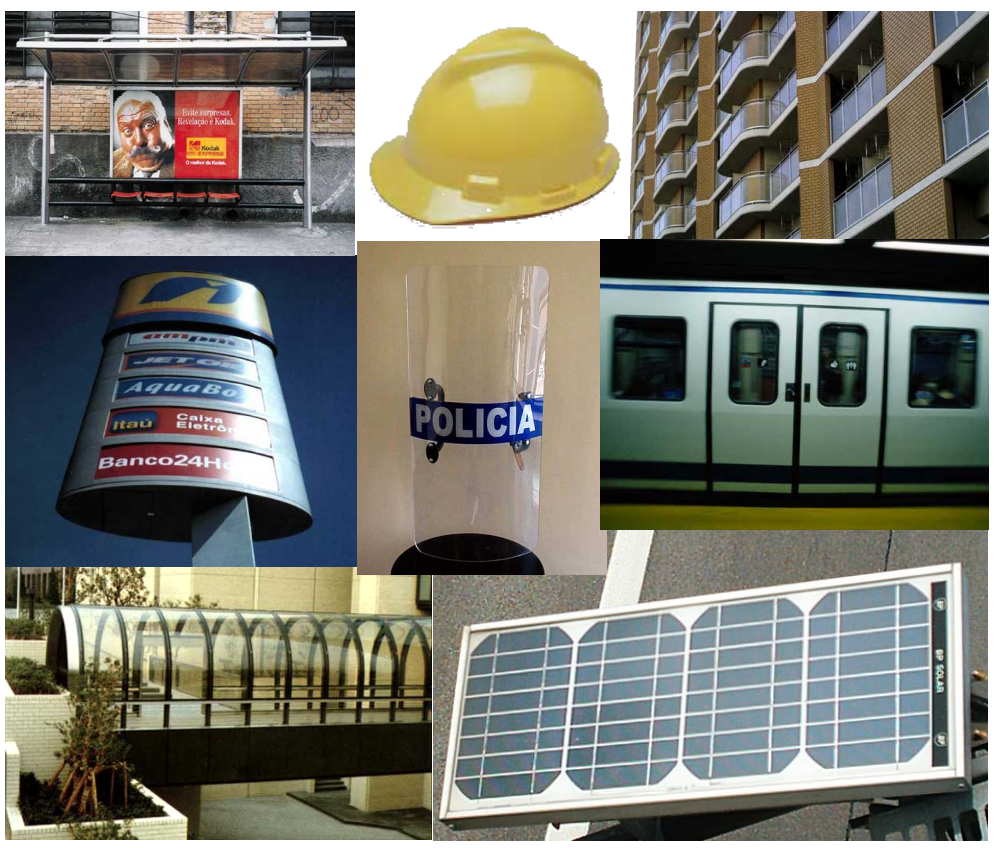

Figura 9: Aplicações comuns do policarbonato

- Indústria

- eletrodomésticos;

- equipamentos de proteção individual (EPI);

- coletores solares.

- Segurança e Sinalização

- blindagem de veículos e ambientes;

- escudos militares;

- isolantes acústicos;

- sinalizadores viários e luminosos.

- Transportes

- proteção de cabine em veículos pesados; 
- janelas e divisórias para meios de transporte (ônibus, metrôs, trens, aeronaves e barcos).

O policarbonato foi denominado de SS-1 e cada detector corresponde a uma amostra de $3 \times 1 \mathrm{~cm}^{2}$. A identificação da face frontal é feita com uma marca no canto superior esquerdo do detector.

\subsubsection{Porta-detector}

O porta-detector projetado constitui-se de um sanduíche de placas de PMMA e polietileno. As primeiras são as paredes externas e as últimas dão suporte aos componentes do dosímetro (detectores TL, blindagem de cádmio e detector de traços).

\subsubsection{Revelação dos traços}

- Solução química PEW-40:

- Água destilada;

- Álcool etílico absoluto $\left(\mathrm{C}_{2} \mathrm{H}_{5} \mathrm{OH}\right)$ P.A., marca Synth;

- Hidróxido de potássio (KOH) P.A., marca Merck.

\subsection{Equipamentos}

\subsubsection{Leitura dos detectores TL}

- Leitora TL, marca Harshaw modelo 2000A/B (IPEN);

- Programa computacional LabVIEW (IPEN). 


\subsubsection{Tratamento térmico dos detectores TL}

- Forno industrial, marca EDG modelo Five II (IPEN);

- Estufa cirúrgica, marca Fornitec (IPEN).

\subsubsection{Revelação dos traços nucleares}

- Balança eletrônica, marca Instrumentos Científicos C. G. Ltda. (IPEN);

- Balança eletrônica, marca Shimadzu modelo AY220 (PRO-RAD ${ }^{6}$ );

- Estufa cirúrgica, marca Fornitec (IPEN);

- Estufa cirúrgica, marca Fornitec (PRO-RAD).

\subsubsection{Leitura dos traços nucleares}

- Microscópio ótico, marca Optovac, modelo OptoNTIM (PRO-RAD);

- Câmera de vídeo, marca Samsung, modelo SDC-312ND (PRO-RAD);

- Microcomputador PC com placa de aquisição de imagem Play TV Pro Ultra (PRO-RAD).

\subsection{Irradiação de amostras e protótipos}

\subsubsection{Partículas alfa}

- Fonte de ${ }^{241} \mathrm{Am}$ do LCl (Laboratório de Calibração de Instrumentos) do IPEN. Atividade nominal: 369,4 kBq.

\subsubsection{Partículas beta}

- Fonte de ${ }^{90} \mathrm{Sr}^{90} \mathrm{Y}$ do LCl do IPEN. Atividade nominal: 1,9 GBq.

6 PRO-RAD - Consultores em Radioproteção S/S Ltda. 


\subsubsection{Radiação gama}

- Fonte de ${ }^{60} \mathrm{Co}$ do LCl do IPEN. Atividade nominal: 111,0 GBq.

- Fonte de ${ }^{137} \mathrm{Cs}$ do LCl do IPEN. Atividade nominal: 111,0 GBq.

\subsubsection{Fótons de energia baixa}

- Aparelho de Raios-X Industrial, marca Pantak/Seifert, modelo ISOVOLT 160HS (IPEN).

A TAB.2 apresenta os parâmetros das qualidades de feixe utilizadas para irradiar os detectores TL.

Tabela 2: Qualidades de feixe de raios-X utilizadas

\begin{tabular}{cccccc}
\hline Qualidade & $\begin{array}{c}\text { Filtro } \\
\left(\mathbf{c m}^{2} / \mathbf{g}\right)\end{array}$ & $\begin{array}{c}\text { Diâmetro do } \\
\text { Colimador } \\
(\mathbf{m m})\end{array}$ & $\begin{array}{c}\text { Tensão } \\
\mathbf{( k V )}\end{array}$ & $\begin{array}{c}\text { Corrente } \\
(\mathbf{m A})\end{array}$ & $\begin{array}{c}\text { Energia Efetiva } \\
(\mathbf{k e V})\end{array}$ \\
RQA 3 & 0,46 & 50,8 & 50 & 20 & 37,3 \\
RQA 5 & 0,87 & 50,8 & 70 & 20 & 49,4 \\
RQA 7 & 1,20 & 50,8 & 90 & 20 & 59,7 \\
RQA 9 & 1,57 & 50,8 & 120 & 20 & 71,15 \\
RQA 10 & 1,76 & 50,8 & 150 & 20 & 82,1 \\
ISON 150 & 0,18 & 70,5 & 150 & 20 & 118 \\
\hline
\end{tabular}

\subsubsection{Nêutrons}

\subsubsection{Fonte de ${ }^{241} \mathrm{Am}-\mathrm{Be}$ do IPEN}

Pertencente ao Centro de Engenharia Nuclear (CEN), produzida pela Amersham com atividade nominal de $3,7 \mathrm{GBq}$ e taxa de emissão de nêutrons de $3,1.10^{5} \mathrm{n} / \mathrm{s}$ em 02/07/1970 (Madi Filho, 1999).

Esta fonte não possui certificado de calibração, portanto, foi empregada exclusivamente para classificação dos detectores TL em lotes de sensibilidade, estudo do policarbonato SS-1 e medidas relativas de tempo e distância sem necessidade de precisão. 
As irradiações foram realizadas no ar e em temperatura ambiente. $O$ arranjo experimental (FIG.10) consta de um suporte metálico com aros concêntricos suspenso a $150 \mathrm{~cm}$ de altura, no centro do qual a fonte é disposta. O material a ser irradiado é posicionado nos aros.

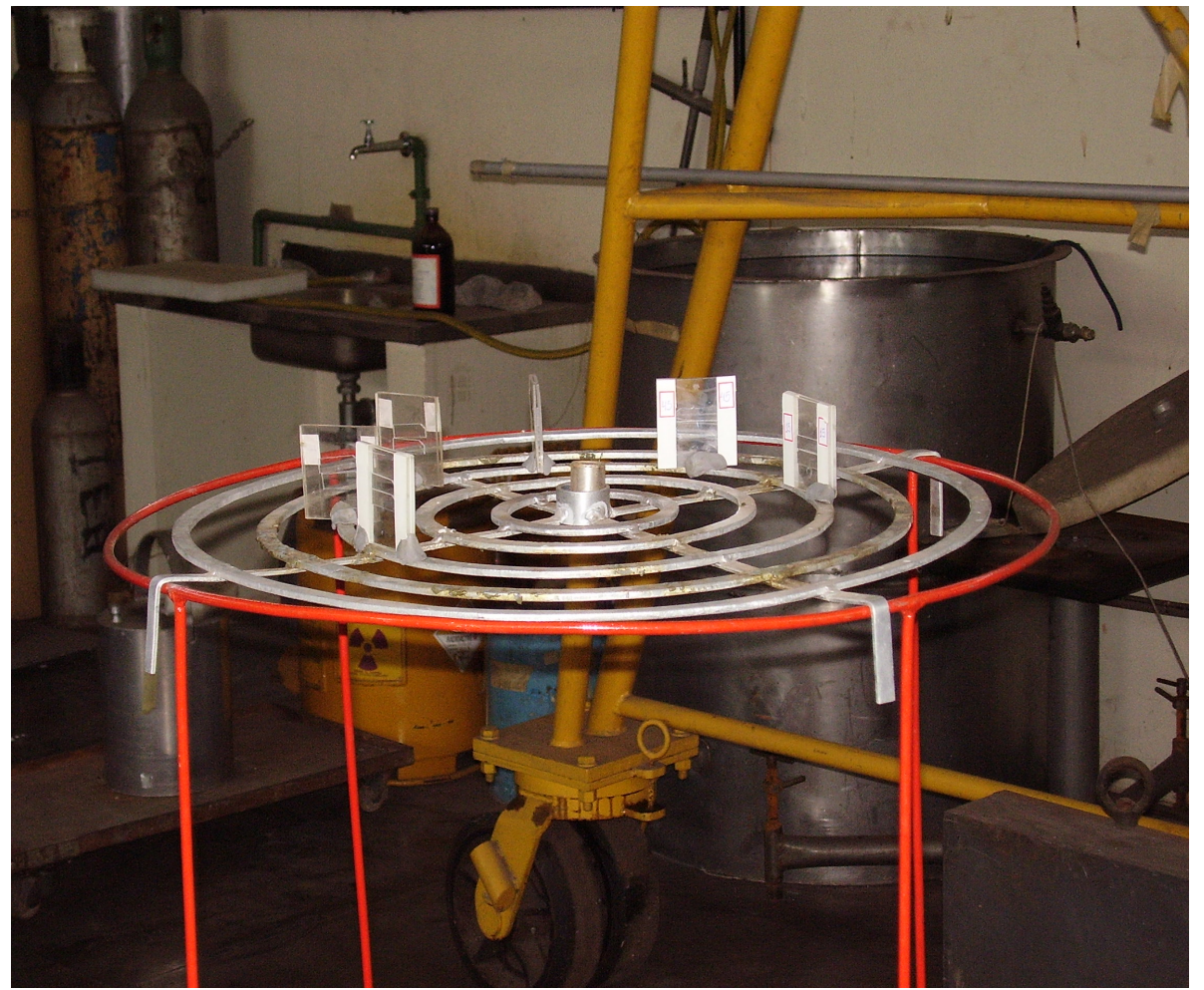

Figura 10: Arranjo experimental para irradiação com nêutrons com a fonte de ${ }^{241} \mathrm{Am}-\mathrm{Be}$ do IPEN

A partir da atividade da fonte e da taxa de emissão de nêutrons é possível estimar a taxa de dose de nêutrons através da Lei do Inverso do Quadrado da Distância $\left(1 / d^{2}\right)$. A taxa de dose foi calculada com base nos dados do manual do fabricante (Amersham, 1977):

- Taxa de emissão de nêutrons: $5,9 \cdot 10^{-6} \mathrm{n} / \mathrm{s}$ por Bq

- Taxa de dose de nêutrons: $5,9.10^{-16} \mathrm{~Sv} / \mathrm{h}$ à $1 \mathrm{~m}$ por $\mathrm{Bq}$

Considerando os dados acima e verdadeira a taxa de emissão de nêutrons dada por Madi Filho (1999), a atividade em 02/07/1970 era de:

$$
A_{0}=\frac{3,1 \cdot 10^{5} \mathrm{n} / \mathrm{s}}{5,9 \cdot 10^{-6} \mathrm{n} / \mathrm{s} / \mathrm{Bq}}=5,2 \mathrm{GBq}
$$


A atividade na data da irradiação é calculada pela equação:

$$
A=A_{0} e^{\frac{-0,693 . t}{432}}=5,2 \cdot e^{\frac{-0,693 . t}{432}}
$$

A dose pode ser estimada utilizando a seguinte equação:

$$
D=5,9 \cdot 10^{-16} \cdot \frac{A \cdot t_{i}}{d^{2}}[m S v]
$$

onde:

$t=$ tempo decorrido entre 02/07/1970 e a data da irradiação, em anos;

$\mathrm{t}_{\mathrm{i}}=$ tempo de irradiação, em horas;

d = distância fonte-detector em centímetros.

Em pequenas distâncias a Lei do Quadrado da Distância não se aplica, uma vez que o detector não pode ser considerado puntiforme em relação a fonte. Para reduzir o máximo possível o desvio dessa lei, a distância mínima fontedetector deve ser três vezes a maior dimensão linear do detector e da fonte (IAEA, 1988).

\subsection{Material moderador}

Uma vez que $83 \%$ dos nêutrons gerados por uma fonte de ${ }^{241} \mathrm{Am}-\mathrm{Be}$ possuem energias superiores a $1,5 \mathrm{MeV}$ (ICRU, 1969), foi necessário utilizar um material moderador entre a fonte e os detectores TL, para classificá-los em lotes de sensibilidade. Este material modera os nêutrons, aumentando a fluência de nêutrons térmicos para obter maior resposta nos detectores TL.

O material moderador utilizado é um bloco de parafina cilindrico, vazado no centro para posicionamento da fonte (FIG.11). Segundo Madi Filho (1999), $7 \mathrm{~cm}$ de parafina apresenta o melhor compromisso entre termalização e fluência dos nêutrons emergentes desta fonte. Nas irradiações realizadas utilizando o material moderador não é possível estimar a dose. 


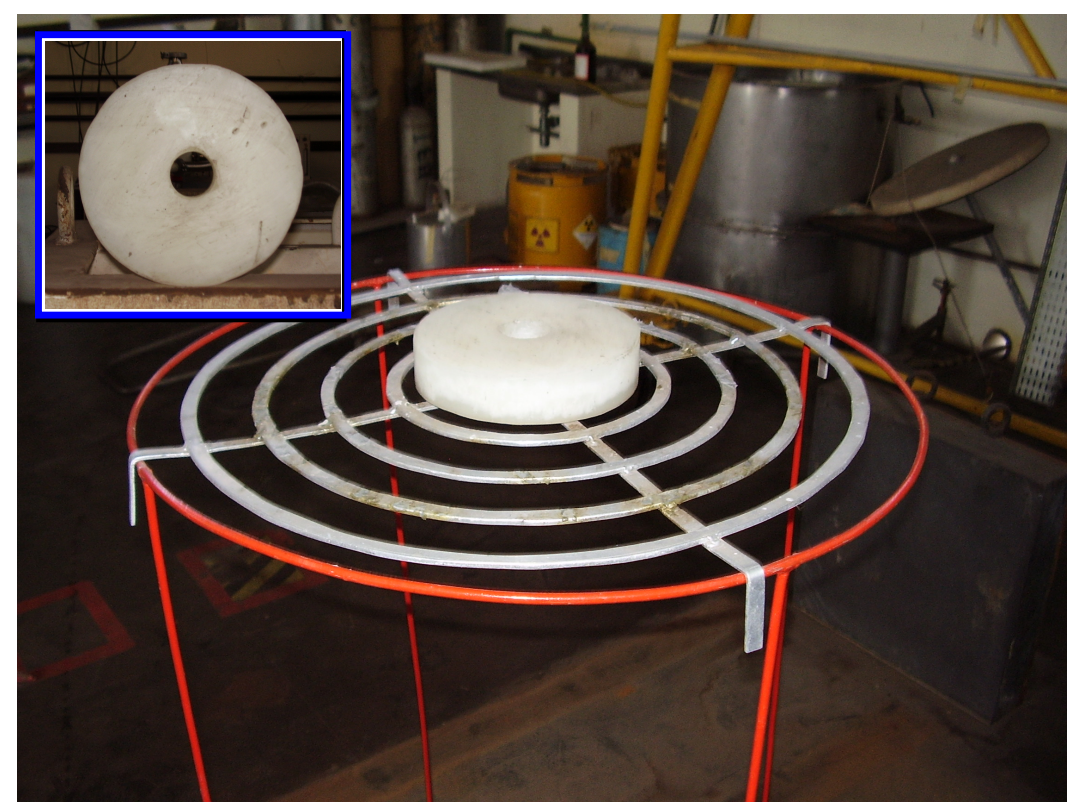

Figura 11: Bloco de parafina para termalizar nêutrons de uma fonte de ${ }^{241} \mathrm{Am}-\mathrm{Be}$

\subsubsection{Fonte de ${ }^{241} \mathrm{Am}-\mathrm{Be}$ do IRD}

As irradiações dos protótipos foram executadas no Laboratório de Baixo Espalhamento do Laboratório de Nêutrons do Laboratório Nacional de Metrologia das Radiações Ionizantes (LN/LNMRI), situado no Instituto de Radioproteção e Dosimetria (IRD / CNEN). Este laboratório é rastreado ao BIPM (Bureal International des Poids et Measures) ${ }^{7}$. As FIG.12 e 13 apresentam o arranjo de irradiação do IRD.

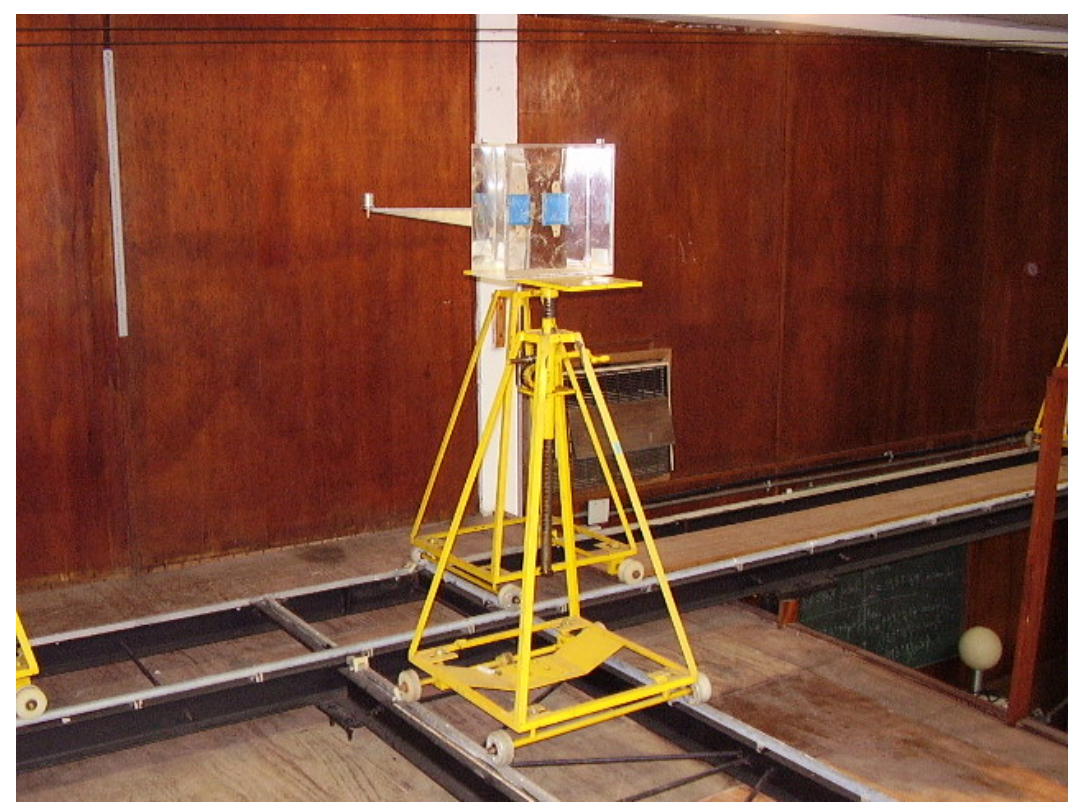

Figura 12: Arranjo de irradiação do IRD para fonte de nêutrons de ${ }^{241} \mathrm{Am}-\mathrm{Be}$

7 www.bipm.fr 
A taxa de emissão de nêutrons da fonte é de 4,015.10-7 $\mathrm{n} / \mathrm{s}$ (18/06/2003) e as irradiações seguiram referência da norma ISO-8529-1 (ISO, 2001).

Os protótipos foram irradiados em temperatura ambiente, sobre a face frontal de um simulador de tronco ISO $\left(300 \times 300 \times 150 \mathrm{~mm}^{3}\right)$. Este objeto simulador tem paredes de $10 \mathrm{~mm}$ PMMA e é preenchido com água.

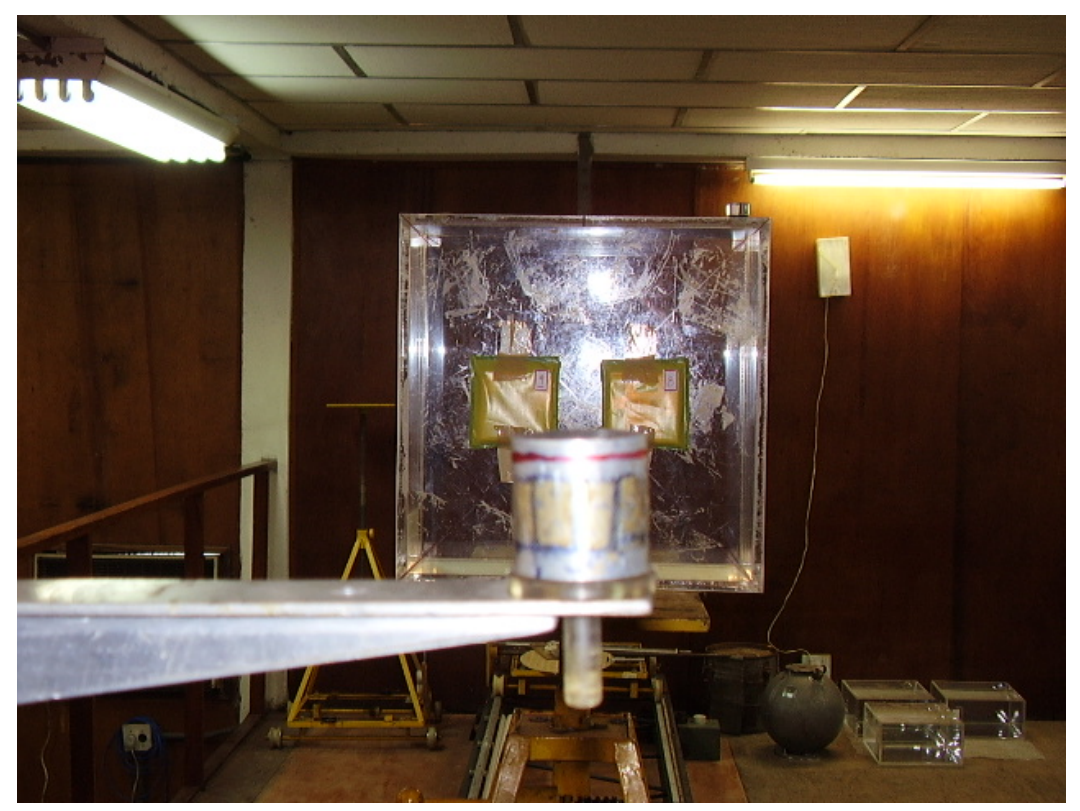

Figura 13: Arranjo de irradiação do IRD para fonte de nêutrons de ${ }^{241} \mathrm{Am}-\mathrm{Be}$ : detalhe dos protótipos no simulador de tronco e da fonte

\subsection{Metodologia}

Inicialmente foram determinados os parâmetros de leitura analisando a resposta da leitora Harshaw aos detectores TL irradiados com ${ }^{241} \mathrm{Am}-\mathrm{Be}$. Após a parametrização da leitora foi realizado um estudo da dependência energética da resposta dos detectores TL quando irradiados com fótons de energias entre $37 \mathrm{e}$ $1332 \mathrm{keV}$ e a resposta em função da dose para fótons da energia do Amerício (59,5 keV). Também foi verificada a resposta do TLD-600 quando exposto à fonte de ${ }^{241} \mathrm{Am}$-Be. Posteriormente estudou-se o desempenho do policarbonato para deteç̧ão de traços e sua resposta aos nêutrons da fonte de ${ }^{241} \mathrm{Am}$-Be. Por fim, um protótipo do dosímetro foi projetado e foram efetuados testes de desempenho. 


\subsubsection{Curva de emissão TL e parâmetros da leitora}

Para definir os parâmetros de leitura da leitora Harshaw 2000A/B, intervalo e tempo de integração, dez TLD-600 e TLD-700 foram irradiados com a fonte de ${ }^{241} \mathrm{Am}$-Be do IPEN dotada do material moderador. Todos os detectores foram irradiados ao mesmo tempo e à mesma distância da fonte.

\subsubsection{Tratamento térmico dos detectores $\mathrm{TL}$}

Antes da utilização dos detectores TL é necessário fazer um tratamento térmico para restabelecer as condições de pré-irradiação dos mesmos. Ainda que a leitura dos detectores deva cumprir esse papel, muitas cargas não são completamente desarmadilhadas durante esse processo.

O tratamento térmico de reutilização dos detectores TL empregado encontra-se descrito na literatura (Oberhofer e Scharmann, 1981 ), $400^{\circ} \mathrm{C} / 1 \mathrm{~h}$, seguido de $100^{\circ} \mathrm{C} / 2 \mathrm{~h}$.

\subsubsection{Seleção dos detectores TL}

Os detectores TL apresentaram um desvio máximo de $40 \%$ em relação a média das respostas quando irradiados com nêutrons ou fótons. Desta forma, para avaliação da dose, o valor da leitura (resposta) dos detectores TL deve ser corrigido por fatores de sensibilidade.

Esses fatores de sensibilidade para cada detector foram determinados irradiando todos os detectores com a mesma dose, calculando-se a média das respostas $\left(X_{m}\right)$ e a variação da resposta de cada detector em relação a essa média $\left(X / X_{m}\right)$.

Em cada lote a sensibilidade varia no máximo $3 \%$ em relação ao valor central do lote. O lote central, de fator de sensibilidade unitário, é designado de "Lote 1". Lotes com sensibilidades maiores são denominados por algarismos e lotes com sensibilidades menores, por letras. (ver TAB.3)

Os TLD-700 possuem um fator de sensibilidade para fótons, enquanto que os TLD-600, além desse, possuem outro fator de sensibilidade para nêutrons térmicos. Por exemplo, os TLD-700 possuem lotes do tipo 1, 2 e A, enquanto os 
TLD-600, do tipo 1A, B3 e AA. Nos TLD-600, o primeiro caractere corresponde ao lote de sensibilidade à fótons e o segundo, à nêutrons térmicos.

Tabela 3: Lotes e fatores de sensibilidade para detectores TL

\begin{tabular}{ccc}
\hline Sensibilidade do Detector & Fs & Lote \\
$0,68 \leq X / X_{m}<0,73$ & 1,41 & $F$ \\
$0,73 \leq X / X_{m}<0,77$ & 1,33 & $E$ \\
$0,77 \leq X / X_{m}<0,82$ & 1,26 & $D$ \\
$0,82 \leq X / X_{m}<0,87$ & 1,19 & $C$ \\
$0,87 \leq X / X_{m}<0,92$ & 1,12 & $B$ \\
$0,92 \leq X / X_{m}<0,97$ & 1,06 & $A$ \\
$0,97 \leq X / X_{m}<1,03$ & 1,00 & 1 \\
$1,03 \leq X / X_{m}<1,09$ & 0,94 & 2 \\
$1,09 \leq X / X_{m}<1,15$ & 0,89 & 3 \\
$1,15 \leq X / X_{m}<1,22$ & 0,84 & 4 \\
$1,22 \leq X / X_{m}<1,30$ & 0,79 & 5 \\
$1,30 \leq X / X_{m}<1,37$ & 0,75 & 6 \\
$1,37 \leq X / X_{m}<1,45$ & 0,71 & 7 \\
\hline
\end{tabular}

Todos os detectores foram irradiados com $5 \mathrm{mGy}$ de radiação gama $\left({ }^{60} \mathrm{Co}\right)$ para classificação quanto à sensibilidade a fótons. Os fatores de sensibilidade foram determinados pela sensibilidade relativa à média aritmética das respostas dos TLD-700.

Posteriormente todos os TLD-600 mais alguns TLD-700 foram expostos à fonte de ${ }^{241} \mathrm{Am}-\mathrm{Be}$ do IPEN durante $24 \mathrm{~h}$, utilizando-se o material moderador para aumentar o fluxo de nêutrons térmicos.

Durante a execução do trabalho foi necessário determinar novos fatores de sensibilidade em virtude do dano causado pelos nêutrons no TLD-600 ser cumulativo. Isto porque em cada reação ${ }^{6} \mathrm{Li}(\mathrm{n}, \alpha)^{3} \mathrm{H}$ o número de núcleos de ${ }^{6} \mathrm{Li}$ diminui. Esta diminuição é significativa para altas doses (acima de $50 \mathrm{mSv}$ ). 


\subsubsection{Resposta TL para fótons}

Para avaliar a resposta dos detectores TL aos fótons emitidos pela fonte de ${ }^{241} \mathrm{Am}$-Be, utilizou-se o equipamento de Raios-X Industrial do IPEN na Qualidade RQA 7. Esta Qualidade é a que gera fótons de energia mais próximas à do Amerício, 59,7 keV. Um gráfico de dependência energética para fótons foi construído irradiando os detectores com outras Qualidades de feixes de raios- $X$ (RQA 3, RQA 5, RQA 9, RQA 10 e ISON 150) e com fontes de Césio e Cobaldo. Para cada energia e dose, quinze detectores TLD-700 foram irradiados com 15 mGy.

\subsubsection{Escolha do detector de traços}

A escolha do policarbonato SS-1 foi motivada por seu monômero químico ser o mesmo do Makrofol, $\mathrm{C}_{16} \mathrm{H}_{14} \mathrm{O}_{3}$, evidenciando sua possível aplicação como detector sólido de traços nucleares para nêutrons rápidos (Józefowicz, 1971).

\subsubsection{Determinação da face mais sensível do SS-1}

Para determinar a face mais sensível do policarbonato foram irradiadas oito amostras de $3 \times 3 \mathrm{~cm}^{2}$ com $2 \mathrm{mSv}$ de nêutrons com a fonte de ${ }^{241} \mathrm{Am}-\mathrm{Be}$ do IPEN. Ambas as faces foram irradiadas, cada qual com e sem o plástico de proteção.

Para a revelação dos traços nesta etapa do trabalho, o ataque químico seguiu o indicado na literatura (Cesar e Franco, 1986), detectores em banho de PEW-40 à $70^{\circ} \mathrm{C} / 2 \mathrm{~h}$.

\subsubsection{Leitura e contagem dos traços no SS-1}

O sistema de leitura utilizado consiste de uma câmera de vídeo acoplada à um microscópio para projetar a imagem da superfície do detector no computador (FIG.14). A densidade de traços é determinada contando-se o número de traços em uma área pré-determinada e dividindo-se o resultado por 
essa área. O método de contagem dos traços é semelhante ao proposto por Alberigi et al. (2005).

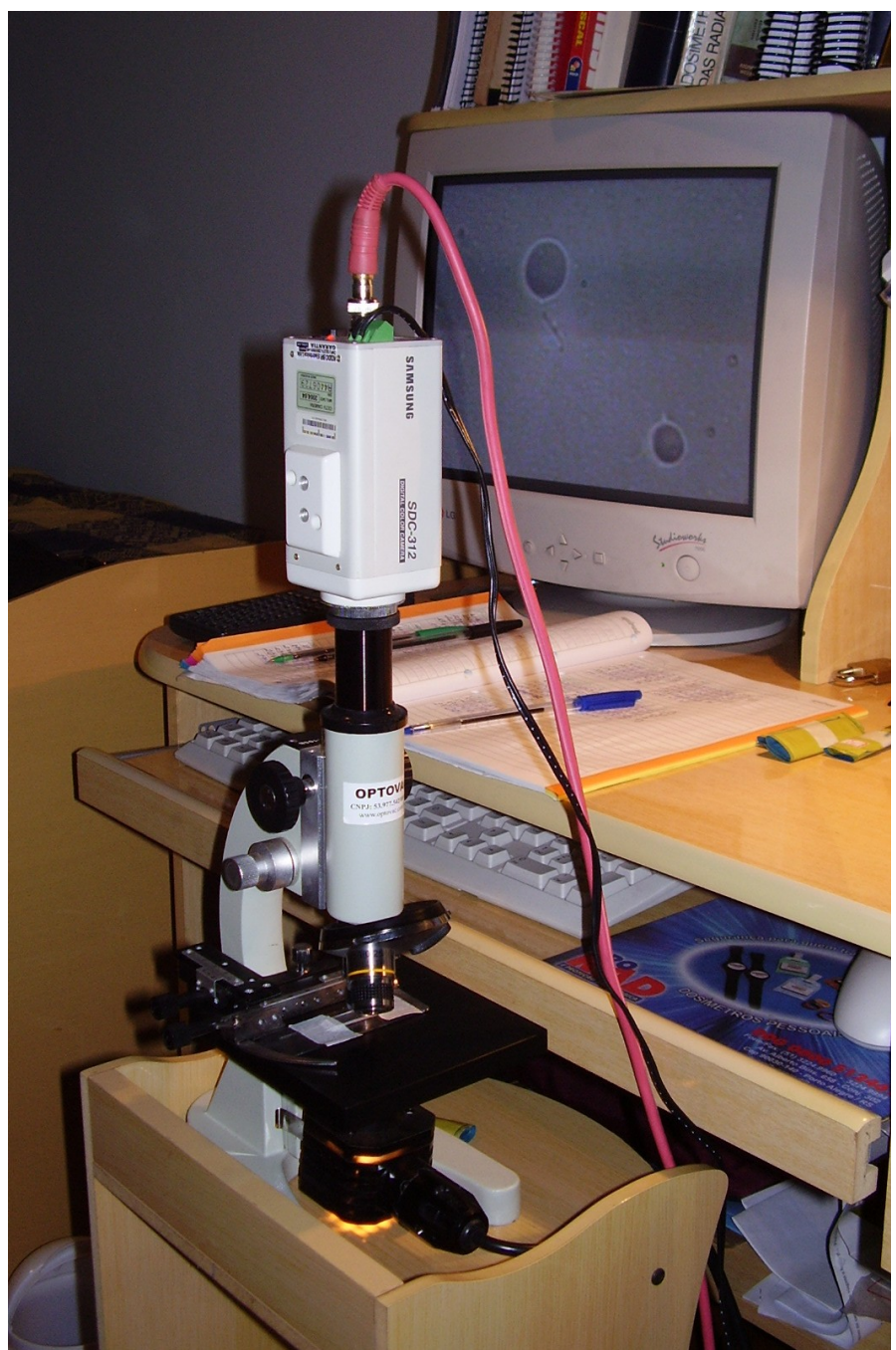

Figura 14: Sistema de leitura dos traços, da PRO-RAD

Percorrendo-se o detector longitudinalmente define-se a área de contagem, denominada faixa. Cada faixa possui $20 \times 0,1 \mathrm{~mm}^{2}$, sendo este $0,1 \mathrm{~mm}$ a largura do campo de visão da câmera de vídeo. Para que a densidade de traços em uma faixa aleatória seja representativa da densidade total de traços, é necessário que a distribuição dos traços na superfície do detector seja uniforme. Isso foi verificado executando a leitura de 48 faixas de um detector irradiado com $2 \mathrm{mSv}$ de nêutrons no IPEN.

O método de contagem, estabelecido empiricamente, ignora traços pouco nítidos (baixo contraste) ou com forma não circular (FIG.15). 


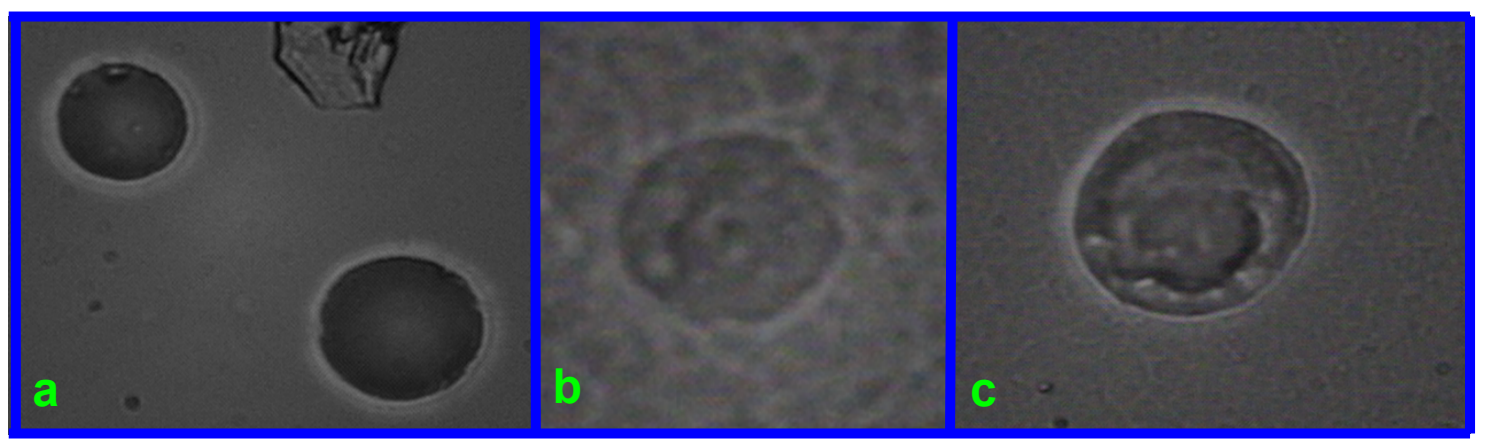

Figura 15: a) traços contáveis; b) traço com baixo contraste; c) traço não circular

\subsubsection{Sensibilidade do SS-1 à outras radiações}

A sensibilidade à outras radiações foi verificada submetendo-se conjuntos de três detectores à $10 \mathrm{mSv}$ de radiação alfa $\left({ }^{241} \mathrm{Am}\right)$, beta $\left({ }^{90} \mathrm{Sr}-{ }^{90} \mathrm{Y}\right) \mathrm{e}$ gama $\left({ }^{60} \mathrm{Co}\right)$ no LCl do IPEN (Souto e Campos, 2006a). Utilizou-se o mesmo ataque químico descrito no item 4.4.6.

\subsubsection{Estudo do melhor ataque químico}

O ataque químico consiste da imersão dos detectores de traços, individualmente, em tubos de ensaio com uma solução alcalina dentro de uma estufa com uma certa temperatura por determinado tempo. $\mathrm{O}$ ataque químico é finalizado submetendo os detectores à água corrente.

O desempenho na revelação e ampliação dos traços está relacionado com os parâmetros do ataque químico: solução química, tempo e temperatura de ataque. $O$ estudo destes parâmetros fornece a melhor relação entre a quantidade de traços revelados, a nitidez dos traços e o tempo despendido para tal. Como a solução química PEW-40 (15\% KOH, 45\% $\left.\mathrm{H}_{2} \mathrm{O}, 40 \% \mathrm{C}_{2} \mathrm{H}_{5} \mathrm{OH}\right)$ é bem conhecida para esta aplicação, não alterou-se a concentração dos seus compostos, apenas se estudou a variação do tempo e da temperatura do ataque.

Grupos de quatro detectores foram irradiados com $5 \mathrm{mSv}$ de nêutrons no IPEN e revelados com temperaturas de 50,65, 75, 90 e $100^{\circ} \mathrm{C}$ com tempos de ataque variando entre uma e seis horas (Souto e Campos, 2006b). O ataque químico mais comum encontrado na literatura é efetuado à $70^{\circ} \mathrm{C}$, entretanto a estufa do IPEN não apresenta boa estabilização para temperaturas abaixo de 
$75^{\circ} \mathrm{C}$. Por isso, os ataques químicos com temperaturas mais baixas foram realizados no laboratório da PRO-RAD.

\subsubsection{Comparação entre o SS-1 e o Makrofol}

Três amostras do policarbonato SS-1 e de Makrofol foram irradiadas com 3,6 mSv de nêutrons no IPEN para comparação das respostas. O ataque químico utilizado foi o determinado para o SS-1.

\subsection{Projeto do porta-dosímetro}

O dosímetro proposto é do tipo (G) da FIG.6 em conseqüência de sua simplicidade e por ser utilizado atualmente por grandes laboratórios de dosimetria, como o RDC (Radiation Detection Company) ${ }^{8}$ e o GDS (Global Dosimetry Solutions) $)^{9}$, dos EUA. É uma configuração bem simples: dois pares de detectores TLD-600/TLD-700 separados por uma lâmina de cádmio, entre placas de PMMA. Um par de detectores está localizado na parte frontal do dosímetro com o objetivo de detectar os nêutrons térmicos incidentes, enquanto que o outro par está na parte posterior e detectará nêutrons de albedo. Incorporado a este sistema, adicionou-se um detector de traços para nêutrons rápidos.

\subsubsection{Montagem dos protótipos}

Esta etapa do trabalho foi feita de forma bastante artesanal. Primeiramente os detectores de traços foram confeccionados manualmente, cortando a placa de policarbonato e depois lixando as bordas (FIG.16a).

Após a colocação dos detectores e da placa de cádmio em suas respectivas posições, os porta-dosímetros foram encapsulados em plástico com cores distintas para a face frontal e posterior (FIG.16b). Convencionou-se utilizar plástico amarelo para a face frontal e preto para a face posterior.

A FIG.17 apresenta o aspecto final dos protótipos, encapsulados e não encapsulados.

8 www.radetco.com

9 www.dosimetry.com 


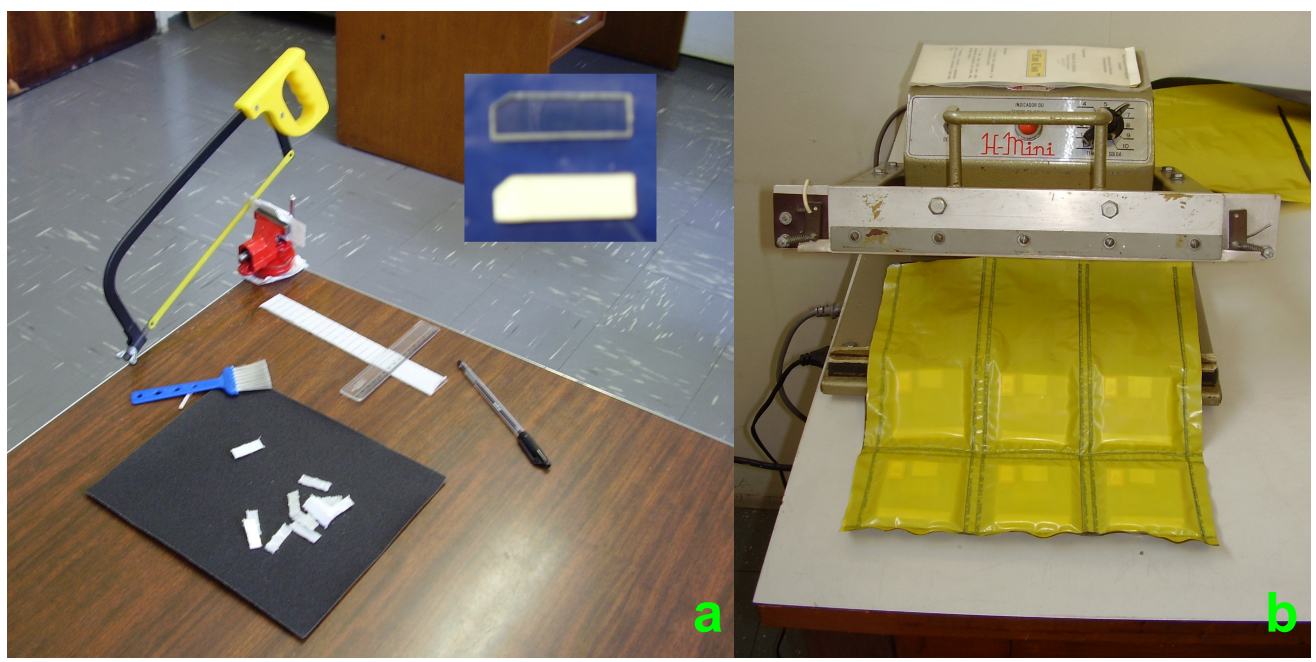

Figura 16: a) Confecção manual dos detectores de traços;

b) Encapsulamento do porta-dosímetro

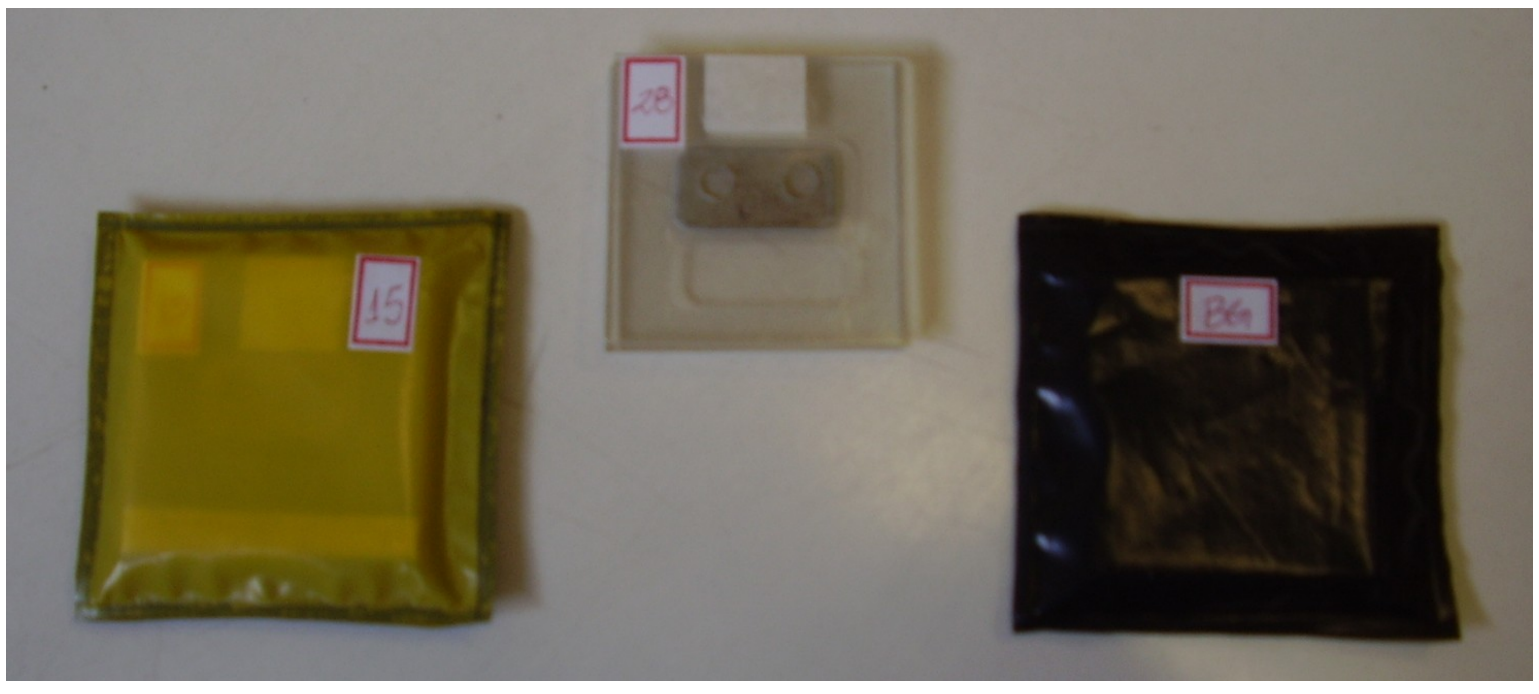

Figura 17: Aspecto final do protótipo do dosímetro

\subsubsection{Testes de desempenho do protótipo}

Os testes de desempenho do novo detector de traços e para o protótipo do dosímetro seguiram as recomendações da norma ISO/DIS 21909 (ISO, 2002). Os protótipos foram irradiados no IRD em quatro oportunidades: dez/05, abr/06, set/06 e dez/06.

Os protótipos foram irradiados com doses entre 0,5 e $500 \mathrm{mSv}$ para avaliar a resposta em função da dose. O algoritmo para cálculo da dose considerou-se apenas os dados referentes a doses de até $20 \mathrm{mSv}$. 
Para determinação da dependência angular, grupos de oito protótipos foram irradiados com $10 \mathrm{mSv}$ e ângulos de incidência normal, $15^{\circ}, 45^{\circ}, 60^{\circ}, 75^{\circ} \mathrm{e}$ $85^{\circ}$ e $90^{\circ}$.

\subsubsection{Irradiação de protótipos com espectro diferente}

Três protótipos foram irradiados com $10 \mathrm{mSv}$ de nêutrons de uma fonte de ${ }^{252} \mathrm{Cf}$, no IRD, para comparar as respostas do dosímetro e avaliar o algoritmo de dose quando o espectro energético dos nêutrons for diferente daquele usado no desenvolvimento do projeto, fonte de ${ }^{241} \mathrm{Am}-\mathrm{Be}$. 


\section{$5 \quad$ RESULTADOS E DISCUSSÕES}

\subsection{Detectores termoluminescentes}

\subsubsection{Curva de emissão TL e parâmetros da leitora}

A FIG.18 apresenta uma curva de emissão TL típica, obtida pelo programa LabView. Na curva de emissão do TLD-700 o pico dosimétrico, em $180^{\circ} \mathrm{C}$, é pronunciado, ao passo que para o TLD-600 percebe-se este pico acentuado em $190^{\circ} \mathrm{C}$ e um segundo pico em $245^{\circ} \mathrm{C}$, de intensidade reduzida. Da análise dessas curvas determinou-se o intervalo de integração do sinal TL entre 100 e $210^{\circ} \mathrm{C}$.

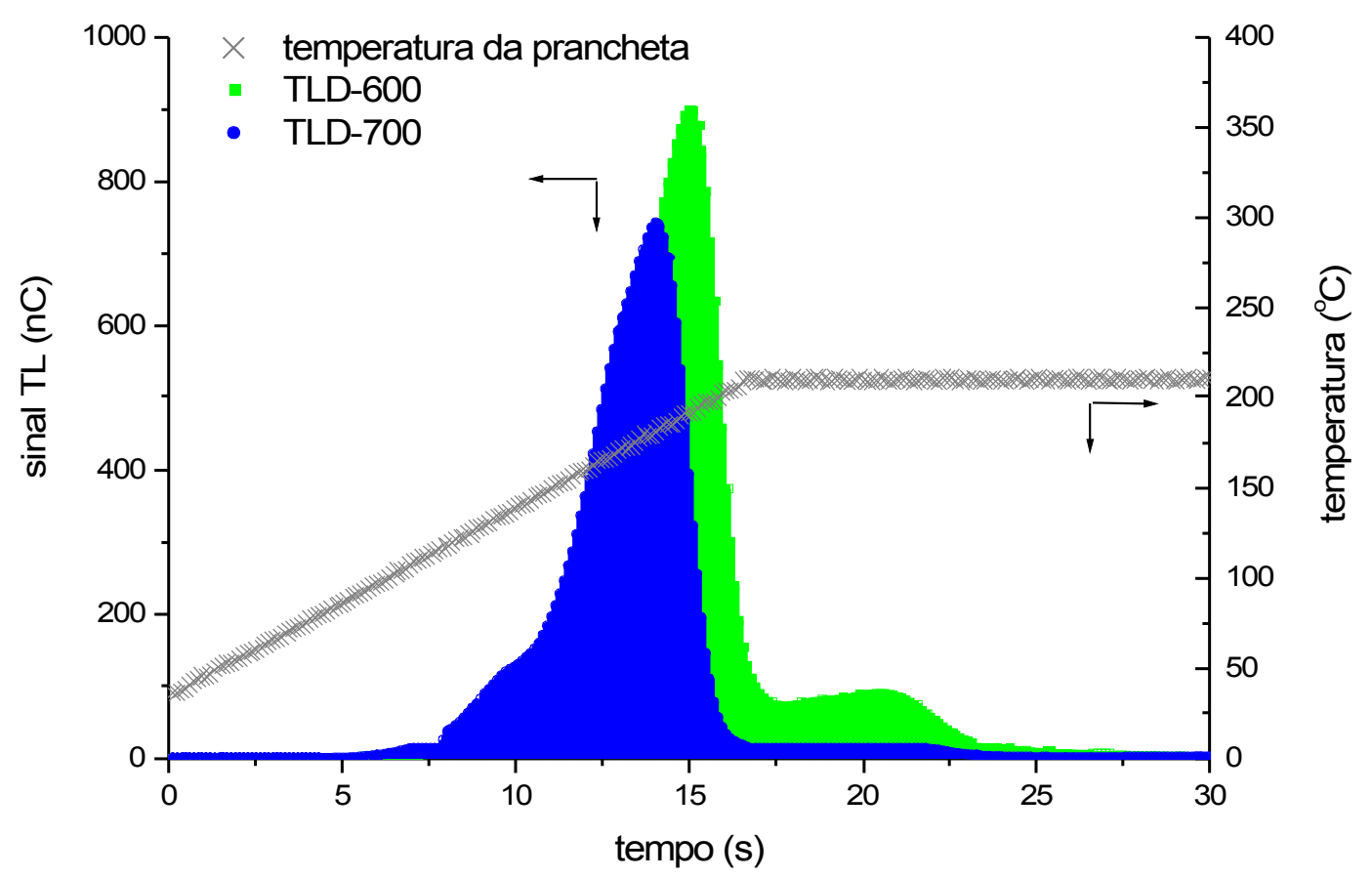

Figura 18: Curva de emissão TL em função do tempo de aquecimento

Selecionando a temperatura máxima de aquecimento da prancheta para o limite superior, $210^{\circ} \mathrm{C}$, comparou-se o tempo de aquecimento do detector com o tempo para leitura do sinal TL (FIG.18). Os $210^{\circ} \mathrm{C}$ são atingidos em, aproximadamente, dezessete segundos, todavia há um gradiente de temperatura 
entre a superfície da prancheta e o detector. Foi necessário manter esta temperatura por tempo suficiente para ocorrer equilíbrio térmico ente a prancheta e o detector e para que todas as cargas sejam desarmadilhadas. Observou-se que $25 \mathrm{~s}$ é suficiente.

\subsubsection{Resposta TL para fótons}

\subsubsection{Dependência energética}

A resposta TL dos detectores TLD-700 para radiação $X$ com energias efetivas entre 37,3 e $118 \mathrm{keV}$ e radiação gama do ${ }^{137} \mathrm{Cs}$ e do ${ }^{60} \mathrm{Co}$ é apresentada na FIG.19. Todas as respostas estão normalizadas para a energia do ${ }^{60} \mathrm{Co}$.

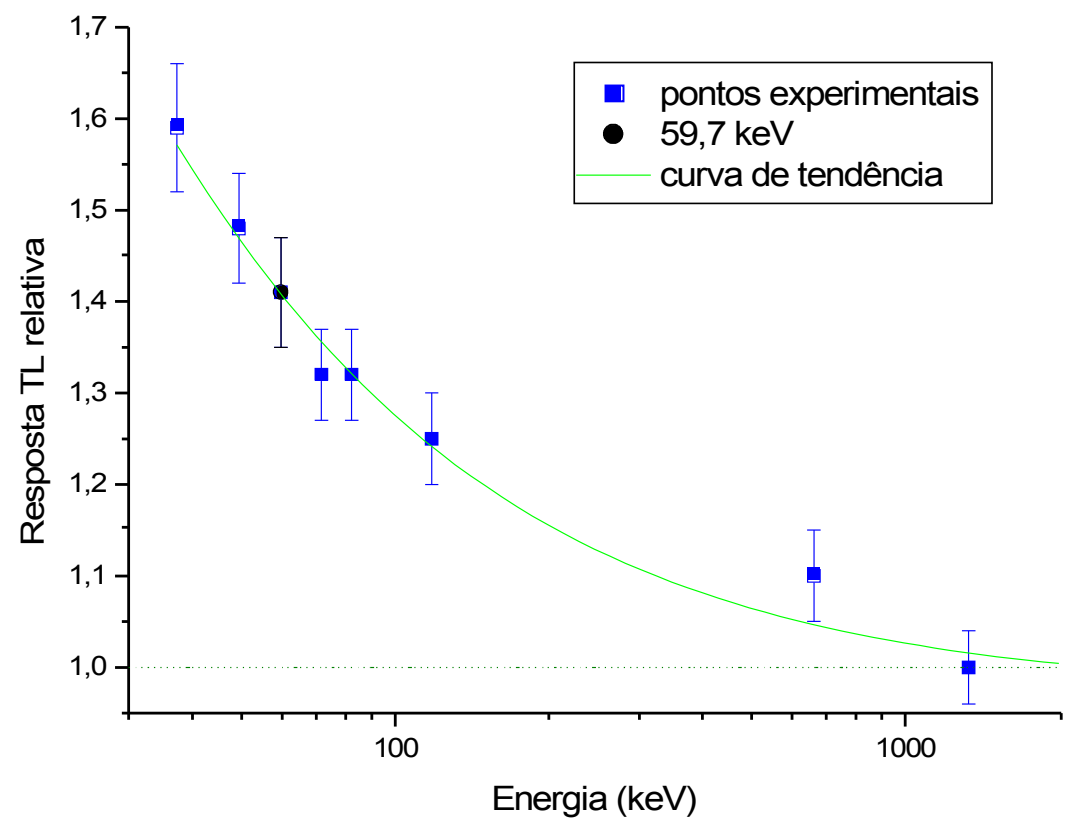

Figura 19: Dependência angular da resposta do TLD-700 para fótons

Este resultado está de acordo com a curva de dependência energética para o LiF enriquecido com ${ }^{7} \mathrm{Li}$ apresentada por Portal (1981).

\subsubsection{Resposta para 59,7 keV}

As curvas de resposta dos detectores TLD-600 e dos TLD-700 em função da dose de radiação $X$ de energia efetiva equivalente à radiação gama da 
fonte de ${ }^{241} \mathrm{Am}-\mathrm{Be}(59,7 \mathrm{keV})$ são apresentadas na FIG.20.

As respostas de ambos os detectores são lineares no intervalo de dose estudado e podem ser consideradas idênticas. Não havendo fótons de outras energia no campo de radiação, será possível estimar a dose de radiação gama proveniente da fonte de ${ }^{241} \mathrm{Am}$-Be pela avaliação da resposta do TLD-700.

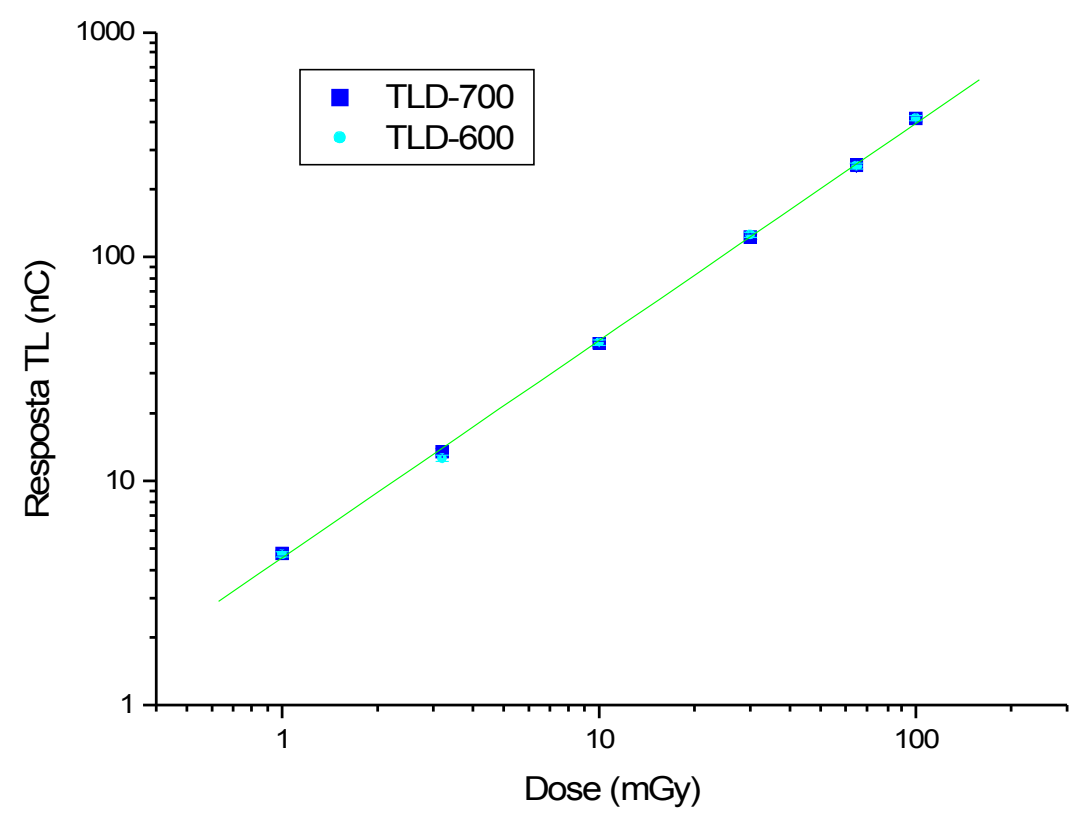

Figura 20: Reposta TL em função da dose para fótons de 59,7 keV

Aplicando o método da regressão linear, a reta que melhor se aproxima dos pontos experimentais para o TLD-700 é:

$$
T L[n C]=4,03( \pm 0,05) \cdot D[m G y]+0,71( \pm 0,11)
$$

Coeficiente de correlação: 0,99972.

Esta equação foi utilizada como algoritmo para o cálculo da dose de radiação gama no dosímetro desenvolvido.

A dose mínima detectável (DMD) foi determinada avaliando-se a resposta de cem detectores não irradiados, conforme ISO/DIS 21909 (ISO, 2002) (DMD $=\sigma . t_{n}$; onde $\sigma$ é o desvio padrão da média e $t_{n}$ é o $t$ de Student). $O$ valor calculado é inferior à $0,1 \mathrm{mGy}$ ), bem abaixo do estabelecido pela CNEN, 0,2 mSv (CNEN, 1995) para radiação $X$ e gama. 


\subsection{Detectores de traços}

\subsubsection{Determinação da face mais sensível do policarbonato SS-1}

Foi feita uma análise qualitativa das amostras irradiadas com nêutrons. A face dotada de proteção para radiação UV, sem a cobertura de plástico, foi a que apresentou maior densidade de traços.

\subsubsection{Contagem dos traços na superfície do detector}

A freqüência de traços de nêutrons por faixa em um detector (FIG.21) apresenta uma distribuição homogênea em toda a superfície do detector, com desvio padrão da média de traços por faixa da ordem de $15 \%$.

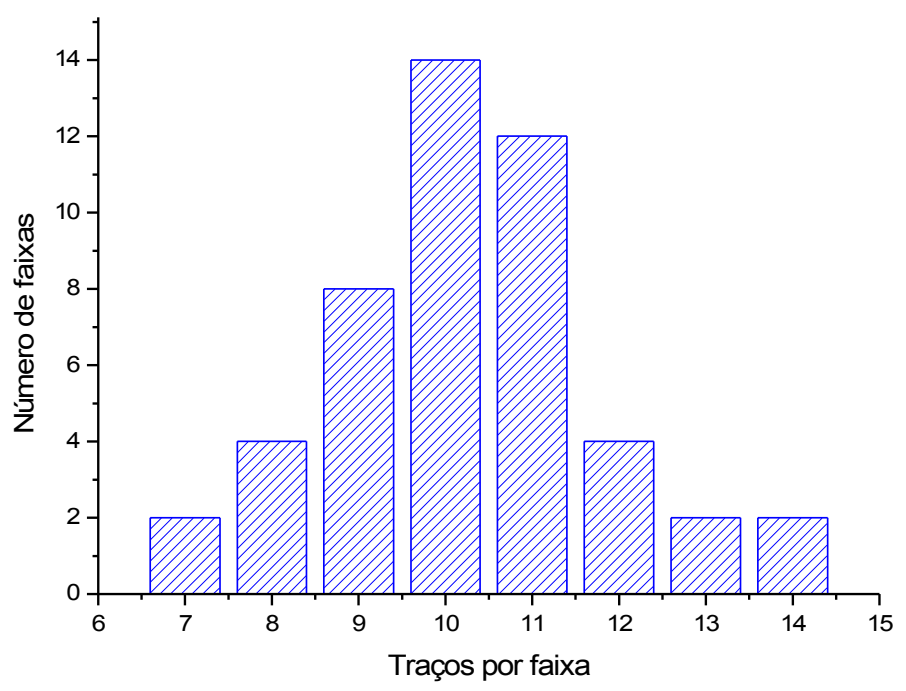

Figura 21: Freqüência de traços de nêutrons por faixa de contagem (2 mSv)

Para reduzir erros estatísticos convencionou-se contar cinco faixas por detector e calcular a média destas contagens como sendo a densidade de traços por faixa, e o desvio padrão dessa média como a incerteza da contagem. As faixas são distribuidas em todo o detector, conforme esquema da FIG.22.

Ainda assim, para minimizar o erro humano na contagem dos traços, utilizou-se o Critério de Chauvenet (Bitelli, 1982) para desprezar contagens que 
provoquem grande variação no cálculo estatístico. Desta forma, foram desconsideradas contagens fora do seguinte intervalo $\bar{x} \pm 1,65 \cdot \sqrt{\bar{x}}$, onde $\bar{x}$ é a média das contagens, substituindo-as pela contagem de faixas ainda não lidas (ver exemplo no Anexo A).

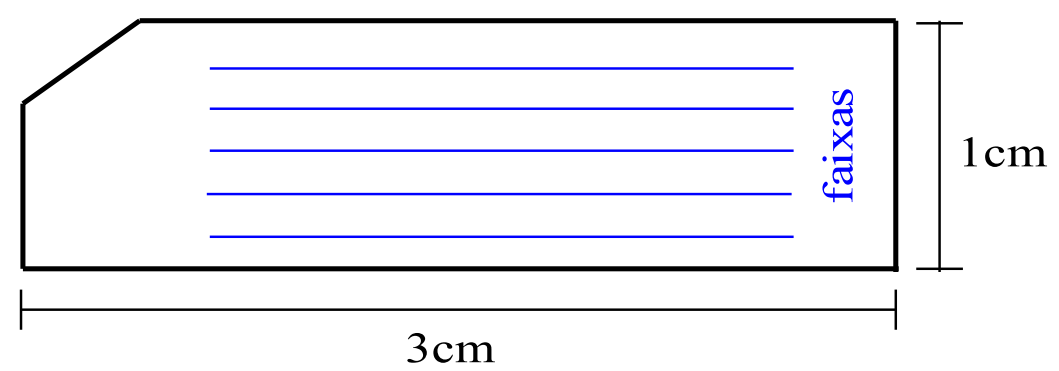

Figura 22: Esquema da distribuição de faixas de contagem nos detectores

A equação para determinação da densidade de traços em um detector é a seguinte:

$$
\text { Traços } / \mathrm{cm}^{2}=\frac{\text { média da contagem de cinco faixas } \pm \text { desvio padrão }}{\text { área da faixa }}
$$

\subsubsection{Sensibilidade do SS-1 à outros tipos de radiação}

Comparando os detectores irradiados com amostras não irradiadas (TAB.4), percebe-se que a densidade de traços nos detectores irradiados com partículas beta e raios gama é da mesma ordem da contagem para detectores não irradiados $(\mathrm{NI})$. O policarbonato apresenta boa sensibilidade a nêutrons, porém a forte sensibilidade a partículas alfa (uma ordem de grandeza maior) pode implicar uma superestimação da contagem de traços em campos mistos ou na presença de Radônio natural. Essa interferência pode ser minimizada protegendo os detectores com um anteparo de PMMA (acrílico); neste caso, contagens não significativas foram obtidas.

Tabela 4: Sensibilidade do SS-1 a $10 \mathrm{mSv}$ de diferentes radiações

\begin{tabular}{lcccccc}
\hline Radiação & NI & alfa & alfa* $^{*}$ & beta & gama & nêutrons \\
Traços $/ \mathbf{c m}^{2}$ & $45,0 \pm 27,4$ & $(24,5 \pm 0,3) \cdot 10^{3}$ & $55,0 \pm 37,1$ & $40,0 \pm 29,6$ & $47,5 \pm 23,7$ & $(2,9 \pm$ \\
$\begin{array}{l}\text { Densidade } \\
\text { relativa }\end{array}$ & 1,0 & 545 & 1,2 & 0,9 & 1,0 & $0,3) \cdot 10^{3}$ \\
\hline
\end{tabular}

*detectores cobertos por um anteparo de PMMA. 


\subsubsection{Blindagem para partículas alfa}

Para que não haja formação de traços espúrios no SS-1 oriundos de partículas alfa é necessário utilizar um anteparo de espessura maior que o alcance das partículas alfa. O alcance das partículas alfa no ar pode ser estimado por equações empíricas, como a de John (Price, 1964):

$$
R=(0,005 \cdot E+0,285) \cdot E^{3 / 2}
$$

onde:

$$
\begin{aligned}
& \mathrm{R}=\text { alcance das partículas alfa, em } \mathrm{cm} ; \\
& \mathrm{E}=\text { energia das partículas, em } \mathrm{MeV} .
\end{aligned}
$$

O alcance no ar é relacionado com o alcance em qualquer outro meio pela relação:

$$
\frac{R_{\text {meio }}}{R_{\text {ar }}} \approx \frac{\rho_{\text {ar. }} \sqrt{A_{\text {meio }}}}{\rho_{\text {meio. }} \sqrt{A_{\text {ar }}}}
$$

onde:

$\rho=$ densidade do material;

$A$ = peso atômico do material.

A principal fonte geradora de traços espúrios nos detectores de traços é o Radônio Natural $\left({ }^{222} \mathrm{Rn}\right)$ presente na atmosfera. A energia média das partículas alfa emitidas por este radionuclídeo é 12,11 MeV. Aplicando a equação (17) na equação (18) para o PMMA:

$$
R_{P P M A}=2,7 \cdot 10^{-3} \cdot(0,005 \cdot 12,11+0,285) \cdot 12,11^{3 / 2}=0,39 \mathrm{~mm}
$$

Logo, um anteparo de 0,4 mm de PMMA é capaz de blindar essa radiação indesejada. 


\subsubsection{Ataque químico do SS-1}

A densidade média de traços nos detectores obtida para cada tempo e temperatura estudados são apresentadas na TAB.5. Para $1 \mathrm{~h}$ de ataque químico, a contagem de traços é semelhante à contagem para detectores não irradiados (NI), exceto para as temperaturas de 90 e $100^{\circ} \mathrm{C}$. Esses traços são muito pequenos, mas se destacam por sua forte coloração. Os detectores revelados com as maiores temperaturas apresentam baixa contagem de traços, provavelmente devido à evaporação da solução química, a qual é suficiente para emergir boa parte do detector durante o procedimento.

Depois de $4 \mathrm{~h}$ de ataque químico, os traços apresentam baixo contraste com a superfície do detector não atingida pelos nêutrons e começam a aparecer sobreposições de traços (FIG.23). Esse fenômeno parece aumentar com o tempo de ataque.
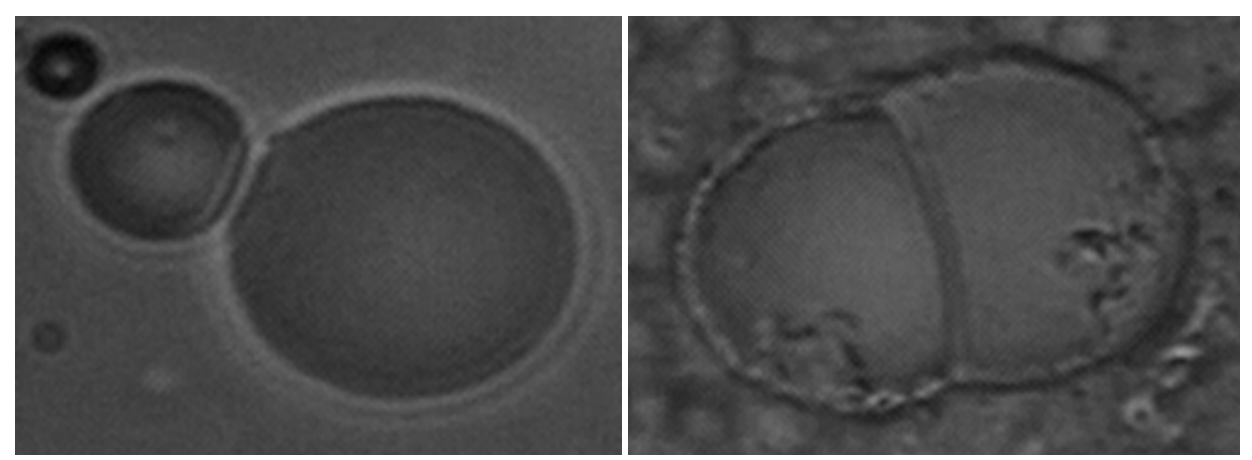

Figura 23: Traços sobrepostos no SS-1

As curvas da FIG.24 apresentam o comportamento da resposta do detector SS-1 para as diferentes condições de ataque químico. Nota-se comportamentos semelhantes: um crescimento no início e um patamar (platô). $\mathrm{O}$ tempo de ataque deve ser ajustado para a região do patamar, para evitar que pequenos erros na contagem do tempo alterem significativamente o número de traços revelados. Mesmo assim, há boa sensibilidade e nitidez dos traços na porção inclinada da curva. 
Tabela 5: Densidade de traços no SS-1 em função do tempo e da temperatura do ataque químico

\begin{tabular}{|c|c|c|c|c|c|c|c|c|c|c|}
\hline \multirow[t]{2}{*}{$\begin{array}{c}\text { Tempo } \\
\text { (h) }\end{array}$} & \multicolumn{2}{|c|}{$\begin{array}{c}50^{\circ} \mathrm{C} \\
\left(10^{3} \text { traços } / \mathrm{cm}^{2}\right)\end{array}$} & \multicolumn{2}{|c|}{$\begin{array}{c}65^{\circ} \mathrm{C} \\
\left(10^{3} \text { traços } / \mathrm{cm}^{2}\right)\end{array}$} & \multicolumn{2}{|c|}{$\begin{array}{c}75^{\circ} \mathrm{C} \\
\left(10^{3} \text { traços } / \mathrm{cm}^{2}\right)\end{array}$} & \multicolumn{2}{|c|}{$\begin{array}{c}90^{\circ} \mathrm{C} \\
\left(10^{3} \text { traços } / \mathrm{cm}^{2}\right)\end{array}$} & \multicolumn{2}{|c|}{$\begin{array}{c}100^{\circ} \mathrm{C} \\
\left(10^{3} \text { traços } / \mathrm{cm}^{2}\right)\end{array}$} \\
\hline & NI & irradiados & NI & irradiados & NI & irradiados & NI & irradiados & NI & irradiados \\
\hline 1 & $0,0 \pm 0,0$ & $0,0 \pm 0,0$ & $0,0 \pm 0,0$ & $0,04 \pm 0,05$ & $0,01 \pm 0,02$ & $0,01 \pm 0,02$ & $0,07 \pm 0,04$ & $0,4 \pm 0,1$ & $0,02 \pm 0,02$ & $0,1 \pm 0,1$ \\
\hline 2 & $0,0 \pm 0,0$ & $0,5 \pm 0,1$ & $0,0 \pm 0,0$ & $1,8 \pm 0,4$ & $0,04 \pm 0,03$ & $1,4 \pm 0,2$ & $0,04 \pm 0,03$ & $0,6 \pm 0,3$ & $0,05 \pm 0,02$ & $0,2 \pm 0,1$ \\
\hline 2,5 & - & - & - & - & $0,02 \pm 0,03$ & $2,3 \pm 0,3$ & - & - & - & - \\
\hline 3 & $0,02 \pm 0,02$ & $1,5 \pm 0,6$ & $0,02 \pm 0,02$ & $2,1 \pm 0,6$ & $0,06 \pm 0,05$ & $2,6 \pm 0,4$ & $0,10 \pm 0,04$ & $0,8 \pm 0,3$ & $0,06 \pm 0,06$ & $0,2 \pm 0,1$ \\
\hline 4 & $0,04 \pm 0,04$ & $2,2 \pm 0,5$ & $0,07 \pm 0,02$ & $(0,2 \pm 0,1) \cdot 10^{1}$ & $0,05 \pm 0,04$ & $2,5 \pm 0,4$ & $0,20 \pm 0,05$ & $1,5 \pm 0,3$ & $0,03 \pm 0,03$ & $0,1 \pm 0,1$ \\
\hline 5 & $0,05 \pm 0,04$ & $2,1 \pm 0,5$ & $0,08 \pm 0,03$ & $(0,2 \pm 0,1) \cdot 10^{1}$ & $0,0 \pm 0,0$ & $2,5 \pm 0,4$ & $0,05 \pm 0,04$ & $1,7 \pm 0,2$ & - & - \\
\hline 6 & $0,05 \pm 0,05$ & $1,8 \pm 0,3$ & $0,07 \pm 0,06$ & $2,0 \pm 0,7$ & $0,0 \pm 0,0$ & $2,1 \pm 0,4$ & $0,06 \pm 0,03$ & $1,6 \pm 0,2$ & - & - \\
\hline
\end{tabular}




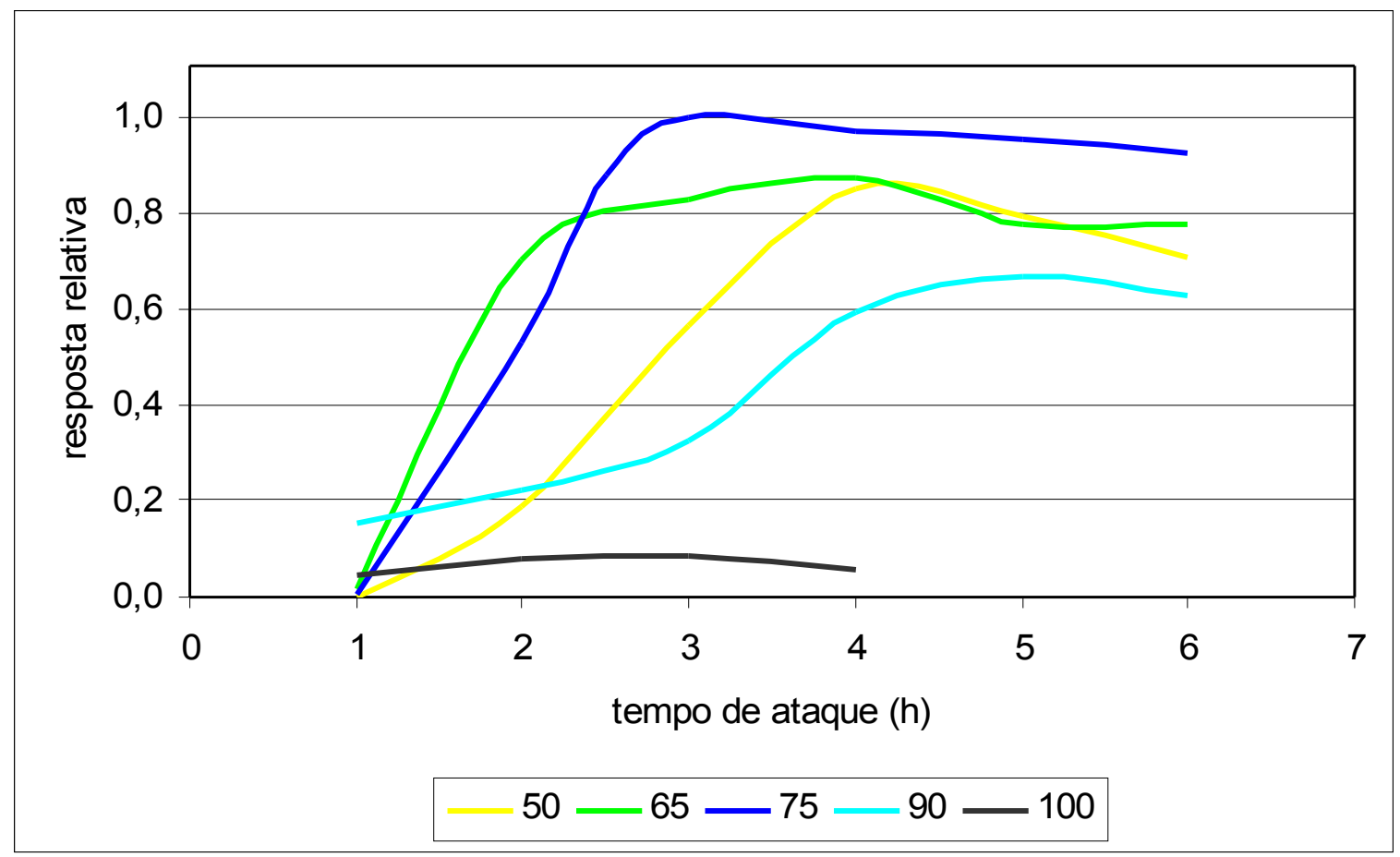

Figura 24: Resposta do SS-1 em função dos parâmetros do ataque químico

As temperaturas de 50 e $90^{\circ} \mathrm{C}$ não são interessantes de serem utilizadas, pois o patamar é atingido após $4 \mathrm{~h}$. Um tempo de ataque químico de $4 \mathrm{~h}$, somado ao tempo necessário para estabilização da temperatura na estufa, implica um tempo excessivo comparado com a jornada de trabalho de um laboratório de dosimetria.

A melhor resposta foi obtida em $75^{\circ} \mathrm{C}$, não somente pela alta contagem de traços, mas também pelas pequenas incertezas associadas às contagens (TAB.5). Ajustando essa temperatura, o patamar é atingido aproximadamente em $3 \mathrm{~h}$. É bem verdade que em $2,5 \mathrm{~h}$ de ataque há uma boa relação entre a quantidade de traços revelados e a nitidez dos mesmos (FIG.25). Após $4 \mathrm{~h}$ os detectores apresentam os problemas já descritos.

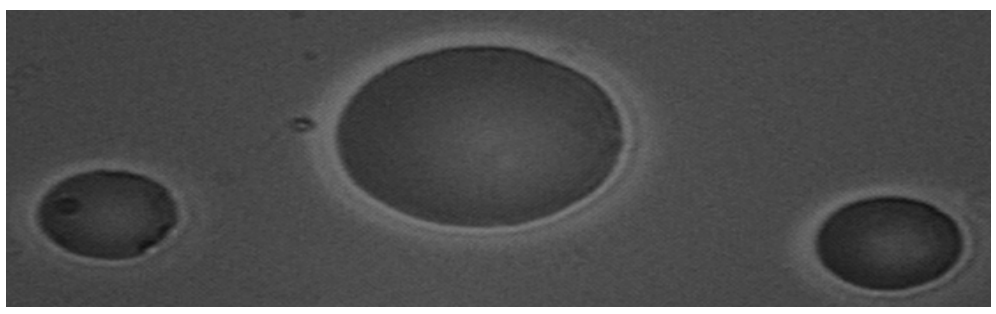

Figura 25: Traços com boa nitidez obtidos no SS-1 $\left(75^{\circ} \mathrm{C} / 2,5 \mathrm{~h}\right)$ 


\subsubsection{Comparação entre o SS-1 e o Makrofol}

A comparação entre as respostas do SS-1 e do Makrofol para 3,6 mSv de nêutrons da fonte de ${ }^{241} \mathrm{Am}-\mathrm{Be}$ é apresentada na TAB.6.

Tabela 6: Comparação da resposta do SS-1 e do Makrofol para nêutrons da fonte $d e{ }^{241} A m-B e$

\begin{tabular}{lcc}
\hline & SS-1 & Makrofol \\
Densidade de traços $\left(10^{3}\right.$ traços $\left./ \mathrm{cm}^{2}\right)$ & $1,5 \pm 0,3$ & $2,2 \pm 0,3$ \\
Resposta relativa & 1,00 & 1,49 \\
\hline
\end{tabular}

Embora possuam o mesmo monômero químico, o Makrofol apresenta resposta cerca de $50 \%$ superior. Isso acarreta uma dose mínima detectável superior para o SS-1, ou seja, com o Makrofol é possível detectar doses menores.

O Makrofol é mais sensível que o SS-1 provavelmente por ser fabricado especialmente para essa aplicação. Todavia pode-se considerar que a resposta do SS-1 é bastante satisfatória, não impedindo seu uso, uma alternativa economicamente mais viável.

\subsubsection{Dose mínima detectável}

A dose mínima detectável (DMD) foi estimada pela resposta de trinta e seis detectores, conforme ISO/DIS 21909 (ISO, 2002) (DMD = $\sigma . \mathrm{t}_{\mathrm{n}}$; onde $\sigma$ é o desvio padrão da média e $t_{n}$ é o t de Student), resultando em 0,12 mSv.

Este valor está abaixo dos $0,3 \mathrm{mSv}$ requeridos pela mesma norma, porém é um valor apenas teórico, pois na prática não há resolução suficiente para diferenciar a quantidade de traços por faixa em $0,12 \mathrm{mSv}$, da quantidade de traços por faixa originados pela radiação de fundo.

\subsection{Projeto do porta-dosímetro}

Três aspectos foram considerados para o projeto do porta-dosímetro: alocação dos detectores e da lâmina de cádmio, utilização de um suporte capaz de blindar o detector de traços para partículas alfa e de materiais prontamente disponíveis. 
O modo mais simples encontrado para satisfazer estes requisitos foi um sanduíche de placas de PMMA e polietileno. As placas de PMMA são as paredes externas e as de polietileno dão suporte aos componentes do dosímetro.

A placa de PMMA, utilizada para confeccionar as placas de sustentação do porta-dosímetro, é do tipo das disponíveis no mercado. Como sua espessura é de $2 \mathrm{~mm}$, serviu tanto de suporte para os detectores TL quanto para blindagem de partículas alfa. Aplicando a equação (19) e raciocinando inversamente, $2 \mathrm{~mm}$ de PMMA são suficientes para blindar partículas alfa com energia de até 30,6 MeV.

Cada porta-dosímetro é composto por três placas polietileno $(1 \mathrm{~mm}$ de espessura), as quais foram vazadas, com base nas dimensões dos detectores e da placa de cádmio, nas posições correspondentes (FIG.26). A primeira placa, na posição frontal, abriga um par de detectores TL e o detector de traços SS-1. Na segunda placa centraliza-se a lâmina de cádmio entre os pares TLD-600/TLD-700 alocados na primeira e terceira placas. A terceira placa é semelhante à primeira, porém apenas com os detectores TL. Na parte superior do porta-dosímetro há quatro posições disponíveis para detectores TL, para fins diversos.
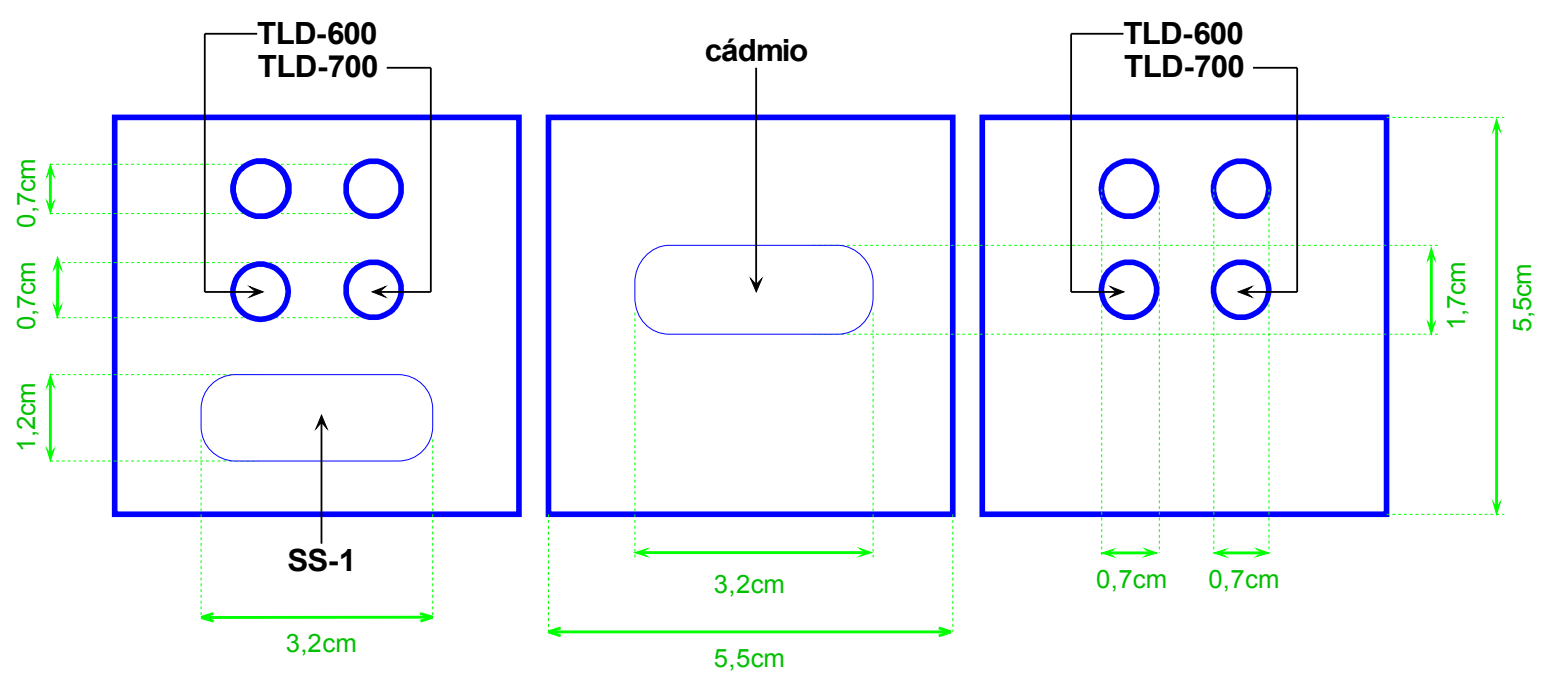

Figura 26: Protótipo e Dimensões das placas internas do porta-dosímetro

Na FIG.27 é apresentada a foto de um porta-dosímetro montado. 


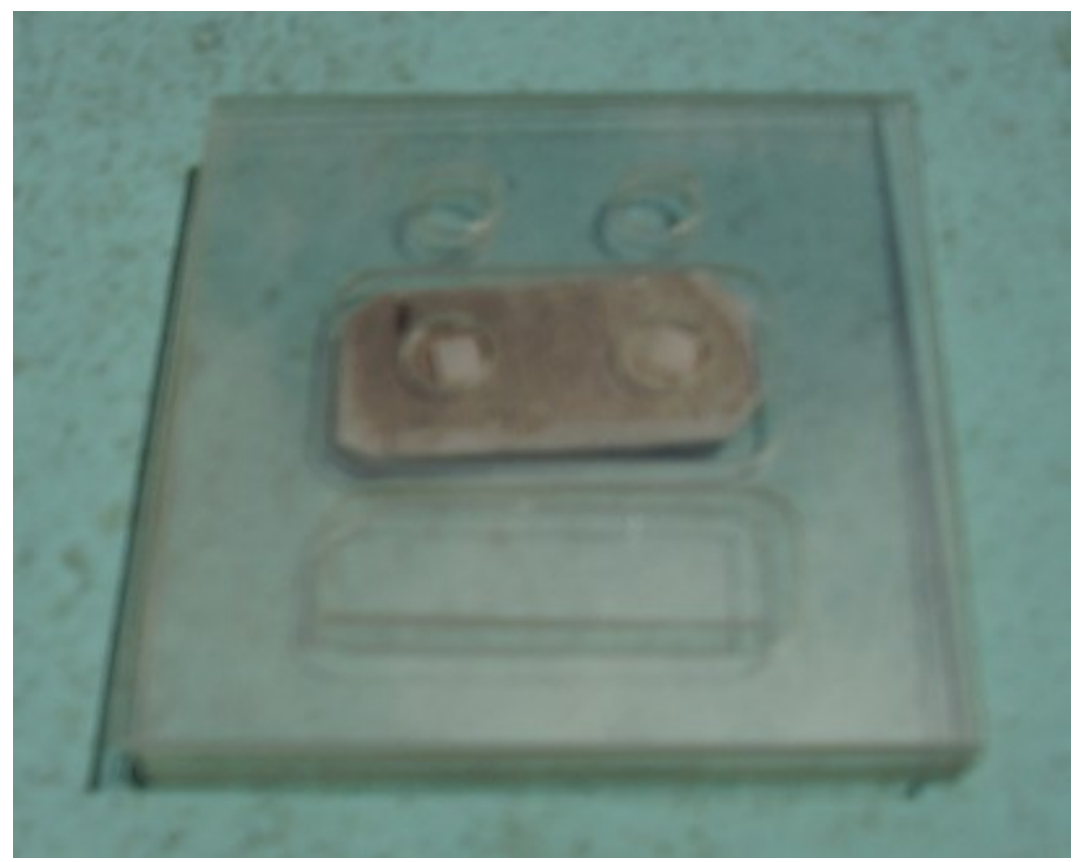

Figura 27: Aspecto de um porta-dosímetro montado

O funcionamento do dosímetro é apresentado esquematicamente na FIG.28. Os nêutrons térmicos incidentes serão detectados pelo TLD-600 frontal ou serão absorvidos pela blindagem de cádmio. Os nêutrons intermediários atravessarão o par de detectores frontal, a lâmina de cádmio e o par de detectores traseiro, interagindo com o corpo humano. Essa interação criará nêutrons de albedo que serão detectados pelo detector TLD-600 traseiro. Os nêutrons rápidos serão detectados pelo policarbonato SS-1.

Com base no gráfico da FIG.3 considerou-se que os nêutrons rápidos não contribuem significativamente na resposta de albedo. Também foi considerado que nêutrons intermediários incidentes interajam com o TLD-600 traseiro, em virtude da baixa seção de choque do ${ }^{6} \mathrm{Li}$ para nêutrons nesse intervalo de energia (FIG.7). 


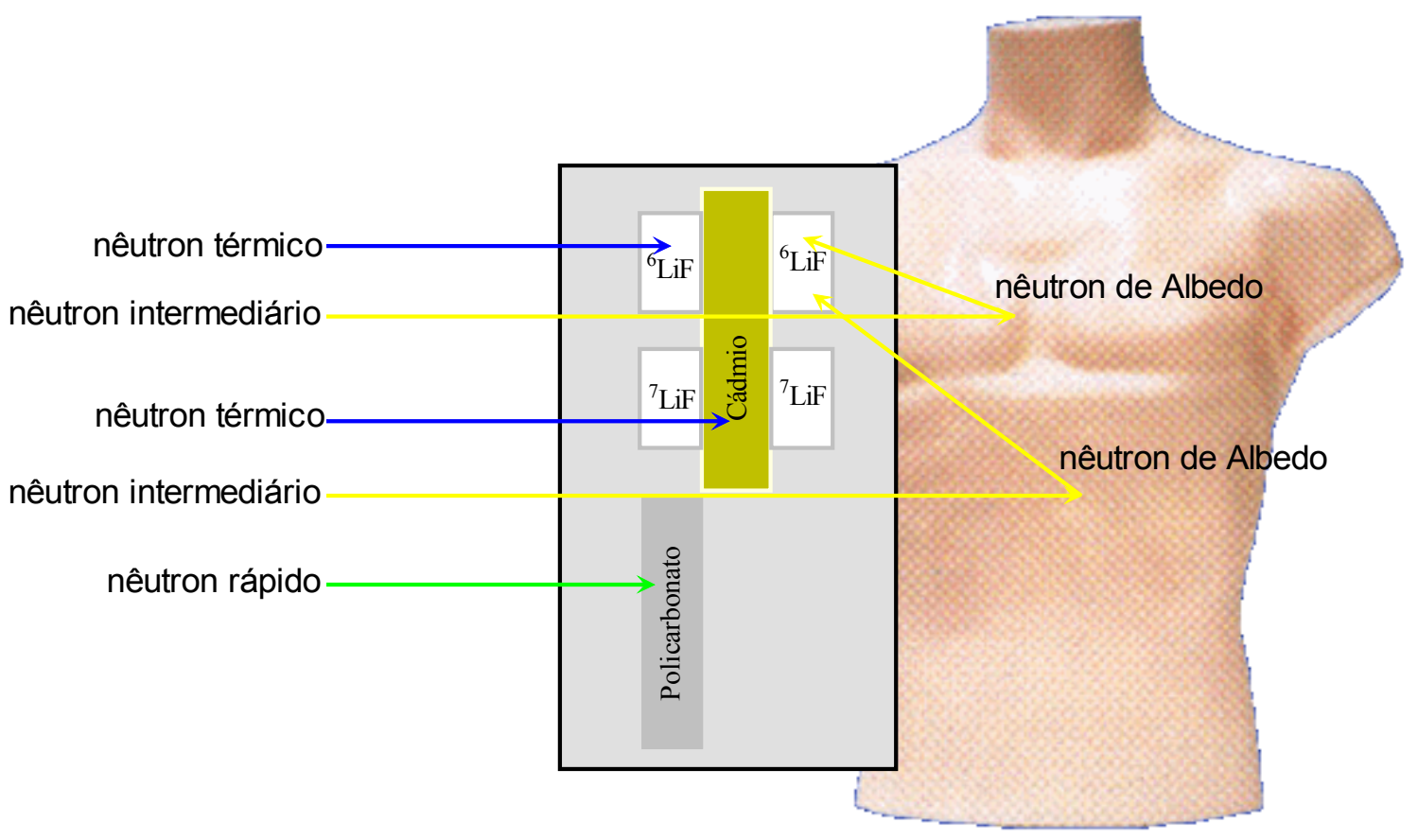

Figura 28: Esquema de funcionamento do dosímetro

\subsection{Testes de desempenho do dosímetro}

\subsubsection{Resposta do dosímetro em função da dose de nêutrons}

A média das respostas de cinco dosímetros irradiados com doses entre 0,5 e $500 \mathrm{mSv}$ de nêutrons da fonte de ${ }^{241} \mathrm{Am}-\mathrm{Be}$ do IRD são apresentadas na TAB.7. A partir dessa tabela foram construídos os gráficos das FIG.29, 30 e 31, que apresentam a resposta em função da dose para cada componente do dosímetro, respectivamente nêutrons térmicos, de albedo e rápidos.

Mediante as retas de $45^{\circ}$ traçadas nos gráficos ${ }^{10}$, observa-se que as componentes do dosímetro para nêutrons térmicos e de albedo apresentaram comportamento linear no intervalo estudado. Para a componente para nêutrons rápidos, o intervalo de linearidade está entre 1 e 20 mSv.

10 Retas de $45^{\circ}$ em gráficos dilog representam que há linearidade em gráficos de qualquer escala. 
Tabela 7: Respostas médias dos dosímetros em função da dose de nêutrons da fonte de ${ }^{241} \mathrm{Am}-\mathrm{Be}$

\begin{tabular}{|c|c|c|c|c|c|}
\hline $\begin{array}{l}\text { Dose } \\
\text { (mSv) }\end{array}$ & $\begin{array}{c}N_{\text {térmicos }} \\
\text { (nC) }\end{array}$ & $\begin{array}{c}N_{\text {albedo }} \\
(\mathrm{nC})\end{array}$ & $\begin{array}{c}N \text { rápidos } \\
\left(10^{3} \text { traços } / \mathrm{cm}^{2}\right)\end{array}$ & $\begin{array}{c}\mathbf{N} \text { albedo / } \mathbf{N} \\
\text { térmicos } \\
\text { (adimensional) }\end{array}$ & $\begin{array}{l}N_{\text {rápidos }} / N_{\text {albedo }} \\
\left(10^{2} \text { traços } / \mathrm{cm}^{2} \cdot \mathrm{nC}\right)\end{array}$ \\
\hline $0,50 \pm 0,03$ & $0,2 \pm 0,1$ & $0,6 \pm 0,1$ & $0,09 \pm 0,06$ & $(0,4 \pm 0,1) \cdot 10^{1}$ & $(0,1 \pm 0,1) \cdot 10^{1}$ \\
\hline $1,00 \pm 0,05$ & $0,3 \pm 0,1$ & $1,2 \pm 0,1$ & $0,3 \pm 0,1$ & $4,3 \pm 0,8$ & $(0,3 \pm 0,1) \cdot 10^{1}$ \\
\hline $1,385 \pm 0,074$ & $0,3 \pm 0,1$ & $1,8 \pm 0,1$ & $0,3 \pm 0,1$ & $(0,5 \pm 0,1) \cdot 10^{1}$ & $1,9 \pm 0,6$ \\
\hline $2,0 \pm 0,1$ & $0,5 \pm 0,1$ & $2,4 \pm 0,1$ & $0,7 \pm 0,2$ & $4,5 \pm 0,7$ & $3,1 \pm 0,8$ \\
\hline $5,0 \pm 0,3$ & $1,1 \pm 0,1$ & $5,2 \pm 0,3$ & $1,3 \pm 0,3$ & $4,6 \pm 0,4$ & $2,5 \pm 0,5$ \\
\hline $7,5 \pm 0,4$ & $1,5 \pm 0,1$ & $7,2 \pm 0,3$ & $3,1 \pm 0,5$ & $4,7 \pm 0,5$ & $4,4 \pm 0,8$ \\
\hline $10,0 \pm 0,5$ & $2,8 \pm 0,2$ & $11,1 \pm 0,5$ & $2,3 \pm 0,4$ & $4,0 \pm 0,3$ & $2,3 \pm 0,4$ \\
\hline $12,0 \pm 0,6$ & $2,3 \pm 0,3$ & $9,4 \pm 0,6$ & $2,7 \pm 0,4$ & $4,1 \pm 0,5$ & $2,9 \pm 0,5$ \\
\hline $15,0 \pm 0,8$ & $4,7 \pm 0,3$ & $18,8 \pm 0,8$ & $4,6 \pm 0,7$ & $4,0 \pm 0,3$ & $2,4 \pm 0,4$ \\
\hline $17,0 \pm 0,9$ & $2,8 \pm 0,3$ & $11,5 \pm 0,6$ & $4,3 \pm 0,6$ & $4,2 \pm 0,5$ & $3,7 \pm 0,5$ \\
\hline $20,0 \pm 1,1$ & $5,3 \pm 0,3$ & $21,8 \pm 1,0$ & $(0,7 \pm 0,1) \cdot 10^{1}$ & $4,1 \pm 0,3$ & $3,3 \pm 0,5$ \\
\hline $50 \pm 3$ & $15,3 \pm 0,9$ & $59,4 \pm 2,6$ & $(0,9 \pm 0,1) \cdot 10^{1}$ & $3,9 \pm 0,3$ & $1,5 \pm 0,2$ \\
\hline $100 \pm 6$ & $26,4 \pm 1,5$ & $112,6 \pm 4,9$ & $(1,6 \pm 0,2) \cdot 10^{1}$ & $4,3 \pm 0,3$ & $1,4 \pm 0,2$ \\
\hline $200 \pm 12$ & $47,0 \pm 2,8$ & $191,1 \pm 8,4$ & $(3,7 \pm 0,4) \cdot 10^{1}$ & $4,1 \pm 0,3$ & $1,9 \pm 0,2$ \\
\hline $500 \pm 32$ & $93,7 \pm 5,9$ & $430,0 \pm 18,8$ & $(6,9 \pm 0,1) \cdot 10^{1}$ & $4,6 \pm 0,4$ & $1,6 \pm 0,2$ \\
\hline
\end{tabular}




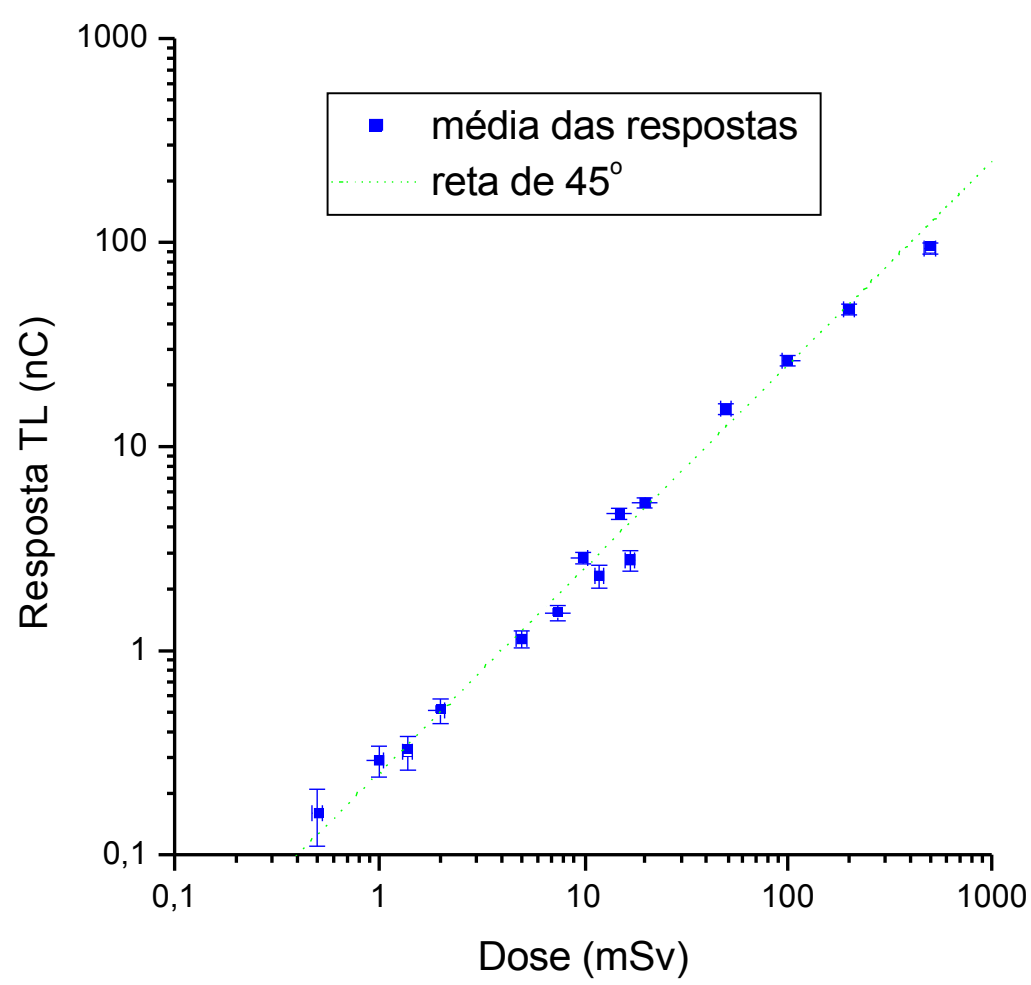

Figura 29: Reposta do dosímetro para nêutrons térmicos em função da dose

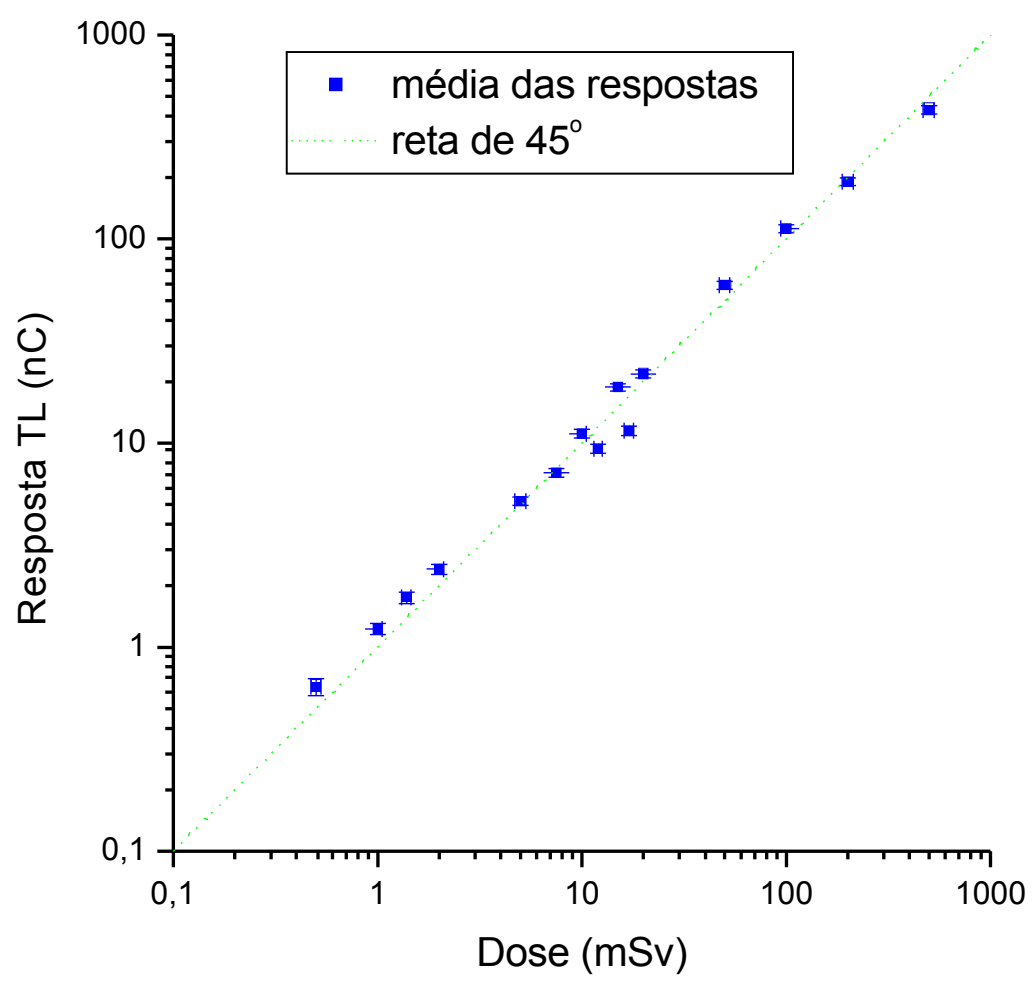

Figura 30: Resposta do dosímetro para nêutrons de albedo em função da dose 


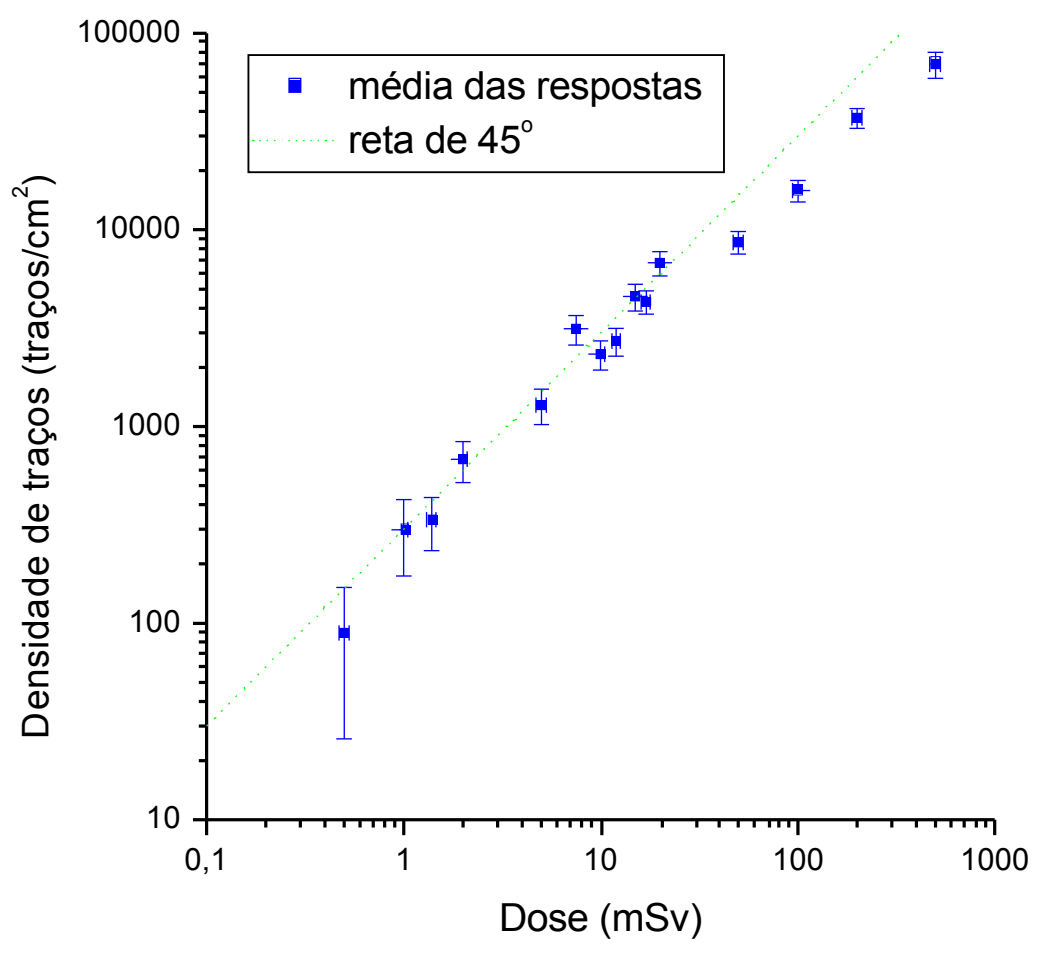

Figura 31: Resposta do dosímetro para nêutrons rápidos em função da dose

Nota-se uma ordem de grandeza de diferença entre as respostas para nêutrons térmicos e nêutrons de albedo. Esse comportamento se deve ao fato da fonte de ${ }^{241} \mathrm{Am}-\mathrm{Be}$ não emitir nêutrons térmicos (FIG.1). Entretanto, a resposta dos detectores frontais confirma a existência de térmicos no campo de radiação. Esses nêutrons podem ter sido gerados pela interação de nêutrons de maior energia com materiais hidrogenados circunvizinhos ou próximos dos detectores ou no caminho entre a fonte e o dosímetro. Desta maneira, a resposta à nêutrons térmicos é um parâmetro de análise espectral, não sendo possível utilizá-la diretamente para o cálculo da dose.

Analisando-se o comportamento da resposta para nêutrons rápidos, existe uma tendência de saturação para doses superiores à $20 \mathrm{mSv}$. A grande dificuldade na contagem dos traços nos detectores dos dosímetros irradiados com doses entre 50 e $500 \mathrm{mSv}$, pela excessiva quantidade de traços e pela ocorrência de muitos traços sobrepostos, pode explicar esse comportamento.

A razão entre as respostas para nêutrons de albedo e térmicos é constante em todo o intervalo estudado, com média de 4,3 \pm 0,6 (FIG.32). 


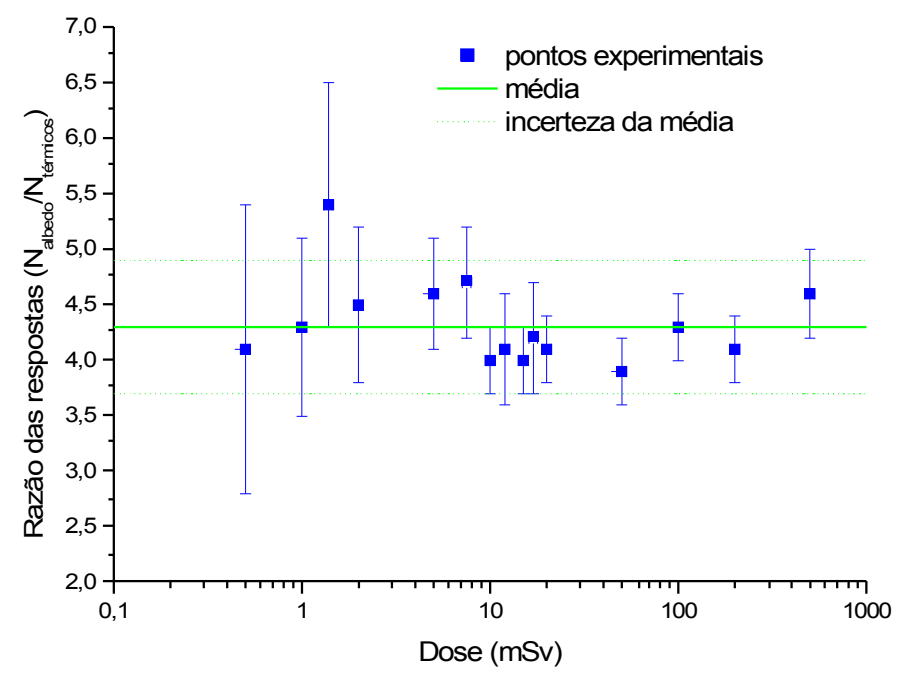

Figura 32: Razão das respostas para nêutrons de albedo e térmicos em função da dose

Já a variação da razão entre as respostas para nêutrons rápidos e de albedo pode ser considerada não significativa apenas no intervalo entre $1 \mathrm{e}$ $20 \mathrm{mSv}$, onde a média calculada foi de $(2,9 \pm 0,7) \cdot 10^{2}$ (FIG.33).

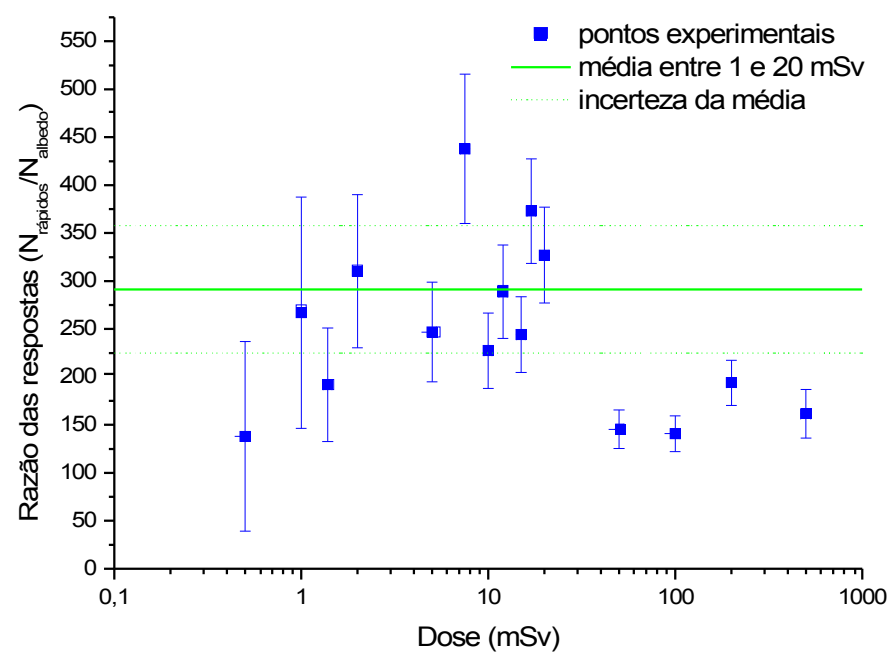

Figura 33: Razão das respostas para nêutrons rápidos e de albedo em função da dose 


\subsubsection{Dependência angular da resposta do dosímetro}

A dependência angular média da resposta do dosímetro, avaliada para ângulos de incidência entre 0 e $75^{\circ}$ é apresentada na TAB.8.

O comportamento das respostas do dosímetro em função do ângulo de incidência do feixe de radiação é exibido nas FIG.34, 35 e 36. No gráfico referente à nêutrons rápidos (FIG.36), acrescentou-se a resposta relativa do policarbonato SS-1 para ângulos de incidência de 85 e $90^{\circ}$ estudada previamente (Souto e Campos, 2006c), uma vez que para os demais ângulos, as repostas apresentaram relações coerentes nos dois estudos.

Tabela 8: Dependência angular média da resposta do dosímetro

\begin{tabular}{ccccc}
\hline Ângulo de incidência & $\begin{array}{c}\mathbf{N} \text { térmicos } \\
(\mathbf{n C})\end{array}$ & $\begin{array}{c}\mathbf{N}_{\text {albedo }} \\
(\mathbf{n C})\end{array}$ & $\begin{array}{c}\mathbf{N} \text { rápidos } \\
\left(\mathbf{1 0}^{2} \text { traços } / \mathbf{c m}^{2}\right)\end{array}$ & $\begin{array}{c}\mathbf{N}_{\text {rápidos }} / \mathbf{N}_{\text {albedo }} \\
\left(\mathbf{1 0 ^ { 2 }} \text { traços } / \mathbf{c m}^{2} / \mathbf{n C}\right)\end{array}$ \\
Normal & $2,64 \pm 0,18$ & $9,7 \pm 0,5$ & $19,9 \pm 3,9$ & $2,0 \pm 0,4$ \\
$15^{\circ}$ & $2,46 \pm 0,17$ & $9,8 \pm 0,5$ & $17,3 \pm 3,6$ & $1,8 \pm 0,4$ \\
$45^{\circ}$ & $2,27 \pm 0,16$ & $8,0 \pm 0,4$ & $12,6 \pm 2,7$ & $1,6 \pm 0,4$ \\
$60^{\circ}$ & $1,85 \pm 0,14$ & $7,1 \pm 0,4$ & $8,6 \pm 2,8$ & $1,2 \pm 0,4$ \\
$75^{\circ}$ & $2,00 \pm 0,23$ & $7,5 \pm 0,4$ & $3,5 \pm 1,8$ & $0,5 \pm 0,3$ \\
\hline
\end{tabular}

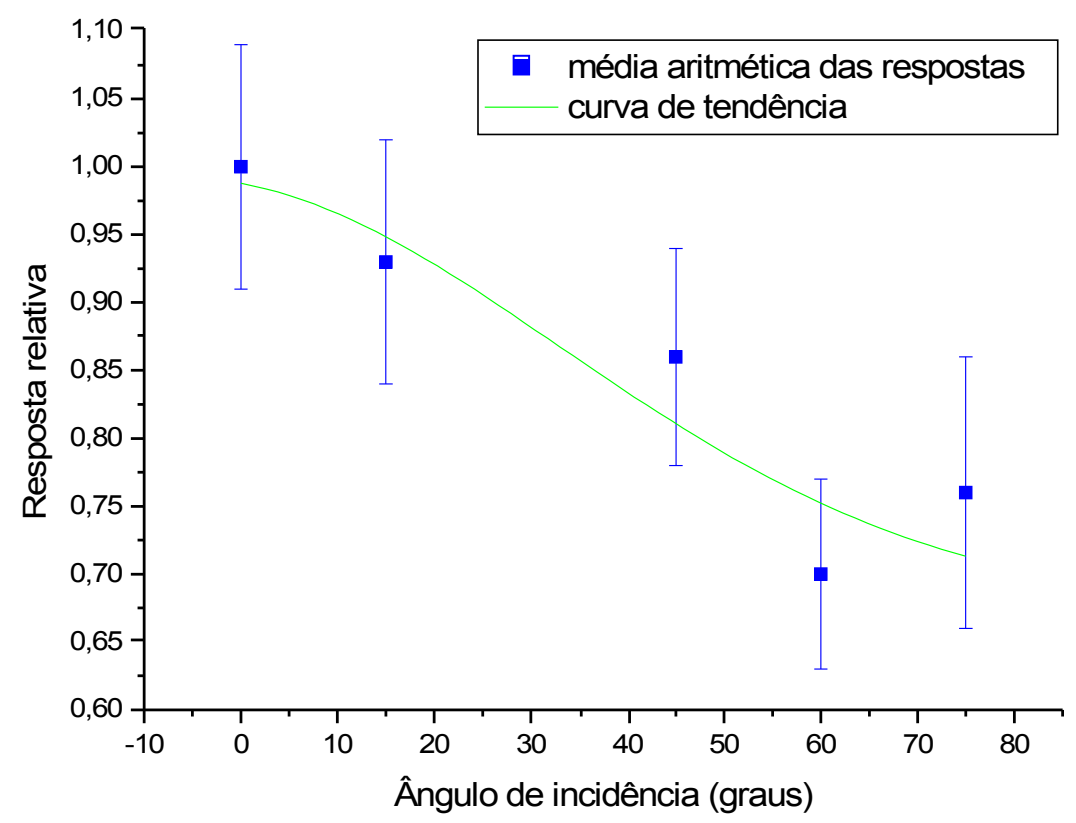

Figura 34: Dependência angular da resposta do dosímetro para nêutrons térmicos 
As médias aritméticas das respostas dos detectores TL dos dosímetros irradiados com diferentes ângulos apresentaram diferenças inferiores à 30\% da resposta para incidência normal, ficando dentro do especificado pela ISO/DIS 21909 (ISO, 2002).

Há um aumento da sensibilidade dos detectores TL entre 60 e $75^{\circ}$ de incidência do feixe de nêutrons, o que pode ser explicado pelo espalhamento dos nêutrons no objeto simulador.

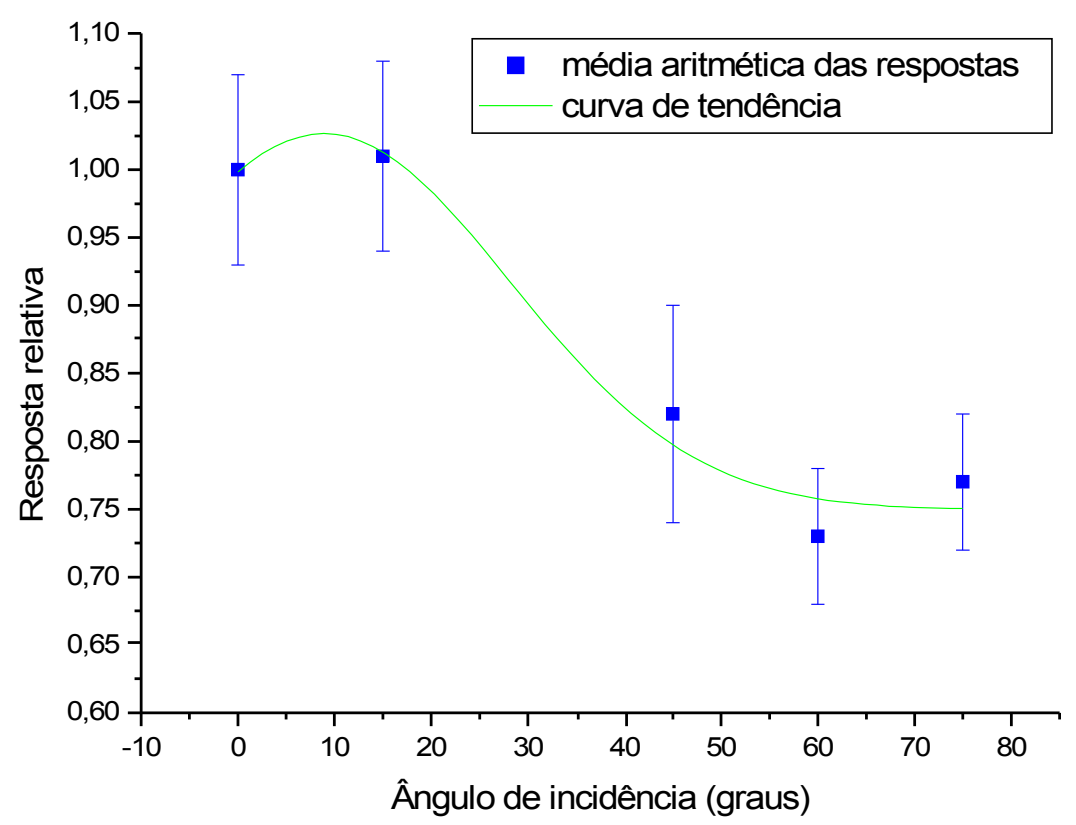

Figura 35: Dependência angular da resposta do dosímetro para nêutrons de albedo

A curva de tendência da dependência angular para nêutrons de albedo (FIG.35) apresenta um pico para ângulos pequenos. Esse tipo de comportamento está de acordo com outros estudos (Oberhofer e Scharmann, 1981).

O dosímetro apresentou forte dependência angular para nêutrons rápidos a para ângulos superiores à $45^{\circ}$ (FIG.36), conforme já esperado (Souto e Campos, 2006c). Um fator de correção deverá ser utilizado para compensar essa variação.

Segundo Faermann (1985), que estudou outro policarbonato comercial, é esperado que a densidade de traços seja proporcional ao cosseno do ângulo de 
incidência. Com base nessa afirmação, uma função cosseno foi acrescentada ao gráfico da FIG.36 para melhor visualização do comportamento.

Considerando essa dependência cossenoidal em função do ângulo de incidência e conhecendo-se este ângulo, um fator de correção igual à $\cos ^{-1}(\theta)$ deverá ser aplicado na resposta dos detectores.

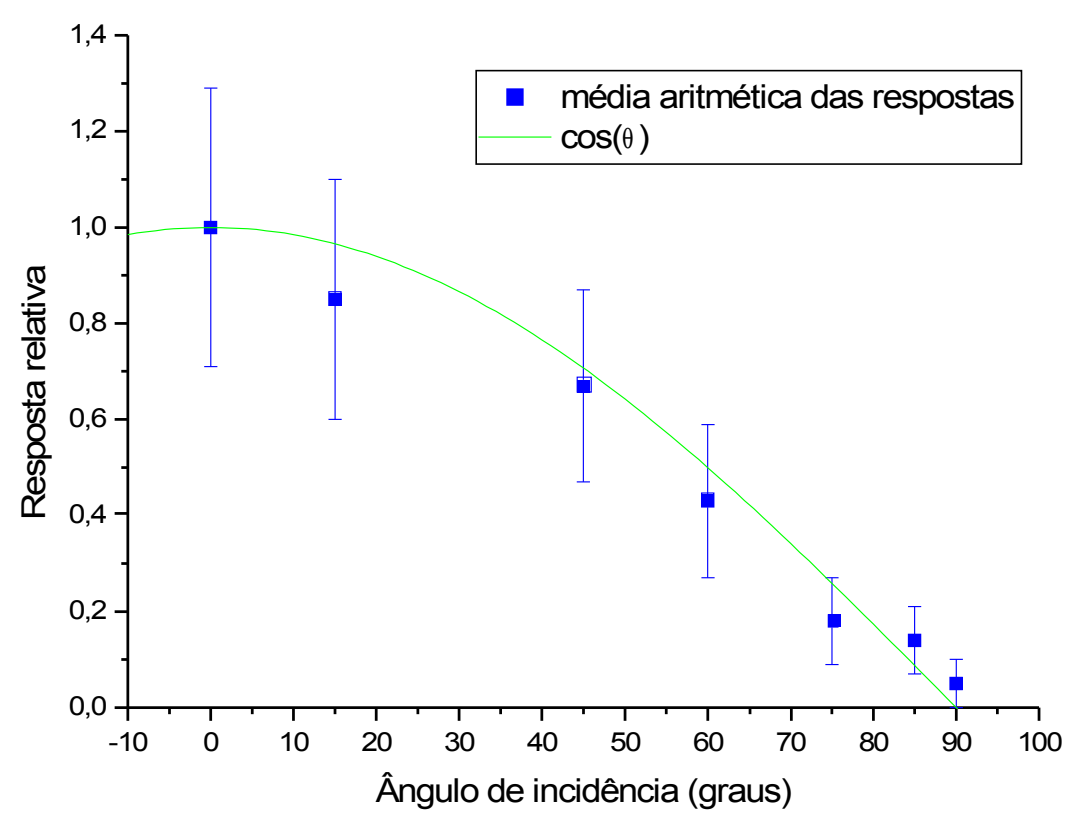

Figura 36: Dependência angular da resposta do dosímetro para nêutrons rápidos

\subsection{Algoritmos para cálculo da dose}

\subsubsection{Cálculo da dose de radiação gama}

Para o cálculo da dose de radiação gama, utilizou-se a curva de calibração da FIG.20, que somente considera fótons de energia da radiação gama da fonte de ${ }^{241} \mathrm{Am}-\mathrm{Be}$.

A presença de materiais com alta seção de choque de captura, como o cádmio, perturba a fluência dos nêutrons na circunvizinhança do dosímetro e pode implicar falsas medidas no TLD-700, por causa de reações do tipo $(n, \gamma)$.

Para o cádmio, a seção de choque de captura radioativa é idêntica à seção de choque de absorção. Da FIG.7, a captura radioativa de nêutrons com 
energias superiores à térmica pode ser considerada desprezível.

Segundo Alfassi et al. (2004), reações $(n, \gamma)$ de nêutrons térmicos no cádmio geram radiação gama de energias entre 473 e 600 keV.

Fazendo-se estas considerações e utilizando os pontos de 59,7 keV e $662 \mathrm{keV}$ da FIG.19, pode-se afirmar que: desconhecendo-se a energia da radiação gama dentro desse intervalo e considerando-a como sendo 59,7 keV, a incerteza máxima na resposta do detector será de 16\%. Para o pior caso, a incerteza expandida da Equação (15), curva de calibração da FIG.20, será, aproximadamente, $21 \%$.

Logo, pode-se considerar insignificante no cálculo da dose de radiação gama, a contribuição dos fótons oriundos de capturas radioativas no cádmio.

Da Equação (15):

$$
D_{\gamma}[m G y]=\frac{R 7 F . F s \gamma-0,71( \pm 0,11)}{4,03( \pm 0,05)}
$$

onde:

$$
\begin{aligned}
& \mathrm{D} \gamma=\text { dose de radiação gama; } \\
& \mathrm{R} 7 \mathrm{~F}=\text { resposta do TLD-700 frontal, em nC; } \\
& \mathrm{Fs} \gamma=\text { fator de sensibilidade para fótons do detector. }
\end{aligned}
$$

\subsubsection{Cálculo da dose de nêutrons}

O cálculo da dose de nêutrons pode ser efetuado utilizando apenas a componente do dosímetro referente à nêutrons de albedo ou à nêutrons rápidos. Não é possível utilizar a resposta à nêutrons térmicos incidentes para cálculo de dose, uma vez que fontes de ${ }^{241} \mathrm{Am}$-Be não emitem nêutrons nesse intervalo de energia e a resposta do dosímetro vai depender da moderação e espalhamento causado pelos materiais na circunvizinhança do dosímetro.

\subsubsection{Cálculo da dose pela dosimetria de albedo}

A partir da FIG.30, foi ajustada uma curva de calibração que melhor representasse os pontos para doses de até $20 \mathrm{mSv}$ para ser utilizada como algoritmo para cálculo da dose: 


$$
D_{\text {albedo }}[m S v]=\frac{(R 6 P . F s \gamma-R 7 P . F s \gamma) . F s n-0,19( \pm 0,05)}{1,03( \pm 0,02)}
$$

Coeficiente de correlação: 0,99201.

onde:

$D_{\text {albedo }}=$ dose de nêutrons pela dosimetria de albedo;

$\mathrm{R} 6 \mathrm{P}=$ resposta do TLD-600 posterior, em nC;

$\mathrm{R} 7 \mathrm{P}=$ resposta do TLD-700 posterior, em nC;

Fs $\gamma=$ fator de sensibilidade para fótons do detector;

Fsn = fator de sensibilidade para nêutrons térmicos do TLD-600 posterior.

\subsubsection{Cálculo da dose pela dosimetria de traços nucleares}

Da mesma forma, para nêutrons rápidos, uma curva foi ajustada para os pontos da FIG.31:

$$
D_{\text {rápidos }}[m S v]=\frac{\frac{C 5( \pm \text { desvpad })}{0,020( \pm 0,002)}+50,4( \pm 55,2)}{301,0( \pm 24,0)}
$$

Coeficiente de correlação: 0,97672.

onde:

$D_{\text {rápidos }}=$ dose de nêutrons pela de dosimetria de traços nucleares;

$0,020( \pm 0,002)=$ área da faixa de contagem, em $\mathrm{cm}^{2}$;

C5 = média da densidade de traços em cinco faixas, em traços/faixa; desvpad $=$ desvio padrão de C5.

\subsubsection{Correção angular para o cálculo da dose por traços nucleares}

Considerando que somente haverá correção para dependência angular quando a razão entre as resposta para nêutrons rápidos e de albedo, somada sua incerteza, for inferior à 200 traços $/ \mathrm{cm}^{2} . \mathrm{nC}\left[\approx(2,9-0,7) \cdot 10^{2}\right]$.

Do Item 5.4.2, conhecendo-se o ângulo de incidência, a dose de nêutrons rápidos calculada pela Equação (22) é corrigida dividindo-se a resposta do SS-1 pelo cosseno deste ângulo. 
Reescrevendo a Equação (22):

$$
D_{\text {rápidos }}[m S v]=\frac{\frac{C 5( \pm \text { desvpad })}{0,020( \pm 0,002)} \cos ^{-1}(\theta)+50,4( \pm 55,2)}{301,0( \pm 24,0)}
$$

O ângulo de incidência pode ser estimado pela variação da razão entre as respostas para nêutrons rápidos e de albedo (R/A). Para incidência normal, essa razão se não varia significativamente no intervalo de dose de interesse (TAB.7 e FIG.33). Contudo, com o aumento do ângulo de incidência, a razão R/A diminui (TAB.8 e FIG.37).

De modo a simplificar os cálculos, optou-se por aproximar a supracitada variação da razão R/A por uma reta. Essa reta foi ajustada aos pontos experimentais e é apresentada na FIG.37.

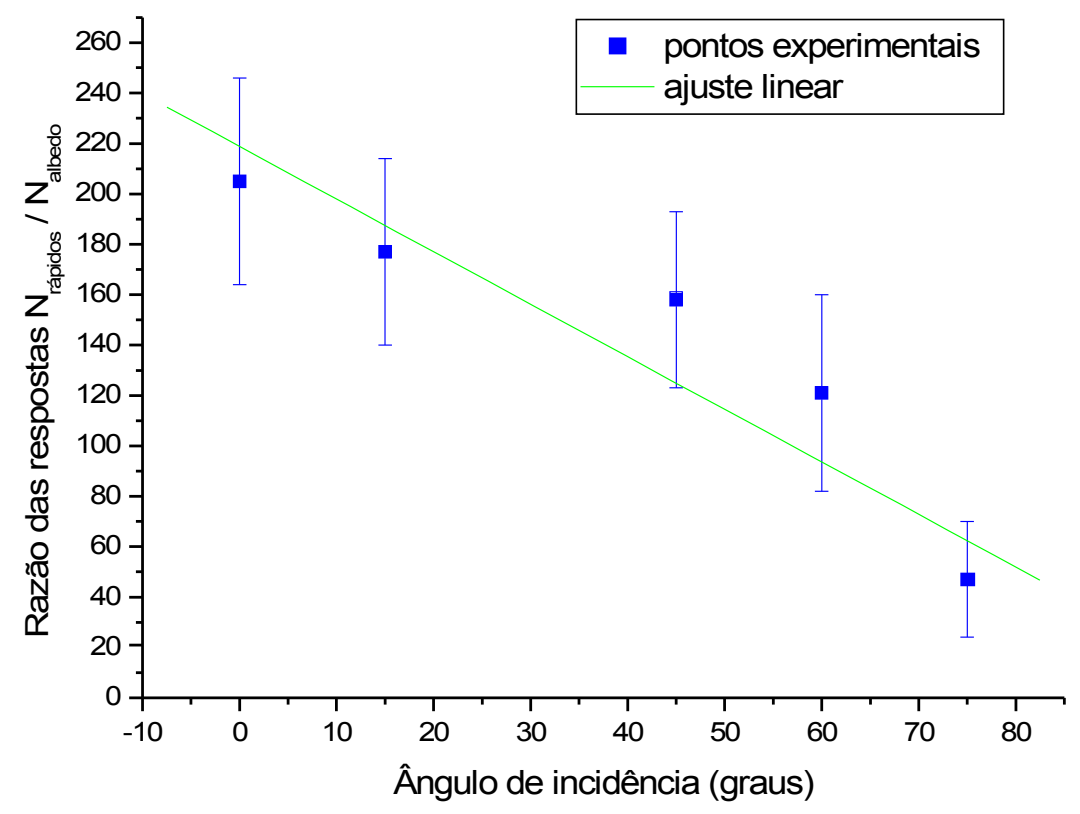

Figura 37: Razão das respostas do dosímetro para nêutrons rápidos e de albedo em função do ângulo de incidência

Do ajuste linear:

$$
\theta=\frac{R / A-218,8( \pm 29,4)}{-2,1( \pm 0,5)}
$$


onde:

$\theta$ = ângulo de incidência do feixe de nêutrons, em graus;

$\mathrm{R} / \mathrm{A}=$ razão das respostas para nêutrons rápidos e de albedo, em traços $/ \mathrm{cm}^{2} / \mathrm{nC}$.

\subsubsection{Fluxograma para cálculo da dose}

A avaliação das doses de radiação gama e de nêutrons para o dosímetro desenvolvido segue o fluxograma da FIG.38.

Como a taxa de dose de fontes como a de ${ }^{241} \mathrm{Am}-\mathrm{Be}$ é calibrada em função da moda de energia dos seus nêutrons, bastaria somente uma técnica dosimétrica para avaliar a dose, DTLA ou DSTN. A dosimetria de albedo é a mais indicada, porque é mais rápida e precisa, além de ser capaz de mensurar dose mais baixas que a dosimetria de traços. Todavia, quando um dosímetro acusa dose alta pela técnica de albedo, convém confirmar essa dose avaliando o detector de traços. A não confirmação da dose alta apontará incorreta utilização do dosímetro, seja no posicionamento ou com o tipo de fonte de nêutrons.

Essa confirmação é efetuada comparando as doses estimadas pelos dois métodos de dosimetria. A partir dos resultados obtidos no presente trabalho, admite-se $20 \%$ de diferença entre as doses calculadas por albedo e por traços nucleares. 


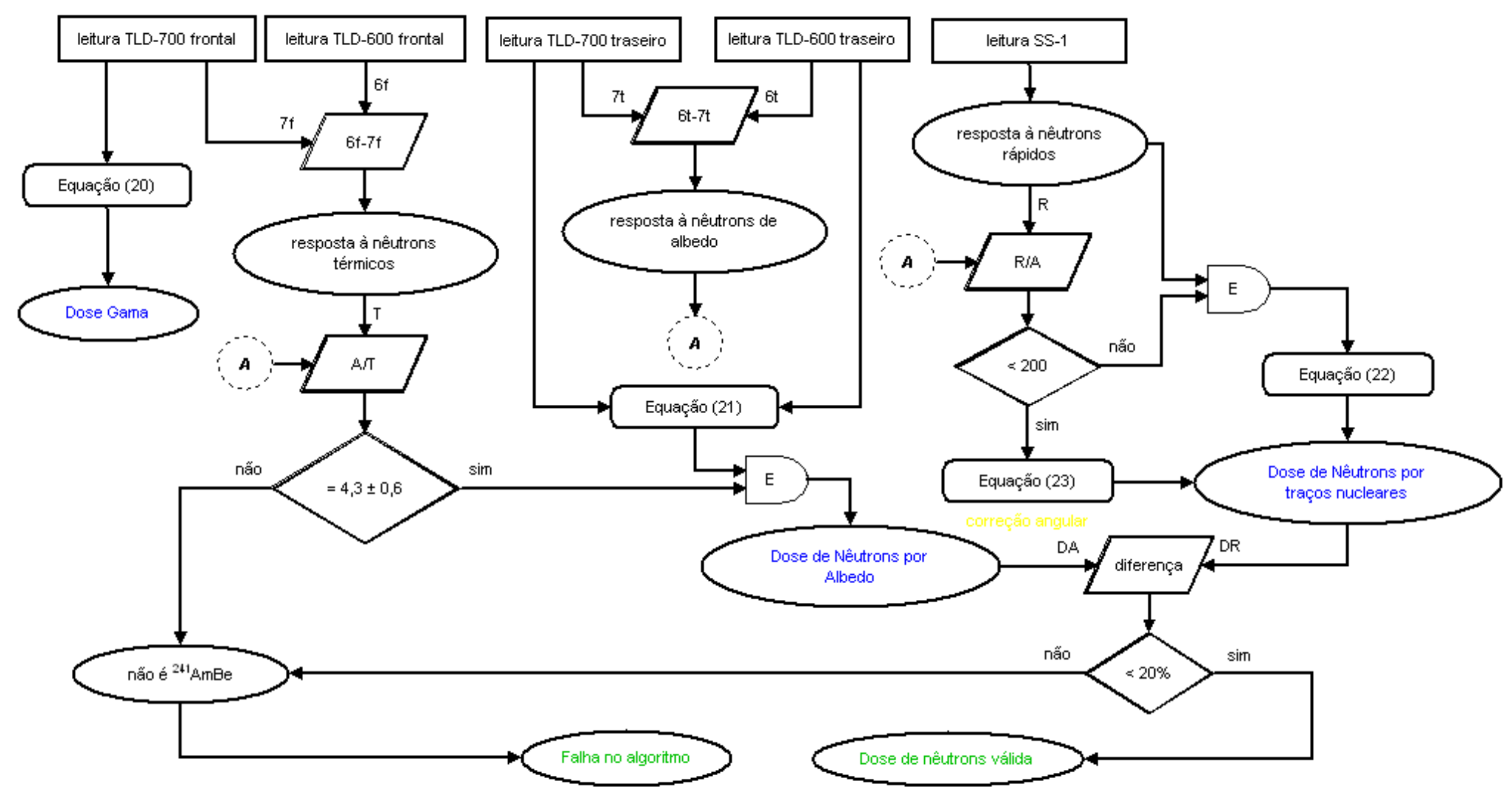

Figura 38: Fluxograma para avaliação da dose do dosímetro desenvolvido 


\subsection{Irradiação de protótipos com espectro diferente}

As respostas dos dosímetros irradiados com $10 \mathrm{mSv}$ de nêutrons de uma fonte de ${ }^{252} \mathrm{Cf}$, bem como as razões entre as mesmas, são apresentadas na TAB.9.

A componente para nêutrons térmicos do dosímetro respondeu cerca de $30 \%$ a mais para a fonte de ${ }^{252} \mathrm{Cf}$ em relação à fonte de ${ }^{241} \mathrm{Am}-\mathrm{Be}$, entretanto a razão entre as respostas para nêutrons de albedo e térmicos é da mesma ordem para as duas fontes.

Burgkhardt e Piesh (1988) estabeleceram quatro campos de aplicação para dosímetros de albedo: Reatores e aceleradores, Ciclo do combustível, Fontes de radionuclídeos e Aceleradores de pesquisa. Dentro de um mesmo campo de aplicação, a razão entre as respostas dos detectores para nêutrons térmicos e de albedo pouco varia. Ou seja, nas irradiações com ${ }^{252} \mathrm{Cf}$ havia mais nêutrons térmicos no espectro, todavia não é possível concluir não se tratar de ${ }^{241} \mathrm{Am}-\mathrm{Be}$.

Tabela 9: Resposta de dosímetros irradiados com fonte de ${ }^{252} \mathrm{Cf}, 10,0( \pm 0,5) \mathrm{mSv}$

\begin{tabular}{lccc}
\hline Protótipo & $\mathrm{D} 16$ & $\mathrm{D} 17$ & $\mathrm{D} 18$ \\
$\mathbf{N}_{\text {térmicos }}(\mathbf{n C})$ & $4,0 \pm 0,3$ & $3,9 \pm 0,3$ & $3,9 \pm 0,3$ \\
$\mathbf{N}_{\text {albedo }}(\mathbf{n C})$ & $16,2 \pm 0,7$ & $15,5 \pm 0,7$ & $16,4 \pm 0,7$ \\
$\mathbf{N}_{\text {rápidos }}\left(\mathbf{1 0}^{3}\right.$ traços $\left./ \mathbf{c m}^{2}\right)$ & $1,1 \pm 0,3$ & $0,9 \pm 0,2$ & $1,1 \pm 0,2$ \\
$\mathbf{N}_{\text {albedo }} / \mathbf{N}$ térmicos $($ adimensional) & $4,0 \pm 0,3$ & $4,0 \pm 0,3$ & $4,2 \pm 0,4$ \\
$\mathbf{N}_{\text {rápidos }} / \mathbf{N}$ albedo $\left(\mathbf{1 0}^{2}\right.$ traços $\left./ \mathbf{c m}^{2} / \mathbf{n C}\right)$ & $0,6 \pm 0,2$ & $0,6 \pm 0,1$ & $0,7 \pm 0,2$ \\
\hline
\end{tabular}

Já a resposta para nêutrons rápidos do ${ }^{252} \mathrm{Cf}$ é $55 \%$ inferior para a mesma dose utilizando a fonte de ${ }^{241} \mathrm{Am}-\mathrm{Be}$, indicando que o dosímetro tem menor sensibilidade à fonte de Califórnio.

Utilizando as Equações (21), (22) e (23), estimou-se a dose de cada protótipo como se tivessem sido irradiados com fonte de ${ }^{241} \mathrm{Am}-\mathrm{Be}$ e calculou-se a diferença percentual com a dose real (TAB.10). 
Tabela 10: Estimativa da dose para os protótipos irradiados com fonte de ${ }^{252} \mathrm{Cf}$

\begin{tabular}{ccccccc}
\hline \multirow{2}{*}{ Protótipo } & \multicolumn{2}{c}{$\mathbf{D}_{\text {albedo }}$} & \multicolumn{2}{c}{$\mathbf{D}_{\text {rápidos }}$} & \multicolumn{2}{c}{$\mathbf{D}_{\text {rápidos }}$ corrigido } \\
& $(\mathbf{m S v})$ & Dif. (\%) & $(\mathbf{m S v})$ & Dif. (\%) & $(\mathbf{1 0} \mathbf{m S v})$ & Dif. (\%) \\
$\mathrm{D} 16$ & $15,5 \pm 0,7$ & +55 & $3,7 \pm 0,1$ & -63 & $1,2 \pm 0,3$ & +23 \\
$\mathrm{D} 17$ & $14,8 \pm 0,7$ & +48 & $3,2 \pm 0,1$ & -68 & $1,3 \pm 0,3$ & +28 \\
$\mathrm{D} 18$ & $15,7 \pm 0,8$ & +57 & $3,8 \pm 0,1$ & -62 & $1,2 \pm 0,3$ & +22 \\
\hline
\end{tabular}

Tanto a dose estimada pela dosimetria de albedo quanto pela de traços nucleares são discrepantes da dose real de $10 \mathrm{mSv}$; em média, a primeira técnica sobrestimou a dose em $50 \%$ e a segunda, subestimou em $65 \%$.

Considerando um suposto erro direcional durante a irradiação, a correção da dose para nêutrons rápidos resultou em uma diferença superior $20 \%$ entre doses calculadas pelas duas técnicas dosimétricas para dois dos protótipos. Por conseguinte o algoritmo para o cálculo da dose falha para esta fonte.

Com base nesse estudo, conclui-se que os algoritmos de dose desenvolvidos são válidos apenas para fontes de ${ }^{241} \mathrm{Am}$-Be e que as razões entres as resposta são úteis para análise espectral. Porém seria necessário um estudo mais aprofundado desses parâmetros em diversas fontes de nêutrons para poder utilizá-los.

\subsection{Considerações sobre o uso do dosímetro}

O uso conjunto da dosimetria termoluminescente com a de traços nucleares provê a possibilidade de confirmar a dose avaliada, analisar o espectro energético dos nêutrons no local da irradiação e verificar a correta utilização do dosímetro.

A razão entre as respostas para nêutrons de albedo e térmicos não se altera com a dose nem com o ângulo de incidência. Se essa razão resultar em um valor muito diferente da média para a fonte de ${ }^{241} \mathrm{Am}-\mathrm{Be}$, significa que o dosímetro foi irradiado com outro tipo de fonte de nêutrons, que não radionuclídeos (Burgkhardt e Piesh, 1988), ou que há materiais perturbando o espectro energético entre a fonte o detector. Essa razão é um parâmetro de análise espectral, denota a quantidade de nêutrons térmicos no ambiente da irradiação. 
Em virtude da forte dependência angular do SS-1, a razão entre as resposta para nêutrons rápidos e de albedo diminui com o aumento do ângulo de incidência do feixe de nêutrons. Essa variação permite estimar o ângulo de incidência e, por conseguinte, corrigir a dose avaliada pelo detector de traços.

Quando um dosímetro apresentar baixa resposta à nêutrons rápidos e alta resposta à nêutrons térmicos, significa que o dosímetro foi posicionado de costas para a fonte ou nas costas do usuário. Neste caso a componente para nêutrons térmicos mensurou nêutrons de albedo ou nêutrons termalizados no corpo do usuário e a componente para nêutrons rápidos teve sua resposta prejudicada.

Da mesma forma, quando um dosímetro apresentar alta resposta à nêutrons rápidos e baixa resposta à nêutrons de albedo, denota que o dosímetro foi posicionado longe do corpo do usuário ou que foi irradiado sem ser utilizado. Ou seja, os nêutrons intermediários não foram retro-espalhados.

Os algoritmos de dose desenvolvidos são válidos apenas para fontes de Amerício-Berílio, para outras aplicações, é necessário calibrar o dosímetro. 


\section{CONCLUSÕES}

Todos os estudos foram realizados empregando fontes de ${ }^{241} \mathrm{Am}-\mathrm{Be}$, que são as mais comumente utilizadas e os algoritmos apresentados são válidos somente para esta fonte de nêutrons. Para utilização em campos com nêutrons provenientes de outras fontes, é necessária calibração apropriada.

O arranjo proposto para o uso dos detectores termoluminescentes TLD-600 e TLD-700 é adequado e atende os requisitos da norma ISO/DIS 21909. Para detecção de fótons, a dose mínima detectável está abaixo do exigido pela CNEN no Regulamento Técnico IRD RT № 002.01/95, que é de 0,2 mSv. As respostas em função da dose de fótons e de nêutrons de albedo são lineares nos intervalos estudados, entre 0,2 e $100 \mathrm{mSv}$ e $500 \mathrm{mSv}$, respectivamente.

Os policarbonatos comerciais apresentam potencial para uso como detectores de traços. Em particular, o SS-1, selecionado para este trabalho, foi caracterizado para aplicação como detector de traços para nêutrons. Sua resposta em função da dose de nêutrons rápidos é linear dentro do intervalo de interesse da radioproteção, entre 0,3 e $20 \mathrm{mSv}$. A dose mínima detectável é $0,12 \mathrm{mSv}$. O policarbonato apresenta forte dependência angular, necessitando de um fator de correção para ângulos superiores à $40^{\circ}$. Apesar de ser menos sensível que os materiais consagrados para esta aplicação, é uma alternativa economicamente mais viável para a realidade brasileira. O SS-1 também pode ser utilizado para dosimetria ambiental e como detector de partículas alfa, desde que feita uma calibração adequada.

Os parâmetros de ataque químico para revelação dos traços no SS-1 foram determinados de acordo com a capacidade dos equipamentos disponíveis e simulando uma jornada de trabalho de um laboratório de dosimetria. A melhor relação entre a quantidade e a nitidez dos traços foi conseguida com um ataque de 3 h à $75^{\circ} \mathrm{C}$, com a solução química PEW-40.

A metodologia de avaliação dos detectores de traços é simples, porém cansativa e tediosa. Para cada detector são contados os traços em cinco faixas de $0,02 \mathrm{~cm}^{2}$. A densidade de traços é determinada pela média dessas cinco contagens. 
Os materiais utilizados no porta-dosímetro são todos de baixo custo e facilmente encontrados no mercado.

Os testes de desempenho realizados em campos mistos nêutron-gama atenderam os requisitos da norma ISO/DIS 21909.

O dosímetro proposto neste trabalho apresenta todas as características desejadas para a sua utilização na monitoração individual de trabalhadores potencialmente expostos à radiação de nêutrons de fontes de ${ }^{241} \mathrm{Am}-\mathrm{Be}$ e está pronto para ser disponibilizado no mercado. 


\section{BIBLIOGRAFIA}

ALBERIGI S.; PECEQUILO B.R.S.; DE CAMPOS M.P. Um método alternativo para contagem de traços em detectores sólidos de traços nucleares. In: 2005 International Nuclear Atlantic Conference - INAC 2005, August 28 - September 2, 2005, Santos. Proceedings...

ALFASSI, Z.B.; ZLATIN, T.; MANOR, O.; DUBINSKY, S.; GERMAN, U. Improved neutron detection by gamma-ray spectroscopy. Radiat. Prot. Dosim., v. 110, n. 1-4, p. 207-211, 2004.

AMERSHAM - THE RADIOCHEMICAL CENTRE, Radiation sources - industrial / laboratory 1977/8. Amersham: AMERSHAM, 1977.

ATTIX, F.H.; ROESCH, W.C.; TOCHILIN, E. Radiation Dosimetry - Vol. 1. $3^{\text {th }}$ Ed. New York: Academic, 1968.

AYYANGAR, K.; CHANDRA, B.; LAKSHMANAN, A.R. Mixed field dosimetry with $\mathrm{CaSO}_{4}$ :Dy. Phys. Med. Biol., v. 19, p. 656-664, 1974.

BECKER, K. Solid State Dosimetry. Cleveland, Ohio: CRC, 1973.

BITELLI, T. Dosimetria e Higiene das Radiações. São Paulo: Grêmio Politécnico, 1982.

BIPM - Bureal International des Poids et Measures $<\underline{w w w . b i p m . f r}>$. Acesso em 01 dez. 2006.

BURGKHARDT, B.; PIESH, E. Field calibration technique for albedo neutron dosemeter. Radiat. Prot. Dosim., v. 23, n. 1/4, p. 121-126, 1988.

BYRNE, J. Neutron, Nuclei and Matter. Bristol: IOP, 1994.

CARTWRIGHT, B.G.; SHIRK, E.K.; PRICE, P.B. A nuclear-track-recording polymer of unique sensitivity and resolution. Nucl. Instrum. Meth., v. 153, p. 457460, 1978.

CESAR, M.F.; FRANCO, M.A.R. Some studies on the registration of particles on Makrofol E. Nuclear Tracks, v. 12,n. 1-6, p. 193-196, 1986.

CHEKA, J.J. Recent developments in film monitoring of fast neutrons. Nucleonics, v. 12, n. 6, p. 40, 1954.

COMISSÃO NACIONAL DE ENERGIA NUCLEAR, IRD RT $\boldsymbol{N}^{\circ}$ 002.01/95 Desempenho de sistemas de monitoração individual - critérios e condições. Rio de Janeiro: CNEN, 1995. (IRD RT Nº 002.01/95). 
COOK, J.E. Fast neutron dosimetry using nuclear emulsion. AERE, 1958. (AERE HP/R 2744).

CROSS, W.G.; TOMMASINO, L. A rapid reading technique for nuclear particle damage tracks in thin foils. Radiat. Eff., v. 5, p. 85-89, 1970.

DILETA - IND. E COM. DE PRODUTOS QUÍMICOS Ltda. <www.dileta.com.br>. Acesso em 01 dez. 2006.

EISEN, Y.; KARPINOVITCH, Z.; GAVRON, A.; TAL, A.; ITZKIN, Y.; SCHLESINGER, T. Development of a polycarbonate fast neutron dosimeter and comparison with the conventional emulsion dosimeter. Health Phys., v. 38, p. 497-505, 1980.

EISEN, Y.;SHAMAI, Y.; OVADIA, E.; KARPINOVITCH, Z.; FAERMANN, S.; SCHLESINGER, T. A Rem equivalent personnel neutron dosimeter for neutron energies of $1 \mathrm{eV}-14 \mathrm{MeV}$. Health Phys., v. 41, p. 349-362, 1981.

EISEN, Y.; ELIAU, A.; FAERMANN, S.; KARPINOVITCH, Z.; OVADIA, E.; ROSMAN, T.; SCHESINGER, T.; SHAMAI, Y.; TAL, A. A wide energy range personnel neutron dosimeter and its dose evaluation system. Radiat. Prot. Dosim., v. 3, n. 1, p. 55-66, 1982.

ENEA - Ente per le Nuove Tecnologie, l'Energia e l'Ambiente <www.enea.it>. Acesso em 01 dez. 2006.

FAERMANN, S.; EISEN, Y., TAL, A.; EVEN, O., SCHLESINGER, T. The directional dependence of the wide energy range Rem response personnel dosimeter. In: JOINT ANNUAL MEETING OF THE NUCLEAR SOCIETIES OF ISRAEL, 1982, Haifa.

FAERMANN, S. Design and development of wide energy neutron Rem equivalent spectrometer-dosimeter based on polycarbonates and CR-39. 1985 Tese (Doutorado) - Soreq Nuclear Research Centre, Beer-Sheva.

FANTUZZI, E.; MORELLI, B.; FALANGI, G.; PATRIZII, L.; TOGO, V. CR-39 acceptance test and optimization for fast neutron dosimetry applications. Radiat. Prot. Dosim., v. 101, n. 1-4, p. 573-578, 2002.

FERNÀNDEZ, F. Personal neutrons dosimetry in nuclear power plants using etched tracks and albedo TL dosimeters. Radiat. Prot. Dosim., v. 110, n. 1-4, p. 701-704, 2004.

GDS - Global Dosimetry Solutions <www.dosimetry.com>. Acesso em $01 \mathrm{dez}$. 2006.

GUEDES O., S.; HADLER N., J.C.; IUNES, P.J.; PAULO, S.R.; TELL S., C.A. On the reproducibility of SSNTD track counting efficiency. Nucl. Instr. and Meth. in phys. Res. , v. A 418, p. 429-433, 1998. 
HARRISON, K.G., HARVEY, J.R.; BOOT, S.J. The calibration of neutorn instruments and dosimeters at intermediate energies. Nucl. Instr. Meth., v. 148, p. 511, 1978.

HARVEY, J.R.; LAVENDER, A.; THOMPSON, I.M.C., The calibration of a number of neutron sensitive instruments with a novel source emitting neutrons around 0.5 keV. Health Phys., v.31, n. 4, p 363, 1976.

HARVEY, W.F.; HOFFMAN, J.M.; BLISS, J.L.; BRAKE, R.J. Personnel neutron dosimetry improvements at Los Alamos National Laboratory. Radiat. Prot. Dosim., v. 47, n. 1-4, p. 391-395, 1993.

HANKINS, D.E. Factors affecting the design of albedo-neutron dosimeters containing lithium fluoride thermoluminescent dosimeters. Los Alamos, 1972. (LA-4832)

HANKINS, D.E. Design of albedo-neutron dosimeters. In: SYMPOSIUM ON NEUTRON MONITORING FOR RADIATION PROTECTION PURPOSES, December 11-15, 1972, Vienna. Proceedings... Vienna: IAEA, 1973. p. 15-29.

INTERNATIONAL ATOMIC ENERGY AGENCY, Neutron monitoring for radiation protection. Vienna: IAEA, 1985. (TRS 252).

INTERNATIONAL ATOMIC ENERGY AGENCY, Guidelines on calibration of neutron spectra and detector responses for radiation pretection purposes supplement to technical reports series No. 318. Vienna: IAEA, 2001. (TRS 403).

INTERNATIONAL ATOMIC ENERGY AGENCY, Compendium of neutron Monitoring for Radiation Protection. Vienna: IAEA, 1985. (TRS 252).

INTERNATIONAL COMMISSION ON RADIATION UNITS AND MEASUREMENTS, Neutron fluence, neutron spectra and kerma, ICRU, 1969. (ICRU 13).

INTERNATIONAL COMMISSION ON RADIATION UNITS AND MEASUREMENTS, Determination of dose equivalents resulting from external radiation sources, ICRU, 1985. (ICRU 39).

INTERNATIONAL COMMISSION ON RADIATION UNITS AND MEASUREMENTS, Quantities and units in radiation protection dosimetry, ICRU, 1993. (ICRU 51).

INTERNATIONAL ORGANIZATION FOR STANDARDIZATION, Reference Neutron Radiations - Part 1: Characteristics and methods of production. Geneva: ISO, 2001. (ISO 8529-1).

INTERNATIONAL ORGANIZATION FOR STANDARDIZATION, Radiation protection - Passive personal neutron dosimeter - Performance and test requirements, Standard. Geneva: ISO, 2002. (ISO/DIS 21909). 
JÓZEFOWICZ, K. Energy threshold for neutron detection in a Makrofol dieletric track detector. Nucl. Instrum. Meth., v. 91, p. 369-370, 1971.

JOZĖFOWICZ, K. Energy dependende of the efficiency of neutron detection in polycarbonate by recording atom recoil tracks. In: SYMPOSIUM ON NEUTRON MONITORING FOR RADIATION PROTECTION PURPOSES, December 11-15, 1972, Vienna. Proceedings... Vienna: IAEA, 1973. p. 183-190.

KATZ, R.; KOBETICH, E.J. Formation of etchable tracks in dieletrics. Phys. Rev., v. 170, n. 2, 1968.

KAERI - KOREA ATOMIC ENERGY RESEARCH INSTITUTE - Nuclear Data Evaluation Lab. <http://atom.kaeri.re.kr> Acesso em 01 dez. 2006.

LAMARSH, J.R. Nuclear Engineering. $2^{\text {nd }}$ ed. Menlo Park, California: AddisonWesley, 1983.

LIDE, D.R. CRC Handbook of Chemistry and Physics. $75^{\text {th }}$ ed. Boca Raton, Florida: CRC, 1995.

MADI FILHO, T. Desenvolvimento de detector de nêutrons utilizando sensor tipo barreira de superfície com conversor (n,p) e conversor (n,a). 1999. Tese (Doutorado) - Instituto de Pesquisas Energéticas e Nucleares - IPEN/CNEN-SP, São Paulo.

MARIOTTI, F.; MORELLI, B.; FANTUZZI, E. Test di qualitá del materiale CR-39 per dosimetria neutronica: risultati e messa a punto dei criteri di accettabilitá. In: AIRP - XXXII CONGRESSO NAZIONALE DI RADIOPROTEZIONE, Settembre 1719, 2003, Bari. Proceedings...

MORELLI, B.; VILELA, E.; FANTUZZI, E. Dosimetric performance of the fast neutron dosemeter for ENEA personal dosimetry service. Radiat. Prot. Dosim., v. 85, n. 1-4, p. 105-108, 1999.

MORELI, B.; BEDOGNI, R.; MARIOTTI, F.; FANTUZZI, E. Implementazione di un sistema de lettura automatico per dosimetri per neutroni veloci di CR-39 nel servizio di dosimetri dell'Instituto di Radioprotezione dell'ENEA. In: AIRP - XXXII CONGRESSO NAZIONALE DI RADIOPROTEZIONE, Settembre 17-19, 2003, Bari. Proceedings...

MUTIULLAH; REHMAN", S.; REHMAN², S.; ZAMAN, W. Discovery of new etchants for CR-39 detector. Radiat. Meas., v. 39, p. 337-343, 2005.

MUTIULLAH; REHMAN', S.; REHMAN², S.; MATI, N.; AHMAD, S. Some more new etchants for CR-39 detector. Radiat. Meas., v. 39, p. 551-555, 2005.

OBERHOFER, M.; SCHARMANN, A. Applied Thermoluminescence Dosimetry. Bristol: Adam Hilger, 1981.

PADILHA, M.C. Detecção de nêutrons utilizando CR-39. 1992. Dissertação (Mestrado) - Instituto de Pesquisas Energéticas e Nucleares - IPEN/CNEN-SP, São Paulo. 
PIEAS - Pakistan Institute of Engineering and Applied Sciences <www.pieas.edu.pk>. Acesso em 01 dez. 2006.

PIESH, E. Progress in albedo neutron dosimetry. Nucl. Instrum. Meth., v. 145, p. 613-619, 1977.

PIESCH, E.; JASIAK, J.; URBAN, M. Makrofol and CR-39 recoil track detectors as a supplement of a universal albedo neutron dosimeter. Nuclear Tracks and Radiation Measurements, v. 8, n. 1-4, p. 323-326-1984.

PIESH, E.; BURGKHARDT, B. Albedo dosimetry system for routine personnel monitoring. Radiat. Prot. Dosim., v. 23, n. 1/4, p. 117-120, 1988.

PORTAL, F. Preparation and properties of principal TL products. In: OBERHOFER, M.; SCHARMANN, A. Applied Thermoluminescence Dosimetry. Bristol: Adam Hilger, 1981. p. 97-122.

PRICE P.B.; WALKER R.M. Chemical etching of charged-particle tracks in solids. J. Appl. Phys., v. 33, n. 12, p. 3407-3412, 1962.

PRICE, W.J. Nuclear radiation detection. New York, N.Y.: McGraw-Hill, 1964).

PRO-RAD - Consultores em Rádioproteção S/S Ltda. <www.prorad.com.br>. Acesso em 01 dez. 2006.

RANDALL, J.T.; WILKINS, M.H.F. Phosphorescence and electron traps. Proc. of the Royal Society of London. v. 184, n. 999, pp. 365-389, 1945. Série ${ }^{a}$

RDC - Radiation Detection Company <www.radetco.com>. Acesso em $01 \mathrm{dez}$. 2006.

Soreq Nuclear Research Center <www.soreq.gov.il>. Acesso em 01 dez. 2006.

SOUTO, E.B.; CAMPOS, L. L. Estudo da resposta de um policarbonato comercial para aplicação na dosimetria de nêutrons. In: XI CONGRESSO BRASILEIRO DE FísICA MÉDICA, Junho 14-17, 2006, Ribeirão Preto.

SOUTO, E.B.; CAMPOS, L. L. Chemical etching studies of a Brazilian polycarbonate to fast neutron detection. In: FIRST AMERICAN IRPA CONGRESS 2006, September 4-8, 2006, Acapulco. Proceedings...

SOUTO, E.B.; CAMPOS, L. L. Fast neutron dose response of a commercial polycarbonate. In: ISRP-10 AIRP $-10^{\text {th }}$ INTERNATIONAL SYMPOSIUM ON RADIATION PHYSICS, September 17-22, 2006, Coimbra. Proceedings...

SZABO, J.L.; BOUTAINE, J.L. Some examples of industrial uses of neutron sources. Radiat. Prot. Dosim., v. 70, n. 1-4, p. 193-196, 1997.

VILELA, E.C. Detecção de nêutrons rápidos utilizando detectores sólidos de traços nucleares. 1990. Dissertação (Mestrado) - Instituto de Pesquisas Energéticas e Nucleares - IPEN/CNEN-SP, São Paulo. 
VILELA, E.C. Desenvolvimento e calibração de um dosímetro pessoal para nêutrons utilizando detectores sólidos de traços nucleares. 1996. Tese (Doutorado) - Instituto de Pesquisas Energéticas e Nucleares - IPEN/CNEN-SP, São Paulo.

WIKIPEDIA - THE FREE ENCYCLOPEDIA <www.wikipedia.org>. Acesso em 01 dez. 2006. 


\section{ANEXOS}

\section{ANEXO A - Exemplos da Aplicação do Critério de Chauvenet}

A.1 Considerando que as contagens em um detector sejam as seguintes:

\begin{tabular}{cc}
\hline Número da Faixa & Traços \\
1 & 55 \\
2 & 56 \\
3 & 49 \\
4 & 58 \\
5 & 43 \\
\hline
\end{tabular}

Média: $\quad \bar{x}=\frac{55+56+49+58+43}{5}=52,2$

Intervalo de aceitação: $\quad 52,2 \pm 1,65 \cdot \sqrt{5 \overline{2}, 2} \rightarrow 41 \leqslant x \leqslant 64$

Todas as contagens se encontram no intervalo de aceitação e são válidas.

A.2 Considerando agora as seguintes contagens:

\begin{tabular}{cc}
\hline Número da Faixa & Traços \\
1 & 76 \\
2 & 103 \\
3 & 72 \\
4 & 86 \\
5 & 90 \\
\hline
\end{tabular}

Média: $\quad \bar{x}=\frac{76+103+72+86+90}{5}=85,4$

Intervalo de aceitação: $\quad 85,4 \pm 1,65 \cdot \sqrt{85,4} \rightarrow 71 \leqslant x \leqslant 100$

Desta vez a contagem da Faixa 2 está fora do intervalo de aceitação e deverá ser substituída. 
Digamos que uma sexta faixa tenha sido contada posteriormente acusando 79 traços. Refazendo os cálculos:

Nova média: $\quad \bar{x}_{1}=\frac{76+79+72+86+90}{5}=81,2$

Novo intervalo de aceitação: $\quad 81,2 \pm 1,65 . \sqrt{8 \overline{1}, 2} \rightarrow 67 \leqslant x \leqslant 96$

Agora todas as contagens são válidas. 